\title{
Embryologie, Fehlbildungen und seltene Erkrankungen der Cochlea
}

\author{
Embryology, Malformations, and Rare Diseases of the \\ Cochlea
}

(ㅇ) (1) $(9)$

Autoren

Athanasia Warnecke ${ }^{1,2}$, Anja Giesemann ${ }^{3}$

Institute

1 Klinik für Hals-, Nasen- und Ohrenheilkunde, Medizinische Hochschule Hannover, Carl-Neuberg-Straße 1, 30625 Hannover

2 Deutsche Forschungsgemeinschaft Exzellenzcluster"Hearing4all” - EXC 2177/1 - Project ID 390895286

3 Institut für Neuroradiologie, Medizinische Hochschule Hannover, Carl-Neuberg-Straße 1, 30625 Hannover

\section{Schlüsselwörter}

seltene Erkrankungen, Cochlea, Embryologie des Innenohrs, cochleäre Malformationen

\section{Key words}

rare diseases, cochlea, embryology of the inner ear, cochlear malformations

Bibliografie

Laryngo-Rhino-Otol 2021; 100: S1-S43

DOI 10.1055/a-1349-3824

ISSN $0935-8943$

(c) 2021. The Author(s).

This is an open access article published by Thieme under the terms of the Creative Commons Attribution-NonDerivative-NonCommercial-License, permitting copying and reproduction so long as the original work is given appropriate credit. Contents may not be used for commecial purposes, or adapted, remixed, transformed or built upon. (https://creativecommons.org/licenses/by-nc-nd/4.0/)

Georg Thieme Verlag KG, Rüdigerstraße 14,

70469 Stuttgart, Germany

Korrespondenzadresse

Prof. Dr. med. Athanasia Warnecke

HNO-Klinik, MH

Carl-Neuberg-Str. 1

D-30625 Hannover

Tel.: + 49 (0) $511 / 5328809$

warnecke.athanasia@mh-hannover.de

\section{ZUSAMMENFASSUNG}

Auch wenn die einzelnen Krankheitsbilder selten sind, stellen seltene Erkrankungen der Cochlea in ihrer Gänze eine doch gehäufte Entität dar, die zu Hörstörungen führt. Ein/Das Ziel des vorliegenden Referates war es, unter Berücksichtigung der Embryonalentwicklung der Hörschnecke und einer systematischen Zusammenfassung eine übersichtliche Darstellung der seltenen cochleären Erkrankungen zu ermöglichen. Auch wenn rapide biotechnologische und bioinformatische Fortschritte die Diagnose einer seltenen Erkrankung erleichtern, so kann oft nur im interdisziplinären Austausch der Verdacht einer seltenen Erkrankung erhoben werden. Trotz gleicher zugrunde liegender Mutationen kann der Phänotyp nicht nur bei den genetisch bedingten Hörstörungen sondern auch bei den syndromalen Erkrankungen stark variieren. Schließlich wird deutlich, dass der Phänotyp der einzelnen seltenen Erkrankungen nicht ausschließlich durch die klassische Genetik bestimmt werden kann.

\section{ABSTRACT}

Despite the low overall prevalence of individual rare diseases, cochlear dysfunction leading to hearing loss represents a symptom in a large proportion. The aim of this work was to provide a clear overview of rare cochlear diseases, taking into account the embryonic development of the cochlea and the systematic presentation of the different disorders. Although rapid biotechnological and bioinformatic advances may facilitate the diagnosis of a rare disease, an interdisciplinary exchange is often required to raise the suspicion of a rare disease. It is important to recognize that the phenotype of rare inner ear diseases can vary greatly not only in non-syndromic but also in syndromic hearing disorders. Finally, it becomes clear that the phenotype of the individual rare diseases cannot be determined exclusively by classical genetics even in monogenetic disorders. 


\section{Inhaltsverzeichnis}

Zusammenfassung

Abstract

Einleitung

1. Embryonalentwicklung und Morphologie der Cochlea

1.1 Morphogenese des Innenohres

1.2 Molekularbiologie der Embryonalentwicklung

1.3 Ausbildung der Haarsinneszellen

1.4 Ausbildung der Spiralganglienzellen

1.5 Regenerative Faktoren

1.6 Embryonale Entwicklungsprinzipien -

Verknüpfung zu anderen Organsystemen

Nicht-syndromale Hörstörungen

Fehlbildungen der Cochlea

X-chromosomale Schwerhörigkeit

(X-linked deafness DFN3, Gusher assoziiert)

Komplette Bogengangsaplasie und CHARGE-Syndrom

Cochlea Implantation bei Fehlbildungen der Cochlea

Schwerhörigkeit und Mikrozirkulation

Seltene Erkrankungen der Cochlea:

Weiterführende Betrachtungen und Zusammenfassung Interessenkonflikt

Literatur
Susac - Syndrom

1

\section{Einleitung}

Die Cochlea ist ein hochkomplexes Mikrosystem. In ihrem vollständig ausgebildeten Stadium besteht sie aus dem Spiralganglion (neuronales Gewebe gestützt von Satellitenzellen), dem Corti-Organ (Neuroepithel zur Sinneswahrnehmung), der Stria vaskularis (hoch vaskularisiertes Epithel, das für den lonentransport verantwortlich ist) sowie der otischen Kapsel (Knochengewebe). Am Vorgang des Hörens ist das Immunsystem (endolymphatischer Sack) beteiligt, auch wenn die Cochlea zunächst als immunprivilegiertes Organ gesehen wurde. Ähnliches Gewebe wie in der Cochlea ist auch in anderen Organsystemen zu finden: Zum Beispiel besitzen Gehirn, Hirnnerven und periphere Nerven ein ähnlich aufgebautes neurales Netzwerk; ein komplexes und hoch-strukturiertes Sinnesepithel wie im Corti-Organ findet sich ebenfalls in der Retina; die Stria vaskularis und die Nierenkörperchen sind metabolisch hoch aktive Gewebe zur Aufrechterhaltung des lonengleichgewichts. Diese strukturellen Ähnlichkeiten der Cochlea mit verschiedenen anderen Geweben spiegelt sich in der Tatsache wider, dass viele der Innenohrerkrankungen auch andere Organsysteme betreffen können.

Erkrankungen der Hörschnecke gehen in der Regel mit einer Hörminderung einher. Auch wenn Typ und Grad der Hörstörung sowohl subjektiv als auch objektiv gut gemessen werden können, so bleibt die Ursache der Hörstörung in den meisten Fällen unbekannt. Insbesondere die seltenen Erkrankungen der Hörschnecke bleiben oft undiagnostiziert und stellen eine besondere Herausforderung dar, v. a., weil vielen Allgemeinmedizinern aber auch Fachärzten viele seltene Erkrankungen weitestgehend unbekannt sind.

Für die Cochlea sind zahlreiche Erkrankungen als selten eingestuft (siehe Tabellen). Moderne molekularbiologische Verfahren haben in den letzten Jahren die Ursache der meisten seltenen $\mathrm{Er}$ krankungen aufgedeckt, sodass sich daraus gelegentlich die Patho- physiologie ableiten lässt. Nicht selten hat das Studium einer seltenen Krankheit neue Erkenntnisse zur Funktion und zum molekularen Aufbau der Hörschnecke hervorgebracht oder könnte gar neue Behandlungsmethoden ermöglichen.

Im vorliegenden Referat werden alle den Autoren bekannten seltenen Erkrankungen gelistet und tabellarisch charakterisiert, bei denen primär auch eine Beteiligung der Cochlea vorliegt. Weitere, primär in den anderen Organsystemen der Hals-Nasen-Ohren-Heilkunde auftretende seltene Erkrankungen, die auch die Cochlea betreffen können, sind den anderen Referaten dieser Ausgabe zu entnehmen (Seltene Erkrankungen des Mittelohres und der lateralen Schädelbasis: Weiss NM; Seltene Erkrankungen im Kopf-Hals-Bereich Teil III: Speicheldrüsen und Nervus Facialis: Scherl C; Seltene Erkrankungen des vestibulären Labyrinths: von Zebras, Chamäleons und Wölfen im Schafspelz: Dlugaiczyk J.) Bei der tabellarischen Listung wurde versucht, die Erkrankungen anhand ihrer Pathophysiologie oder Pathogenese zu gruppieren und so einen Überblick zu schaffen.

Ein weiterer Ansatz zum Verständnis der seltenen Erkrankungen der Hörschnecke ist die Kenntnis der Embryonalentwicklung. Dies ist insbesondere für die Malformationen und syndromalen Schwerhörigkeiten wichtig. Über die Embryonalentwicklung der Cochlea werden die molekularen Verbindungsglieder zwischen Herz, Niere und Augen, die bekannt sind, deutlich. Insbesondere die syndromalen Erkrankungen können lehrreich solche Verknüpfungen aufdecken.

Anhand der vaskulär bedingten seltenen Erkrankungen der Hörschnecke wird am Beispiel des SUSAC-Syndroms skizziert, wie schwierig die Diagnose sein kann und wie wichtig Interdisziplinarität und auch internationale Vernetzung sind. Vor allem wird deutlich, wie schwierig und langwierig der Weg zur Diagnose v. a. für den Patienten sein kann.

Anhand weiterer Beispiele (CHARGE-Syndrom, X-linked deafness) wird ebenfalls der Stellenwert der Interdisziplinarität gezeigt, insbesondere aber auch die Bedeutung der Bildgebung v. a. im Rahmen einer anstehenden symptomorientierten Versorgung mit einem Cochlea-Implantat.

Schließlich wird in der Zusammenfassung gezeigt, dass die meisten Erkrankungen trotz des gleichen genetischen Defektes eine Variabilität des Phänotyps aufweisen, die den klassischen Ansatz zur Diagnose anhand der Symptome erschwert. Andererseits zeigen sich Überlappungen bei bestimmten Erkrankungen, obwohl unterschiedliche genetische Defekte der Entstehung zugrunde liegen. Diese Beobachtungen stärken den Stellenwert der Elektrophysiologie, der Bildgebung und v. a. der modernen molekularen Diagnostik einschließlich der Proteom-Analysen, die die Basis in der fortschrittlichen HNO-Medizin der Zukunft darstellen könnte.

\section{Embryonalentwicklung und Morphologie der Cochlea}

Ein fundamentaler Teil für das tiefe Begreifen eines Organsystems ist das Verständnis der molekularen Evolution der phänotypischen Ausbildung. Die Kenntnis der molekularen Mechanismen, die die Entwicklung des Innenohres bedingen, kann zur besseren Charakterisierung und Klassifizierung der seltenen Erkrankungen und Fehlbildungen beitragen. Daher wird im Folgenden die Embryonalentwicklung des Innenohres skizziert. 


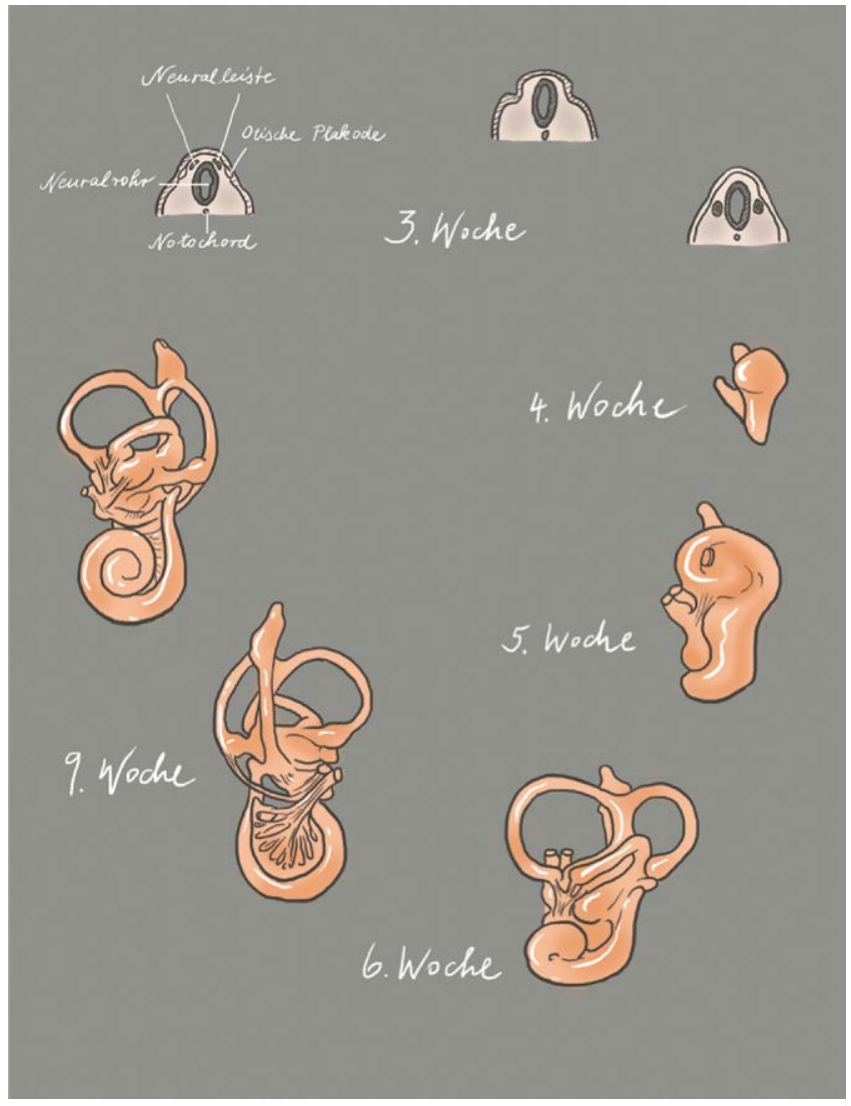

- Abb. 1 Skizzierung der Morphogenese des Innenohres. Modifiziert nach Gray's Anatomy, 41. Edition, 2016 [8], und nach Cummings, 7. Edition, 2020 [9]; Copyright Elsevier

Man unterscheidet die Entwicklung von häutigem und knöchernem Labyrinth: während ersteres aus einem vom Ektoderm abgeschnürten Ohrbläschen entsteht, ist das knöcherne Labyrinth ein Derivat des Mesenchyms.

Die Ausbildung des Innenohres erfordert neben der Morphogenese auch die Spezifizierung des Zellschicksals. Die Morphogenese beschreibt die Ausbildung der Otozyste bis hin zu den flüssigkeitsgefüllten Räumen des Labyrinths und der Cochlea, beginnend aus einer flachen Verdickung des Ektoderms. Spezifizierung des Zellschicksals meint die Entwicklung von Neuronen, sensorischen Zellen sowie den zahlreichen nicht sensorischen Zellen des Innenohres. An diesen Prozessen ist eine Vielzahl von Genen und dadurch induzierte biochemische Prozesse beteiligt, die ein hochkomplexes spatiotemporales Expressionsmuster aufweisen. Die genauen Mechanismen, die dabei eine Rolle spielen, sind bislang nur teilweise geklärt.

\subsection{Morphogenese des Innenohres}

Die meisten der Zelltypen, die das Innenohr eines Erwachsenen ausmachen, haben einen gemeinsamen Entwicklungsursprung in der otischen Plakode. Die otische Plakode ist der erste Schritt zur Entwicklung des Innenohres ( $\triangleright$ Abb. 1; 3. Woche links). Es handelt sich hierbei um eine Verdickung des Ektoderms lateral des Rautenhirns, die sich durch Invagination ( $\triangleright$ Abb. 1; 3. Woche) in das darunterliegende Mesenchym zu einer vesikulären Struktur, der Oto- zyste (Synonyme: Ohrblase, Ohrvesikel), entwickelt [1] ( $>$ Abb. 1; 3. Woche, rechte Graphik). Die Otozyste teilt sich in einen vestibulären und cochleären Anteil ( $\triangleright$ Abb. 1; 4. Woche), wobei die vestibulären Kompartimente des häutigen Labyrinths aus dem dorsolateralen und die cochleären Strukturen einschließlich Sacculus aus dem ventromedialen Abschnitt des Ohrvesikels hervorgehen [2].

Der cochleäre Anteil verlängert sich zu einer tubulären Struktur, dem Ductus cochlearis ( $>$ Abb. 1; 5. Woche). Während des Längenwachstums entwickelt sich der Ductus cochlearis zu einer Spirale, und in der 8. Woche der Embryonalentwicklung sind die 2 1/2 Windungen bereits vollständig ausgebildet ( Abb. 1; 6. +9. Woche). In der 9. Embryonalwoche entwickelt sich das Corti-Organ: anfänglich zeigt es sich als eine Anordnung polygonaler Zellen, von denen alle mit einem Kinozilium und zahlreichen Mikrovilli auf ihrer Oberfläche [3] ausgestattet sind. Die Mikrovilli verschwinden innerhalb der nächsten Wochen zugunsten der Stereozilien [4], wobei diese sich zuerst auf den inneren und später auf den äußeren Haarsinneszellen entwickeln. Die Ausbildung der Stereozilien ist im Bereich der Basis der Cochlea deutlicher ausgeprägt als im apikalen Bereich. Sie ist das erste morphologische Zeichen der Haarsinneszelldifferenzierung. Nun zeigt sich auch die Anordnung der inneren und äuBeren Haarsinneszellen: während sich eine einzelne Reihe innerer Haarsinneszellen entwickelt, kann die Anzahl der Reihen der äußeren Haarsinneszellen zwischen 3 und 4 variieren. Parallel dazu, also zwischen der 9. und 13. Embryonalwoche, bildet sich die Tektorialmembran, die sich über dem Corti-Organ ausbreitet. Die Bindung der Tektorialmembran mit den Stereozilien scheint über ein anfänglich unreifes Stadium, gekennzeichnet durch eine lockere Bindung, sich zu einem reiferen Stadium zu entwickeln, wo eine feste Verbindung zwischen äußeren Haarsinneszellen und Stereozillien ausgebildet wird. Bis zur 15. Woche erscheint das Corti-Organ als eine solide Zellmasse, die von einer dünnen Tektorialmembran bedeckt ist.

Alle Haarsinneszellen haben eine Reihe von Stereozillen entwickelt, allerdings erscheinen die inneren Haarsinneszellen reifer als die äußeren, mit einer ausgeprägten U-Form in der Anordnung der Stereozillien. Bis zur 22. Woche ist dieser Prozess abgeschlossen, die Stereozillien sind ausgereift und zeigen das gleiche Verteilungsmuster wie beim Erwachsenen.

Am Ende der 11. Embryonalwoche ist der Ductus cochlearis von Knorpel umgeben und es bilden sich flüssigkeitsgefüllte Räume aus, die sich bis zur 15 . Woche in die Scalae tympani et vestibuli entwickelt haben. In der 18. Woche hat sich aus der soliden Zellmasse des Corti-Organs (benannt nach dem italienischen Anatomen Alfonso Giacomo Gaspare Corti, 1822-1876) bereits der Corti-Tunnel (Synonym: innerer Tunnel, Cuniculum internum) ausgebildet. Auch der Nuellsche Raum (Synonyme: mittlerer Tunnel, Cuniculus medius; benannt nach dem belgischen HNO-Arzt Jean Pierre Nuell, 1847-1920) hat sich ausgebildet und durch die Regression des Kölliker'sches Organs (benannt nach dem deutschen Anatomen und Physiologen Rudolf Albert von Kölliker, 18171905), wird die Tektorialmembran frei. Beim Kölliker'schen Organ handelt es sich um eine Struktur (greater epithelial ridge, große epitheliale Leiste), die sich in der entwickelnden Cochlea vorübergehend ausbildet [5]. Sie besteht aus säulenförmigen Stützzellen, die ATP freisetzen. Dieses bindet sich an die ionotropen purinergen Rezeptoren (P2X-Rezeptoren) der inneren Haarsinneszellen und 
führt zur Depolarisation und zum Kalziumeinstrom. Dadurch wird der Effekt der Depolarisation durch Schall nachgeahmt, was zu einer periodischen Exzitation der Spiralganglienzellen führt. Auch andere Studien haben gezeigt, dass $\mathrm{Ca}^{2+}$-Spikes in neonatalen inneren Haarsinneszellen exzitatorische postsynaptische Ströme in den afferenten Dendriten der Spiralganglienzellen induzieren [6]. Nach Reifung der Cochlea und Einsetzen des Hörvermögens verschwindet diese ATP-induzierte intrinsische Aktivität der inneren Haarsinneszellen. Es wird angenommen, dass diese spontane Aktivität der inneren Haarsinneszellen und der Fasern des auditorischen Nervens auch beim Menschen vor dem Einsetzen des Hörens wesentlich für das Überleben der Neuronen des Nucleus cochlearis, für die korrekte Verschaltung der auditorischen Bahn und für das Ausbilden/Verfeinern der Tonotopie in den auditorischen Nuclei ist. Anders ausgedrückt bedeutet das, dass periphere, nicht sensorische Zellen, die sich im Kölliker'schen Organ befinden, für die Reifung der Hörbahn verantwortlich sind [7].

Zwischen der 20. und 22. Fetalwoche ist der Ductus cochlearis bereits deutlich länger und größer im Durchmesser, die Stria vascularis hat ihre charakteristischen 3 Zelllagen entwickelt und die Tektorialmembran ist deutlich ausgeprägter. Es kommt anschließend nach und nach zu einer Verlängerung der äußeren Pfeillerzellen und der äußeren Haarsinneszellen, und die Deitersschen und Hensenschen Stützzellen bilden sich aus. Am Ende des 2. Trimenons hat die Cochlea eine bereits reife Erscheinung, wobei die Synapsen der efferenten Hirnstammfasern noch nicht komplett ausgebildet sind.

Der N. cochlearis entwickelt sich aus einer Gruppe von Zellen (Neuroblasten), die sich aus dem medialen Abschnitt des Ohrepithels ablösen und in das darunter liegende Mesenchym einwandern. Sie bilden das VIII. (vestibulocochläere) Ganglion, woraus sich der 8. Hirnnerv entwickelt [10]. Die Ganglienzellen, aus denen sich der akustische Teil des Hörnervens ausbilden wird, ordnen sich um den Modiolus an, um das Spiralganglion zu formen. Aus diesen Ganglienzellen bilden sich Axone, die sich zentral zum Hirn und peripher zum Corti-Organ ausrichten. Die Axone bilden während der 5./6. Gestationswoche als Erstes eine Synapse mit den Hirnstammneuronen aus. Die Dendriten erreichen die Basis der Cochlea erst gegen Ende der 9. Embryonalwoche und bilden Kontakte mit den sich entwickelnden Haarsinneszellen zwischen der 10. und 12. Embryonalwoche aus [11]. Bereits Ende der 12. Gestationswoche beginnt die Ausbildung der klassischen afferenten Synapsen zwischen Neuronen und Haarsinneszellen. Dieses zeigt sich durch die Formung von mit Vesikeln umgebenden präsynaptischen Körpern an der Basis der inneren Haarsinneszellen, welche in der 13. Woche auch bei den äußeren Haarsinneszellen zu beobachten sind. In der 14. Fetalwoche sind die Synapsen der Spiralganglienzellen mit den inneren und äußeren Haarsinneszellen von basal nach apikal ausgebildet, wobei die Myelin-formenden Schwannzellen sich erst mit der 15. Fetalwoche nachweisen lassen. In diesem frühen Stadium sind die äußeren Haarsinneszellen ausschließlich afferent innerviert; die Ausbildung axo-somatischer Synapsen mit dem efferenten System entwickelt sich beim Menschen erst mit dem Einsetzen der cochleären Funktion, also erst um die 20. Woche. Diese Beobachtung in der Embryonalentwicklung der Synapsenformung scheint einen evolutionären Prozess widerzuspiegeln. Während die äußere Haarsinneszellen am Anfang durch die Synapsenausbildung rein sensorische Aufgaben übernimmt (die Weiterleitung auditorischer Signale an das Gehirn), können durch die efferente Verschaltung am Ende der Reifung des Corti-Organs spezifische Aufgaben übernommen werden, wie z. B. die Beeinflussung der cochleären Mikromechanik. Dieser Prozess ist in den basalen und mittleren Regionen der Cochlea deutlicher ausgeprägt als in den apikalen Regionen. Dies scheint insbesondere an den wenigen efferenten Fasern zu liegen, die nach apikal auswachsen und den äußeren Haarsinneszellen das Innervationsmuster für eine rein sensorische Funktion erhalten. Betrachtetet man parallel die Ziliogenese, so wird deutlich, dass der apikale Bereich in einem unreiferen Stadium verbleibt, sodass basierend auf der Embryonalentwicklung die Cochlea korrekterweise in einen basalen und einen apikalen Part unterteilt werden sollte. Ab der 22. Fetalwoche zeigt sich eine Myelinisierung innerhalb der Cochlea und dünne Myelinscheiden sind bereits sichtbar [12]. In der 24. Fetalwoche zeigt sich die Ausdehnung der Myelinscheide bis zu dem Austritt des Nervens aus dem Temporalknochen. Ab diesem Punkt erfolgt die Myelinisierung durch Oligodendrozyten, welche sich bereits am Nerven angesiedelt haben. Die zentrale Myelinisierung ist zu diesem Zeitpunkt aber noch nicht erfolgt [13].

Zwischen der 7. und 8. Embryonalwoche sind die Zentren und Bahnen der Hörbahn bereits entwickelt. Die Neuronen des Hirnstamms, die von den unreifen Axonen des Hörnervens Informationen enthalten, lassen sich am Rande des Hirnstammes als Nuclei cochleares identifizieren. Ein Teil davon kreuzt im Hirnstamm und projiziert seine Ausläufer weiter zentral in den kontralateralen Nucleus olivaris superior [14]. Der andere Teil steigt als Lemniscus lateralis in den Colliculus inferior. Im dorsalen Bereich des Thalamus lässt sich in der 8. Embryonalwoche ein Teil als Corpus geniculatum mediale identifizieren, der von den Axonen aus dem Colliculus erreicht wird. Zwischen der 9. und 13. Woche kommt es lediglich zum Größenwachstum im Bereich des Hirnstammes und zu keiner weiteren strukturellen Veränderung. Dennoch sind die Neurone des Hirnstamms noch sehr klein und unreif, obwohl der Zellkern relativ gut entwickelt ist. Im Verlauf des 2. Trimenons kommt es nicht nur zu einer Vergrößerung der Neurone, sondern auch zur Ausbildung von Zytoplasma und Zellorganellen. Gegen Ende der 24. Fetalwoche zeigen sich auch vermehrt Zytofilamente in den auditorischen Neuronen. Auch in den Axonen der Neurone des Hirnstamms kommt es im 2. Trimenon zu einer beschleunigten Reifung. Neurofilament, gegen Ende der 16. Woche nur in wenigen Neuronen des Nervus cochlearis nachweisbar, ist am Ende des 2. Trimenons gebündelt als Faszikel im Bereich des Nervus cochlearis und des Hirnstammes deutlich zu sehen.

\subsection{Molekularbiologie der Embryonalentwicklung}

Die otische Plakode, aus der das gesamte Innenohr sich entwickelt, ist Teil einer Reihe von kraniofazialen Plakoden, aus denen sich verschiedene Strukturen entwickeln (z. B. das olfaktorische Epithel, Neuronen verschiedener kranialer sensorischer Ganglien, die Augenlinse). All diese Plakoden entstehen in der prä-plakodalen Region, die durch die Expression eines gemeinsamen Satzes von Transkriptionsfaktoren (Six1, Eya2 und Foxi3) gekennzeichnet ist [15]. Die Ohrblase (Otozyste) entwickelt sich aus der prä-plakodalen Region auf Höhe der Rhombomere 5 und 6 unter Einfluss des FGF-Signalweges [15]. Die Transkriptionsfaktoren Pax2 und Pax8 sind Marker der Ohrblase. 


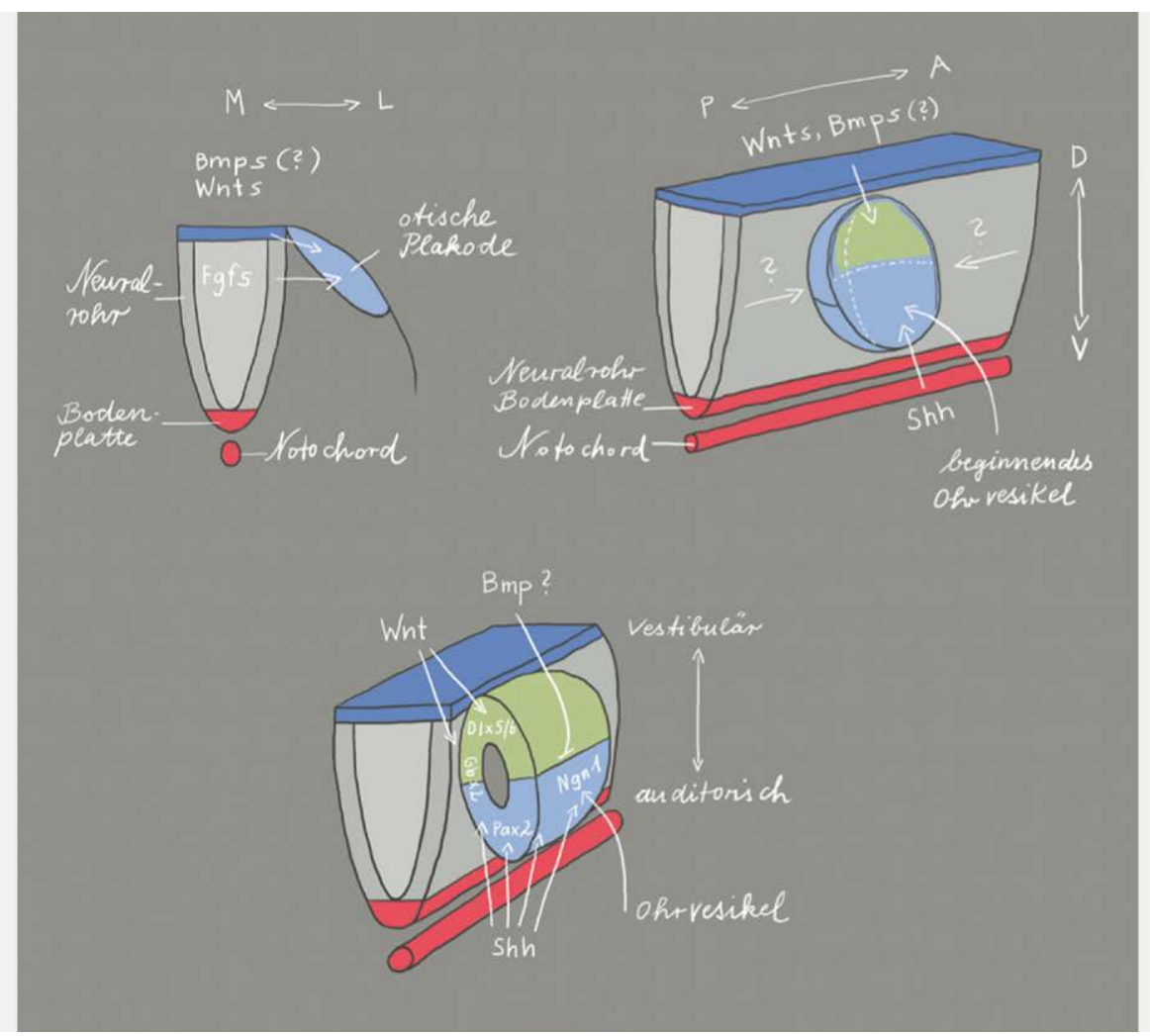

- Abb. 2 Der Ort der Ausbildung der otischen Plakode entlang der Körperachse wird über die Expression von „fibroblast growth factors“ (FGF) aus dem Neuralrohr definiert [20]. Durch die Freisetzung von FGF im periotischen Mesoderm kurz vor der Ausbildung der otischen Plakode [21] kommt es zur Expression etlicher Transkriptionsfaktoren, die für Entwicklung des Innenohrs notwendig sind [22, 23]. Die Ausrichtung der anteroposterioren Achse beginnt mit der Expression von FGF10, „lunatic fringe“ (Lfng), Delta 1, Neurogenin1 (Ngn1) und „,neuronal differentiation factor“ (NeuroD1) in der vorderen Region der invaginierenden otischen Plakode. Dieses Genexpressionsmuster beschränkt sich auf die vordere Region der Otozyste. Diese Beschränkung wird durch Tbx1 vermittelt, das ausschließlich in der posterioren Hälfte der Otozyste exprimiert wird. Die dorsoventrale Achse ist abhängig von der WNT- und SHH-Expression im Rautenhirn. WNT wird im dorsalen Bereich exprimiert und bedingt die Hochregulierung von Dlx5, Dlx6, Hmx2, Hmx3 und Gbx2, Gene, die die Entwicklung der vestibulären Strukturen in der dorsalen Region der Otozyste verantworten. Demgegenüber steht die Expression von SHH aus dem Notochord, welches das Schicksal (auditorisch) der Zellen im ventralen Teil der Otozyste bestimmt, indem es die Expression der Transkriptionsfaktoren Pax2, Ngn1, Lfng, NeuroD1, Sox2 und Six1 reguliert. BMP („,bone morphogenetic protein“) und $\mathrm{SHH}$ hemmen sich gegenseitig, sodass BMP eine wesentliche Rolle bei der Morphogenese des Innenohrs zugesprochen wird. (Skizze modifiziert nach $[24,25])$.

Für die Ausrichtung des Innenohres werden Genexpressionsprofile innerhalb der Ohrblase, in dem an der sich entwickelnden Ohrblase angrenzenden Gewebe, innerhalb der Grenzen zwischen otischem und angrenzendem Gewebe sowie innerhalb der Grenzen der Kompartimente, in denen die entwickelnde Ohrblase schematisch eingeteilt werden kann, verantwortlich gemacht ( $>$ Abb. 2 und 3). Das Rautenhirn ist in Segmenten angeordnet, die als Rhombomere bezeichnet werden. Jedes Rhombomer ist in der Lage, spezifische Gene zu exprimieren. Die otische Plakode grenzt an Rhombomer 5 und 6 , weshalb diesem Bereich eine bedeutende Rolle in der axialen Organisation sowie in der Spezifizierung der Schicksale der Zellen des Innenohres zugewiesen wird. Mausmutanten, die Defekte des Rhombenzephalons im Bereich der Rhombomere 5 und 6 aufweisen, bei denen allerdings die Grenze zwischen Rhombomer 5 und 6 erhalten ist, zeigen eine normale Ausbildung des Innenohres. Die Grenze zwischen den beiden Rhombomeren entspricht nahezu exakt der Mittellinie der Ohrblase und bedingt womöglich die Spezifizierung der Zellen der Otozyste zum anterioren und posterioren Kompartiment. Da diese beiden Rhombomere sich sehr früh entwickeln, können sie mit unterschiedlichen Signalen die Entwicklung der anterioren und posterioren Otozyste beeinflussen [16]. Für die Signaltransmission zwischen Zellen der Otozyste und Zellen des Rhombenzephalons konnte das Eph/Ephrin System verantwortlich gemacht werden [17]. Während die Zellen des Rhombomers 6 hohe Konzentrationen der Liganden Ephrin B2 und B3, exprimieren, ist in Rhombomer 5 eine hohe Dichte der Rezeptoren EphA4, A7, B2 und B3 vorhanden $[18,19]$. Das bedeutet, dass die postero-medialen Zellen der Otozyste, welche sich in direktem Kontakt zu Rhombomer 6 befinden, Ephrin-vermittelte Signale erhalten, hingegen Zellen, die zu Rhombomer 5 benachbart sind, dies nicht tun. Womöglich werden diese Signale direkt an den dorsalen Pol der Ohrblase weitergeleitet, wo die Zellen der otischen Plakode in direktem Kontakt zu Zellen aus dem Neuralrohr kommen, weil es dort zu keiner Abgrenzung durch eine Basallamina kommt. Das würde von Anfang an bedingen, dass in der sich entwickelnden Otozyste sich gegeneinander abgegrenzte Kompartimente ausbilden, nämlich das antero-mediale und postero-mediale Kompartiment [16]. Diese Kompartimente sollen für die Anordnung der Zellen und die innenohrspezifische Ausbildung 


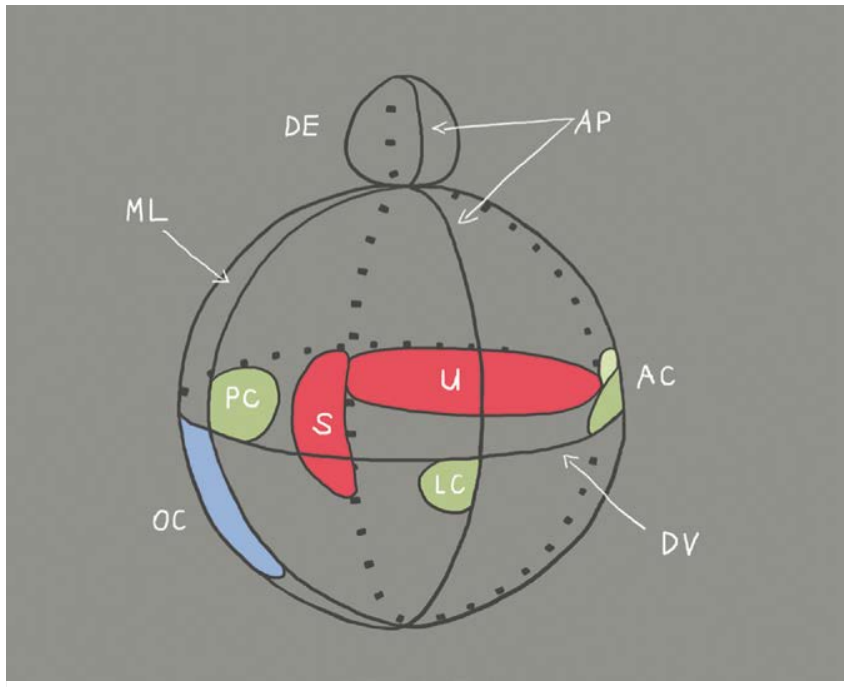

- Abb. 3 Schematische Darstellung der Kompartimente des sich entwickelnden Innenohres und Lokalisation der verschiedenen Organe (Corti-Organ: OC, Sacculus: S, Utriculus: U, Ductus endolymphaticus: ED, Cristae der Bogengänge: AC, PC und LC) sowie der Achsen (AP: antero-posterior; DV: dorso-ventral; ML: medio-lateral). Die Ausrichtung in der antero-posterioren Achse erfolgt vor der Ausrichtung nach dorso-ventral [26]. Die dorsoventrale Achse ist bis zur Ausbildung der Otozyste noch nicht festgelegt [27]. Die Achsenspezifikation beginnt bereits mit der Ausbildung der otischen Plakode und hängt von Faktoren ab ( $\bullet$ Abb. 2), die von den Rhombomeren 5 und 6 des Rautenhirns exprimiert werden. Sobald ein Rhombomer entlang der dorso-ventralen Achse in ovo rotiert ist, verschiebt die Expression der ventralen Gene Lfng, NeuroD1 und Six 1 (siehe Tabelle BOR-Syndrom) in die dorsalen Regionen der Otozyste, wohingegen die Expression dorsaler Gene wie Gbx2 gehemmt ist. Dies bedeutet, dass durch Rotation der Rhombomere ventrale Bezirke des Rautenhirns ventrale Bereiche der Otozyste in dorsales otisches Gewebe transformieren können [26]. Die Ausbildung der Organe des Innenohres nach dem Stadium der Otozyste ist von der Expression von Gata3 (Siehe Tabelle Bakarat-HDR-Syndrom), Eya1 (siehe Tabelle BOR-Syndrom) und FGF3/8 (siehe Tabelle Kallmann-Syndrom) abhängig, wie Untersuchungen an Gata3-, Eya1- und FGF3/8-defizienten Mäusen gezeigt haben [28-30]. SHH (siehe Tabelle Inkomplette Partition und Carpenter-Syndrom) sowie Pax2 sind cochleäre Gene, da Mutationen in diesen Genen, lediglich die Ausbildung eines kurzen, geraden Ductus cochlearis erlauben. Als vestibuläre Gene werden hingegen $\mathrm{Gbx2}$, Hmx2, Hmx3 sowie WNT bezeichnet, da ein Ausfall einer dieser Gene zu morphologischen Defekten in Sacculus, Utriculus oder den Bogengängen führt. (Zeichnung modifiziert nach Brigande et al., 2000 [16].)

und Ausrichtung des Organs verantwortlich sein. Sie sind durch ihr Genexpressionsprofil gekennzeichnet und definieren und begrenzen die Zellabstammung. Das bedeutet, dass zum einen Zellen in den entsprechenden Kompartimenten die Lokalisation und Struktur der Cochlea und der Bogengänge, des Utriculus, Sacculus sowie des Ductus endolymphaticus bedingen, zum anderen die Vermengung der Zellen unterschiedlicher Linien nicht oder nur erschwert möglich ist ( Abb. 3). Darüber hinaus entscheidet wahrscheinlich die Genexpression innerhalb des Kompartiments, welches sensorische Organ (Cortisches Organ, Crista oder Macula) sich ausbilden soll. Lösliche Faktoren sowie Oberflächenmoleküle von Zellen könnten dann durchaus die Zellen entlang der Grenze zwischen den Kompartimen- ten beeinflussen, allerdings nur solche, die sich in unmittelbarer Nähe der Grenze befinden. Deren Diffusion erscheint zwar möglich, allerdings nur in einem Umkreis von wenigen hundert Mikrometern. Solche Faktoren könnten zum Beispiel Morphogene sein, was bedeuten würde, dass Strukturen, die in die Länge auswachsen, durch die Grenzzone zwischen 2 Kompartimenten induziert werden, hingegen morphologisch punktuell begrenzte Organe wie die Crista sich nur an der Grenze zwischen drei Kompartimenten ausbilden können, damit eine höchst genaue Lokalisation erreicht werden kann.

\subsection{Ausbildung der Haarsinneszellen}

Verschiedene lösliche Faktoren sind zur Induktion der otischen Plakode notwendig: FGF aus dem Mesoderm und dem Neuroektoderm, SHH vom Notochord und der Bodenplatte des Neuralrohrs, WNT aus dem Rautenhirn sowie BMP aus dem Ektoderm. Der anteriore Bereich der Otozyste, in dem sich die neurosensorischen Zellen des Innenohres entwickeln, ist durch die Expression von Lfng, Sox2 und Eya1 gekennzeichnet [31], während im dorsalen Anteil in der nichtsensorischen Region Tbx1 und Lmx1a exprimiert werden. Innerhalb der prosensorischen Region wird sehr früh der proneuronale Transkriptionsfaktor Neurog1 hochreguliert. Dieser ist nicht nur für die Ausbildung der Neuronen notwendig, sondern ist ebenso maßgeblich an der Ausbildung des sensorischen Epithels inklusive der Haarsinneszellen beteiligt [32]. Er gehört zu den basischen „helix-loophelix“ (bHLH)-Transkriptionsfaktoren und wird gemeinsam mit Neurod1 von proliferierenden Vorläuferzellen exprimiert. Für die Ausbildung von Haarsinneszellen ist das bHLH-Gen Atoh1 (Atoh1 (Atonal-homolog-1)/Math1 (murine atonal homolog 1)/ Hath1 (Human atonal homolog 1) notwendig [33, 34]. Darüber hinaus sind zum Erhalt und zur Ausbildung der Haarsinneszellen der Pou-Domänen-Transkriptionsfaktor Pou4f3, der Zinkfingertranskriptionsfaktor Gfi1 und der Homöodomänenfaktor Barhl1 notwendig [32]. Das einzigartige und hochspezifische Muster der Zellanordnung im sensorischen Epithel des Innenohres, wo Haarsinneszellen und Stützzellen alternierend angeordnet sind, lässt vermuten, dass hierbei eher lokale Zellkommunikationsmechanismen eine übergeordnete Rolle spielen und weniger prädeterminierte Zellspezifikation. Der NotchSignalweg reguliert die Determination des Zellschicksals in zahlreichen Organsystemen [35]. Während der Entwicklung des Innenohrs ist Notch (siehe Tabelle Hajdu-Cheney-Syndrom) anfänglich im gesamten Epithel verbreitet, mit Differenzierung der Haarsinneszellen jedoch wird seine Expression auf die Stützzellen beschränkt. Delta1 und Jagged 2 hingegen werden von Haarsinneszellen der Maus-Cochlea etwa einen Tag nach Beginn der Math1-Expression synthetisiert [36]. Hierbei exprimieren die Zellen, die sich zu Haarsinneszellen entwickeln sollen, Jagged 1 , welches die Notch-Aktivität in den benachbarten Zellen steigert und sie somit zur Adoption eines anderen Zelltyps (den der Stützzelle) zwingt. Dieser Prozess wird laterale Inhibition genannt.

Die Ausbildung der apikalen mechanosensorischen Region (des Ortes, an dem die Stereozillien lokalisiert sind) spielt für die Funktion der Haarsinneszellen eine vitale Rolle. Die mit Aktin und anderen zytoskelettalen Proteinen bepackten Stereozillien der Haarsinneszellen sind V-förmig in Reihen aufsteigender Höhe organisiert. Diese Organisation ist durch das gesamte Corti-Organ uniform, wobei die Spitze des V immer in die Peripherie des Ductus cochlearis zeigt und für die korrekte Funktion unabdingbar ist [37]. Bei der 
Orientierung der Haarsinneszellbündel spielt der Wnt/planare ZellPolarität Signalweg eine wesentliche Rolle. Die asymmetrische Verteilung der planaren Zell-Polarität-Proteine Frizzled (Fzd), Dishevelled (Dvl), Van Gogh (Vangl) und Prickle (Pk) führen zur Polarisation der Haarsinneszellen. Es hat sich gezeigt, dass Fzd und Dvl Proteine einen Komplex auf der einen Seite der Zelle formen, hingegen Vangl und Pk sich auf der kontralateralen Seite anordnen [38]. Es wird davon ausgegangen, dass die Untereinheit des Kinesin-II Motor Komplexes, Kif3a, die Haarsinneszellorganisation reguliert. In Kif3a mutanten Mäusen fehlt das Kinozilium, der Ductus cochlearis ist verkürzt und die Form der Haarsinneszellbündel erscheint abgeflacht [39]. Störung der Zilien, sog. Ziliopathien sind das Charkteristikum des Bardet-Biedl- und des Senior-Løken-Syndroms ( Tab. 1).

\subsection{Ausbildung der Spiralganglienzellen}

Bei der Entwicklung des zentralen Nervensystems sind basische „helix-loop-helix“ (bHLH) Transkriptionsfaktoren für die proneuronale Spezifikation von Zellen verantwortlich, wohingegen die laterale Inhibition, bedingt durch das Delta/Notch-System, die neuronale Differenzierung in den Nachbarzellen durch Aktivierung der inhibitorischen Effektorgene Hes und Hey hemmt [40]. Etliche lösliche Faktoren wie Wnt (Wingless), FGF, BMP und Shh (sonic hedgehog) induzieren neuronale Progenitorzellen [41], die proneuronale Gene exprimieren und den Schicksalswechsel zur Gliaformation über Aktivierung des COUP-TF/II Transkriptionsfaktors erlauben [42]. Diese basalen Muster der Embryonalentwicklung des Nervensystems sind auch bei der Ontogenese des Innenohres zu beobachten. Es ist anzunehmen, dass die gesamte Otozyste zur Neuroblastenformation befähigt ist. Bereits kurz nach der Invagination der otischen Placode, erfolgt eine Delamination von Neuroblasten aus der anterioren und ventralen Region, die als neurosensorische Domäne bezeichnet wird und aus der das VIII. kraniale Ganglion (auch als Cochleovestibularganglion bekannt) entsteht [15]. Zur Differenzierung von Spiralganglienzellen wird der proneuronale bHLH Transkriptionsfaktor Neurogenin1 ( $\mathrm{Ngn} 1$ ) benötigt. Nach einer initialen Überexpression von Ngn1 findet innerhalb der sich ausbildenden Spiralganglien eine Hochregulierung von Neurod1 sowie Delta- und Notch-Genen statt, während Ngn1 selbst runterreguliert wird [43]. Die Expression von Gata3 scheint ebenfalls bei der Ausbildung der Neuronen eine wesentliche Rolle zu spielen, insbesondere bei der Anbindung nach zentral. Allerdings konnte dies bislang nicht detailliert geklärt werden, da Gata3 bereits frühzeitig in der Embryonalentwicklung wesentlich zur Ausbildung des Innenohrs beiträgt und eine systemische Deletion von Gata zur Einschränkung der Ausbildung des Innenohres führt [44]. Die Entwicklung der Neuronen hängt unter anderem auch von der Expression von Pou4f1 (frühere Bezeichnung Brn3a) ab [45]. Während ihrer Entwicklung migrieren Spiralganglienzellen vom Ductus cochlearis zum Canalis spiralis modiolus (Rosenthal-Kanal). Sie erreichen ihre postmitotische Phase bereits im Ductus cochlearis in einem basoapikalen Gradienten, d. h. erst treten die Neurone der basalen und mittleren Cochleaabschnitte aus dem Zellzyklus, etwas später die der apikalen Abschnitte. Die auswachsenden Dendriten sortieren und retrahieren sich so, dass die inneren und äußeren Haarsinneszellen nach einem entsprechenden Muster innerviert werden. Dieser Prozess scheint über das G-Protein RhoA-GTP und die Rho- assoziierten GTP-bindenden Proteine Rnd 2 und Rnd 3 reguliert zu sein. Es hat sich gezeigt, dass ektope Haarsinneszellen in der Lage sind, Verbindungen mit den Spiralganglienneuronen auszubilden [46], sodass man davon ausgehen kann, dass die Haarsinneszellen die Dendriten der Neurone anziehen. Dies könnte möglicherweise erklären, warum Patienten mit schweren Fehlbildungen des Innenohres (z. B. inkomplette Partition) dennoch von einer Cochlea Implantation profitieren können.

Die Region, die sich zum Corti-Organ entwickelt, exprimiert neurotrophe Faktoren interessanterweise noch vor der Haarsinneszelldifferenzierung, sodass sich entwickelnde Neuriten in das Corti-Organ auswachsen, auch wenn die Ausbildung der Haarsinneszellen fehlt [47]. Erreichen sie jedoch die Habenula perforata, benötigen sie einen Reiz, der von den Haarsinneszellen ausgeht, damit sie weiter in Richtung der großen epithelialen Leiste bzw. der Haarsinneszellen auswachsen [48]. Solche Faktoren können Semaphorin/Neuropilin1, Eph/Ephrin sowie Slit/Robo sein, deren Expression einen Weg definiert, entlang dessen die Dendriten auswachsen können [49]. Morphogene wie Wnt und Shhs werden so exprimiert, dass sich ein dorso-ventraler Gradient ausbildet, der für die Ausbildung der Cochlea notwendig ist [24]. Ferner werden Wnt und Shh eine wesentliche Rolle beim richtungsorientierten Auswachsen der Axone zugesprochen. Damit die Neuriten der Spiralganglienneurone auswachsen, wirken Wnt und Shh gemeinsam mit den Wachstumsfaktoren FGF und BMP [48]. Typ I und Typ II Spiralganglienneurone leiten Reize aus den inneren und äußeren Haarsinneszellen respektive nach zentral weiter. Wann sich dieses Innervationsmuster, welches sich ganz klar beim Erwachsenen zeigt, ausbildet, ist noch unklar. Allerdings scheint dieser Prozess eng an die Peripherin-Expression der Typ II Spiralganglienneurone gekoppelt [50]. Ein weiteres Protein, das bei der Koordinierung des Auswachsens der Neuriten von Typ II Neuronen nicht nur in den Spiralganglienzellen, sondern womöglich auch in den Stützzellen, an denen die afferenten Fasern entlangwachsen sollen, hochreguliert wird, ist Prox1 [51].

Die Expression der Neurotrophine BDNF und NT3, sowie deren Rezeptoren NTRK2 und NTRK3 regulieren sowohl das Überleben als auch das Auswachsen der sich entwickelnden Spiralganglienneurone. Bei der sich entwickelnden Cochlea bildet sich von apikal nach basal ein BDNF-NT3-Gradient aus [52]. Fehlt BDNF, so kommt es zur Ausbildung einer normalen Cochlea mit einer Reduktion der Neurone um ca. 7-15\%. Fehlt hingegen NT3, so fehlt die Innervation der basalen Cochlea komplett und ist im mittleren Abschnitt reduziert [48]. Beim Fehlen der Neurotrophine kommt es jedoch nicht nur zu Aberrationen bei der neuronalen Entwicklung im Innenohr. Auch der Ductus cochlearis ist deutlich kürzer, die Haarsinneszellen bilden multiple, unorganisierte Reihen aus, ähnlich wie bei Neurod1-defizienten Mäusen [43].

\subsection{Regenerative Faktoren}

Obwohl die Entwicklung des Innenohrs ein sehr komplexer und multifaktoriell beeinflussbarer Prozess ist, kann die gezielte Modulation einzelner Signalwege einen Ansatz für regenerative Therapien ermöglichen. Die Studie REGAIN (REgeneration of hair cells with a GAmma-secretase-INhibitor) zielt darauf ab, durch Hemmung des Notch-Signalwegs Patienten mit bis zu mittelgradigem Hörverlust zu behandeln. Hierbei soll mit dem Notch-Inhibitor LY3056480 die Regeneration von Haarsinneszellen im Innenohr, 


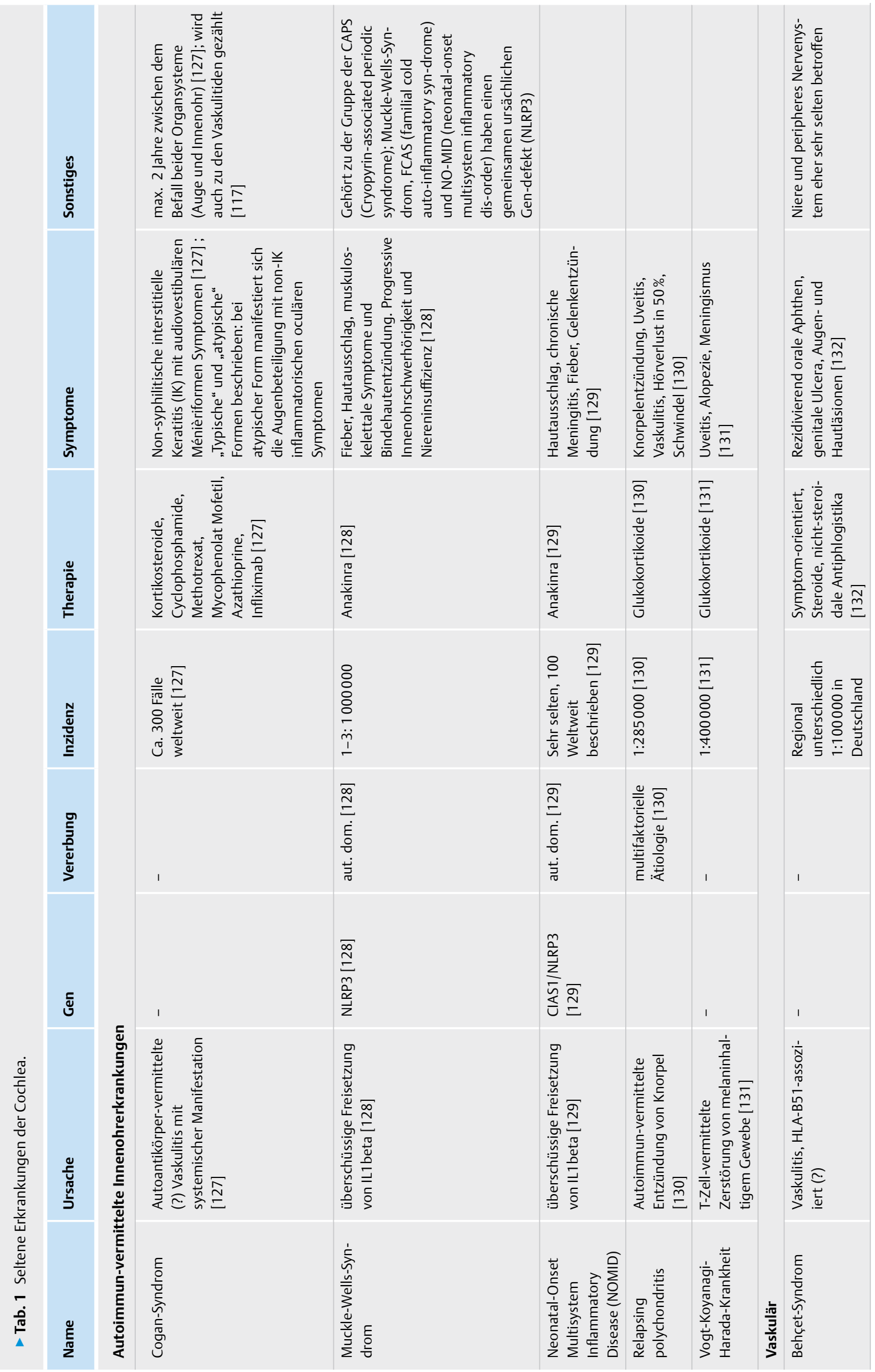




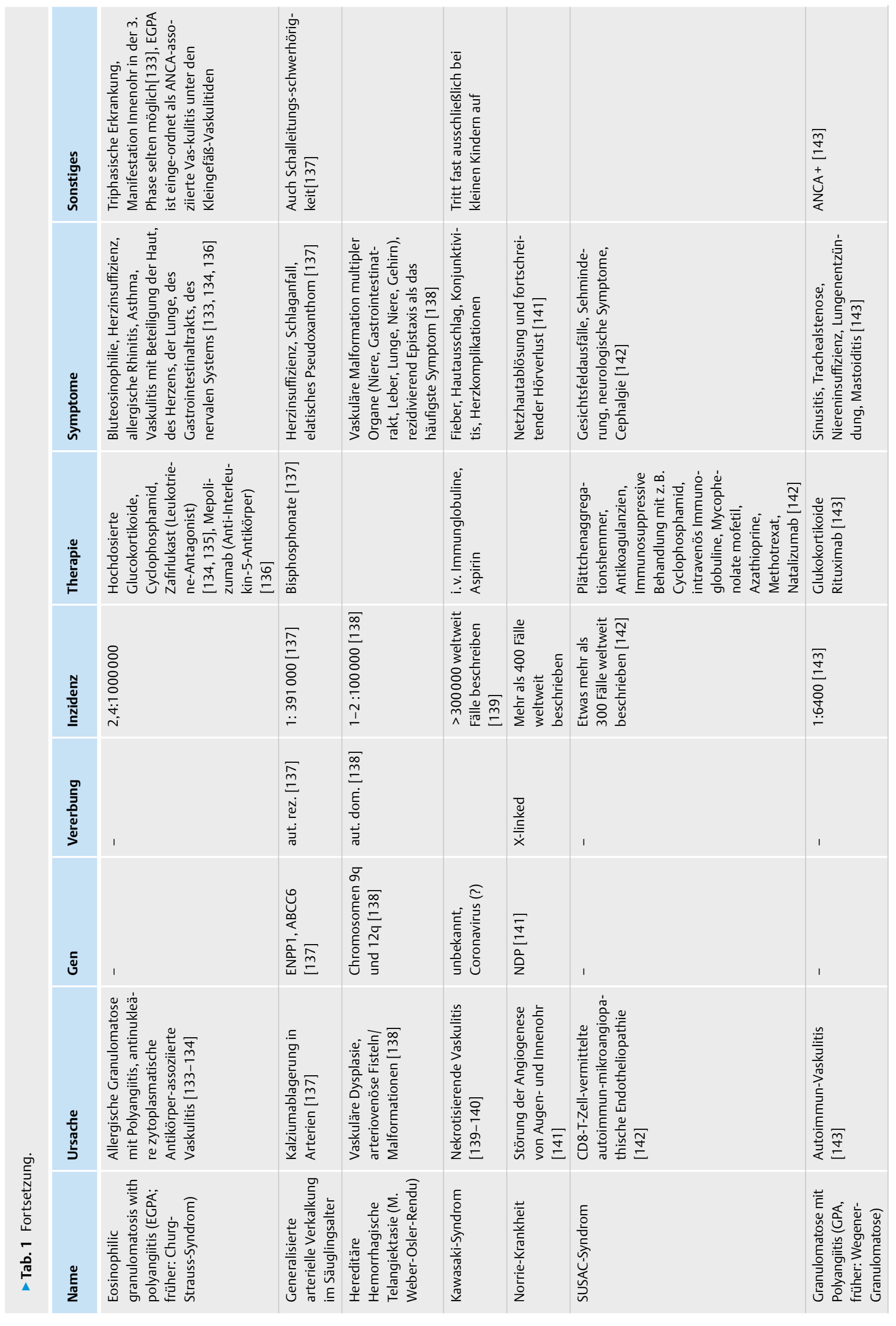



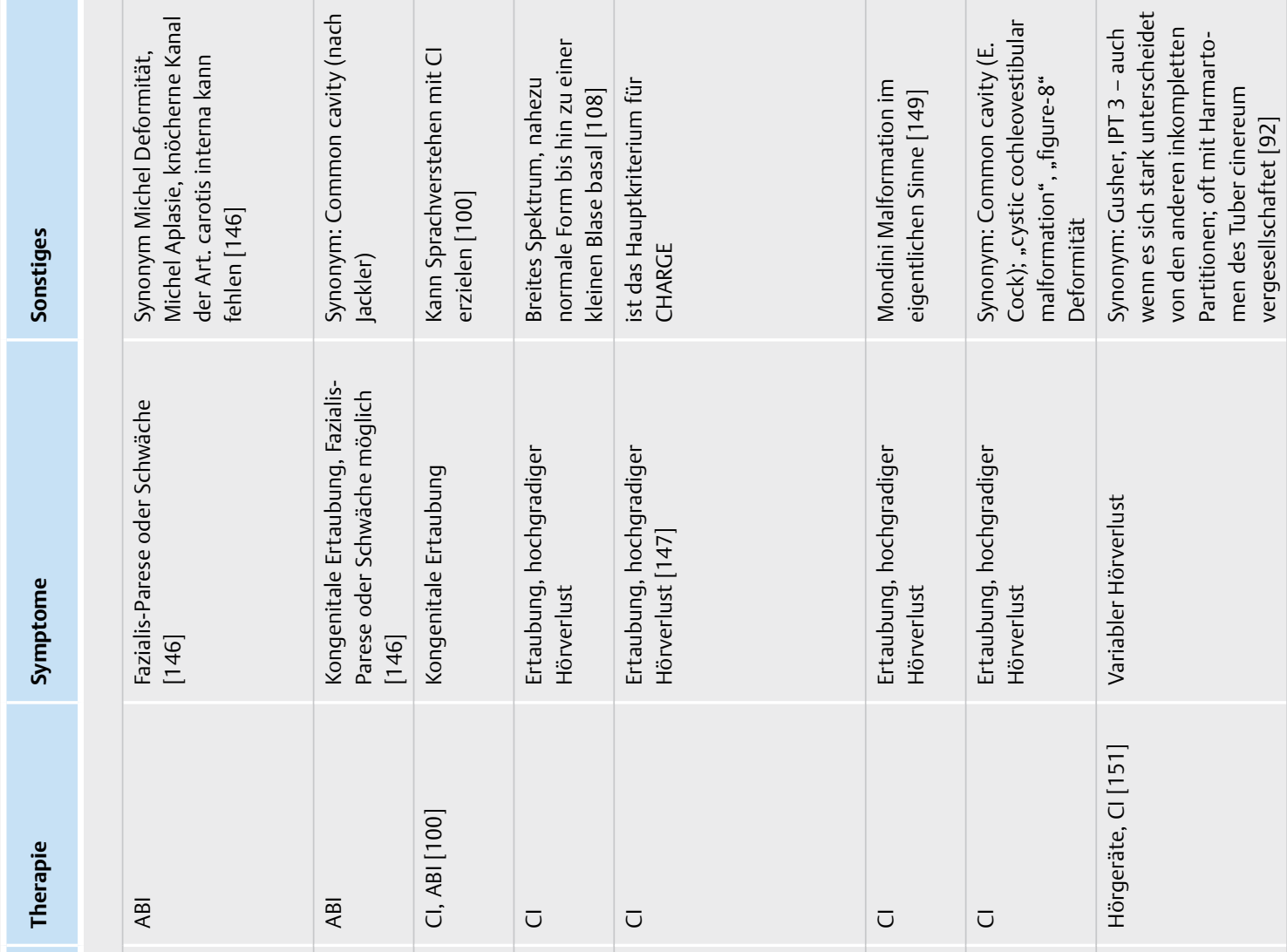

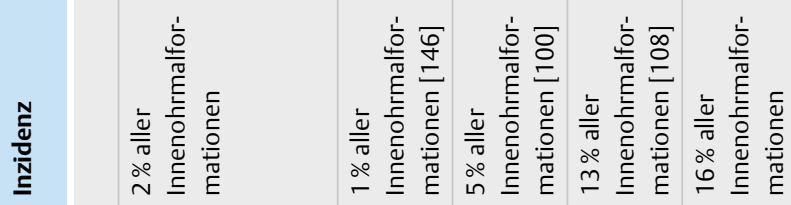

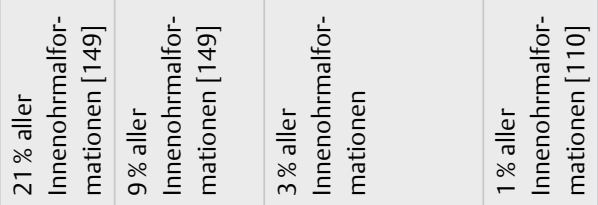

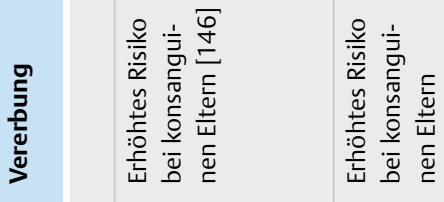
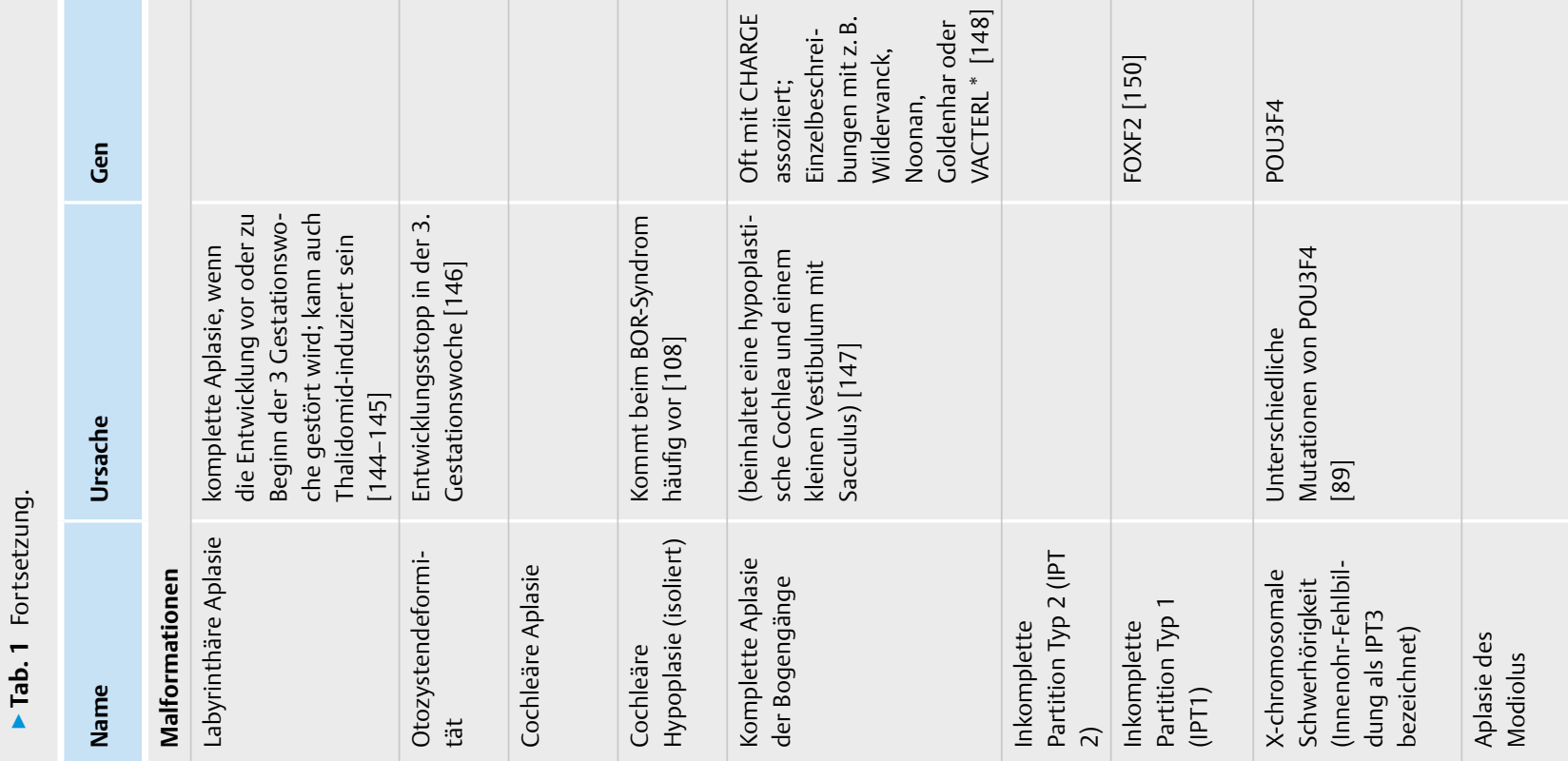

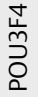




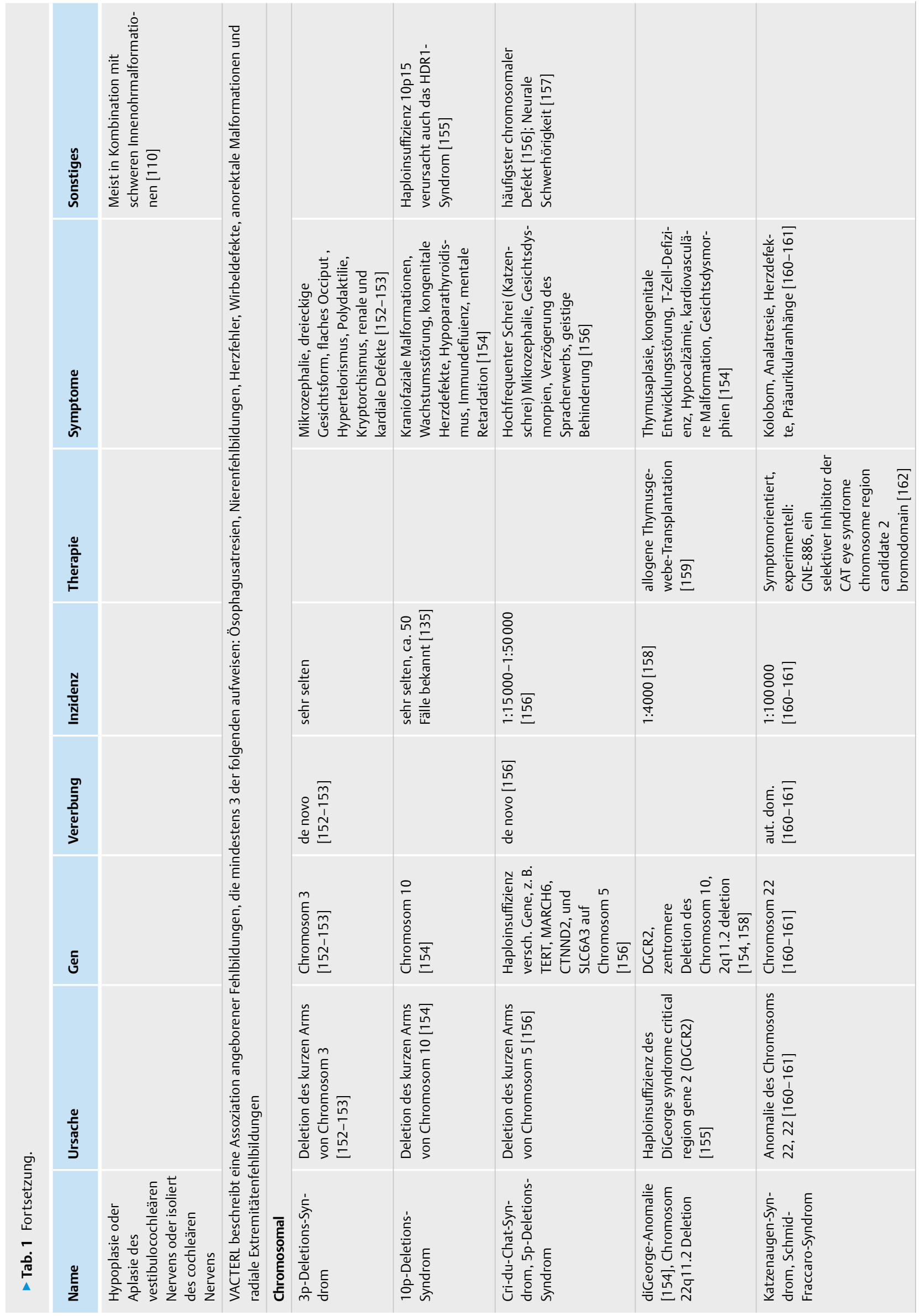




\begin{tabular}{|c|c|c|c|c|c|c|c|c|c|}
\hline 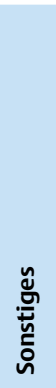 & 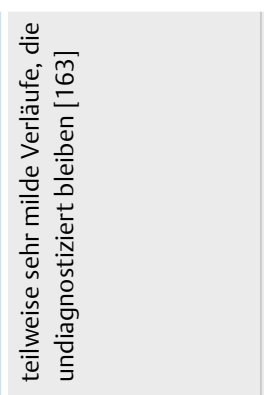 & 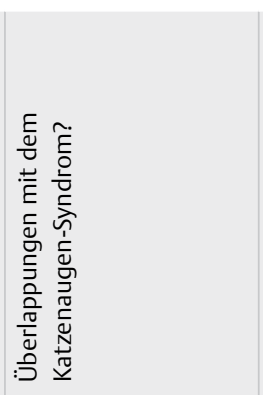 & & 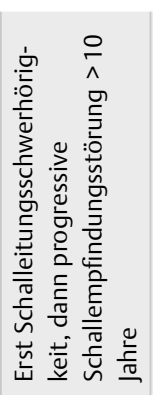 & 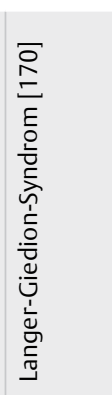 & & & 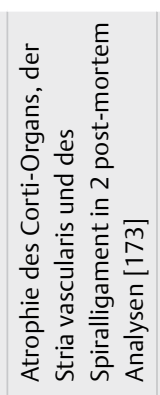 & 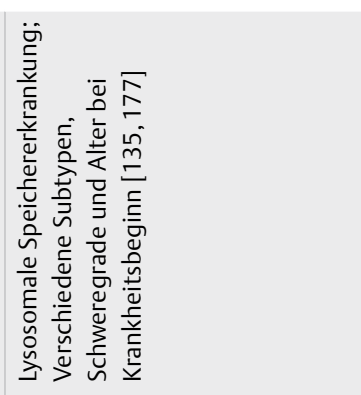 \\
\hline 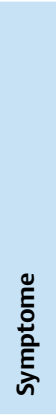 & 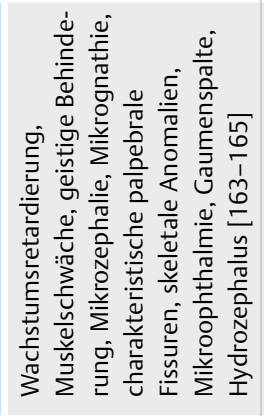 & 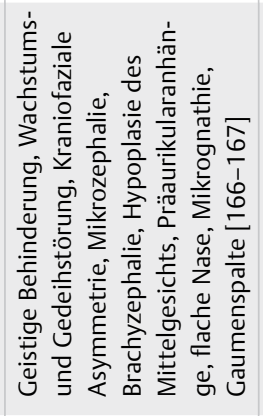 & 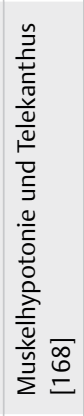 & 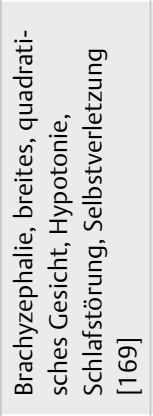 & 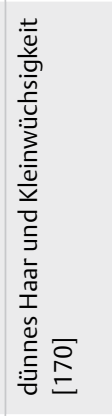 & & 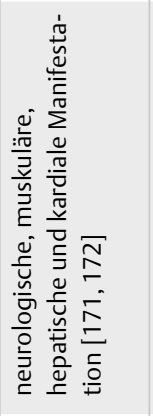 & 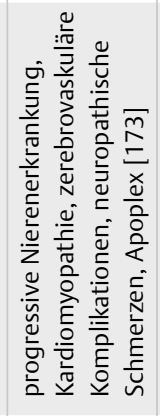 & 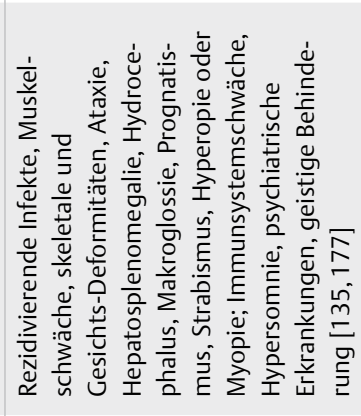 \\
\hline 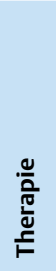 & & & & & & & 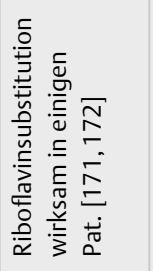 & 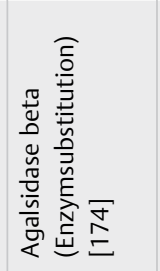 & 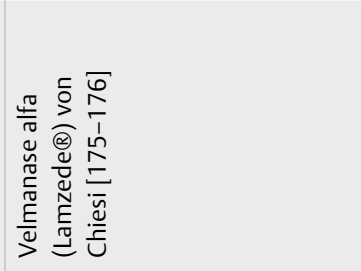 \\
\hline 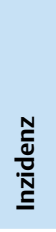 & & & 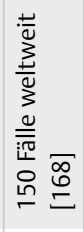 & 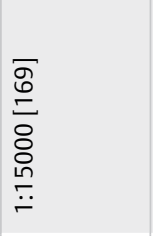 & 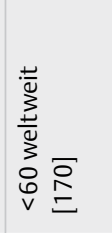 & & 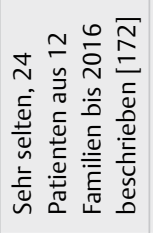 & 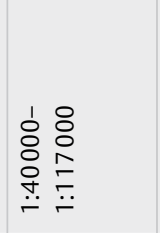 & 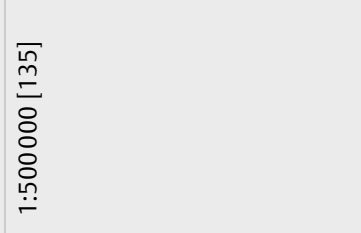 \\
\hline 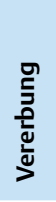 & & & & & & & 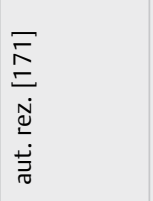 & 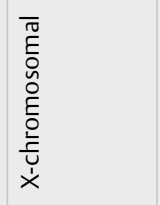 & $\begin{array}{l}\stackrel{N}{\stackrel{N}{L}} \\
\dot{\vec{J}}\end{array}$ \\
\hline ভ్ & 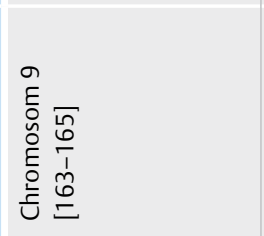 & 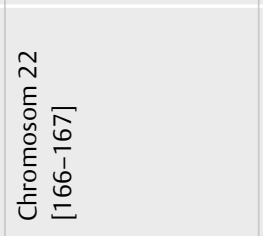 & & $\begin{array}{l}\frac{\bar{\sigma}}{6} \\
\frac{\bar{\sigma}}{\bar{\sigma}} \\
\check{\Sigma}\end{array}$ & 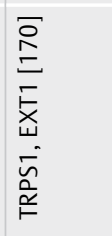 & & 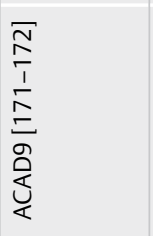 & & 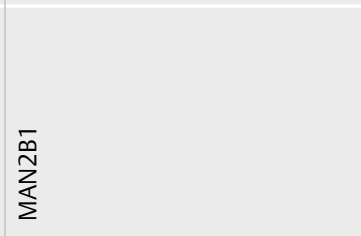 \\
\hline 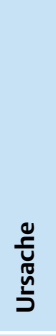 & 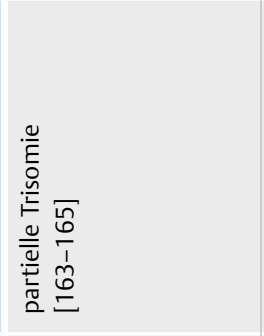 & 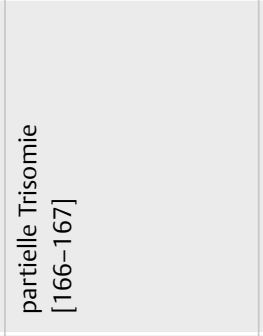 & 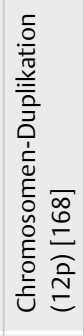 & 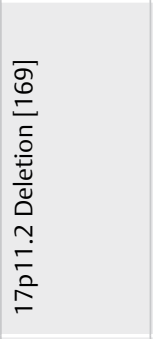 & 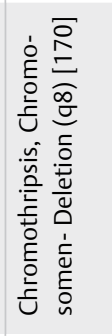 & פ & 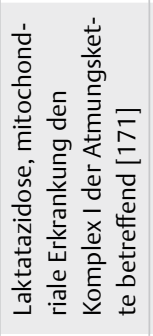 & 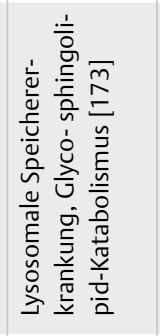 & 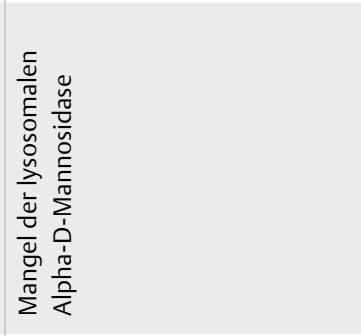 \\
\hline $\begin{array}{l}\frac{\pi}{\tilde{I}} \\
\frac{\pi}{2}\end{array}$ & 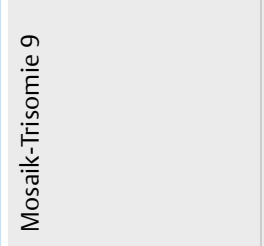 & 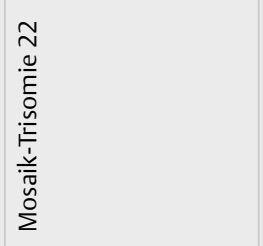 & 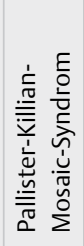 & 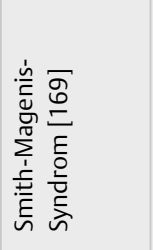 & 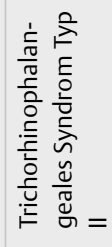 & 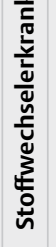 & 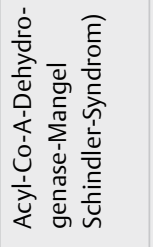 & 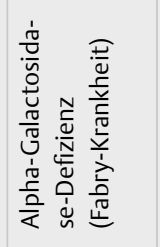 & 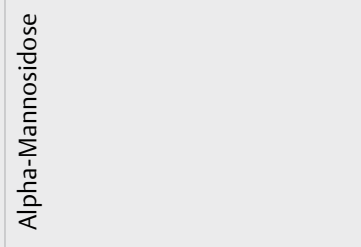 \\
\hline
\end{tabular}




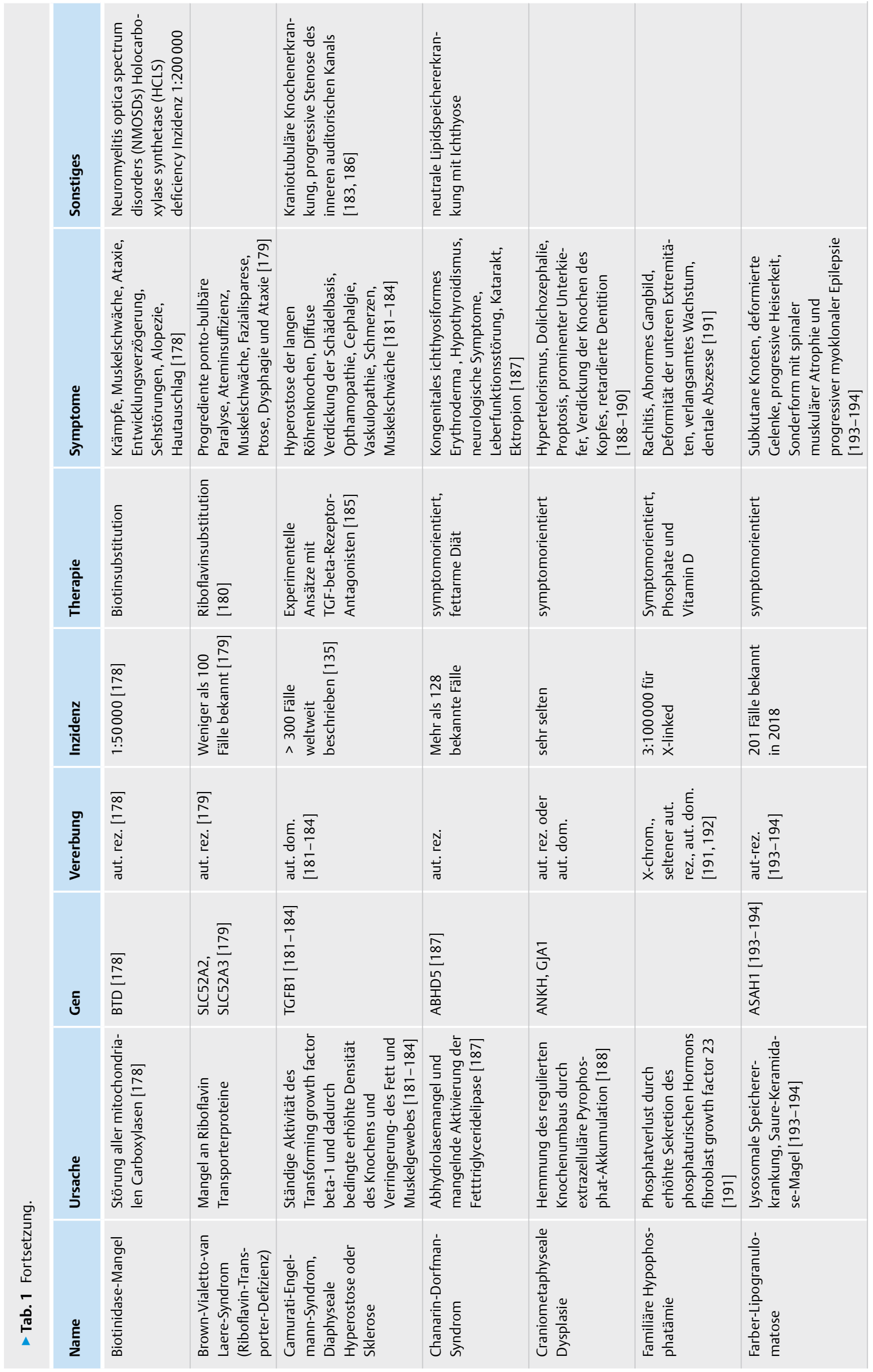




\begin{tabular}{|c|c|c|c|c|c|c|c|}
\hline 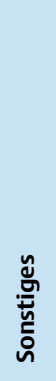 & & 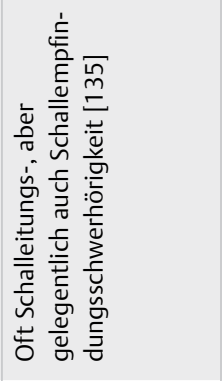 & 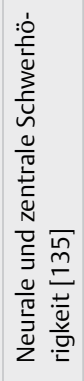 & 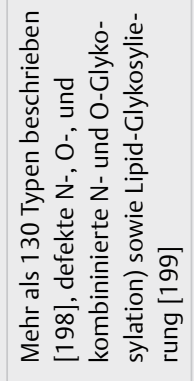 & & & 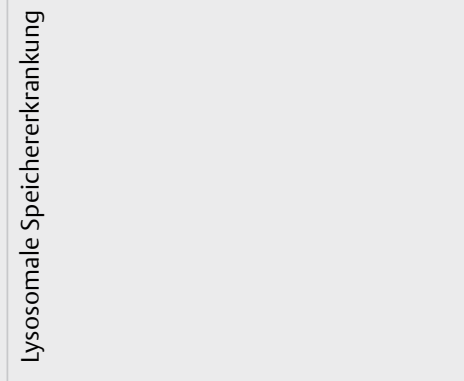 \\
\hline 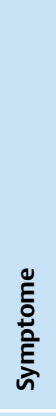 & 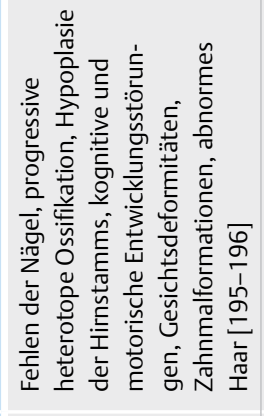 & 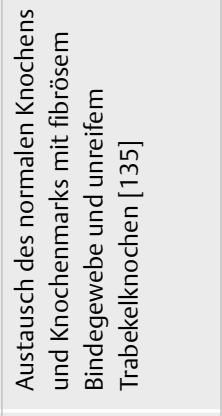 & 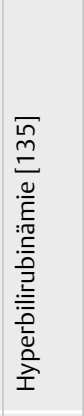 & 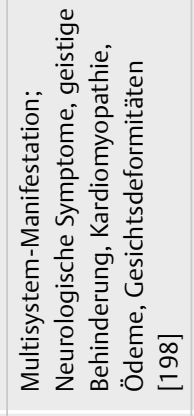 & 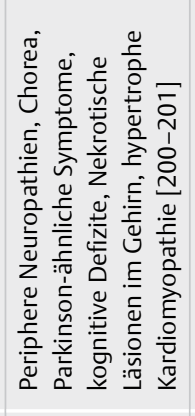 & 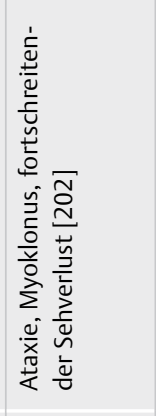 & 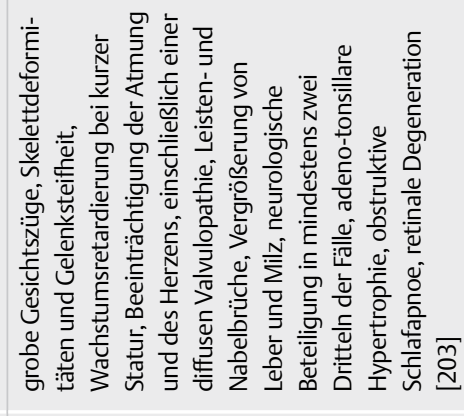 \\
\hline 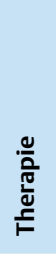 & 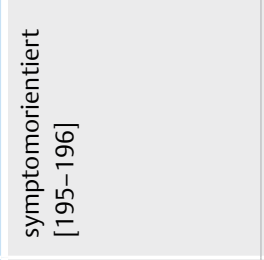 & 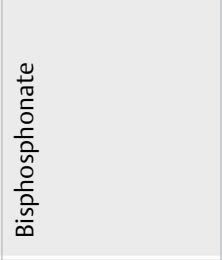 & & 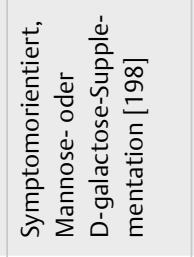 & 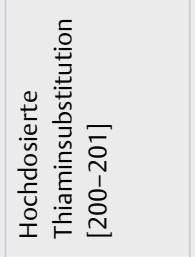 & & 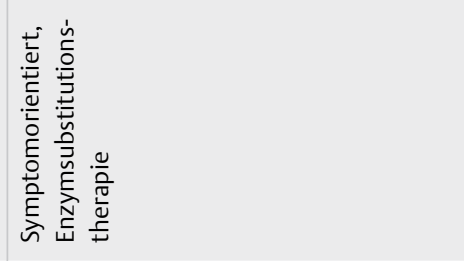 \\
\hline 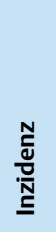 & 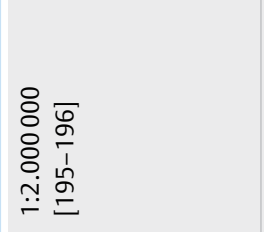 & 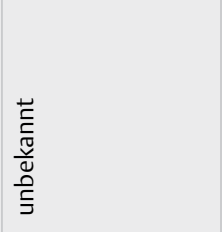 & 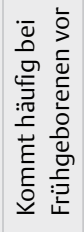 & 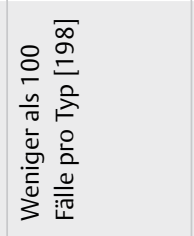 & 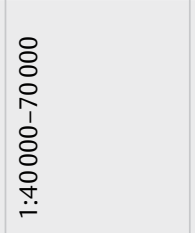 & 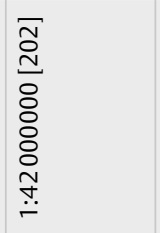 & 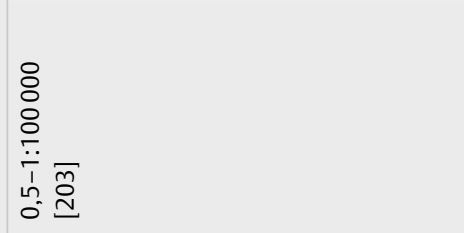 \\
\hline 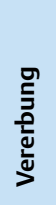 & 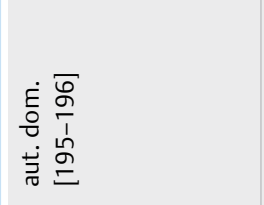 & 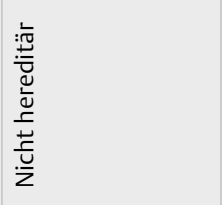 & 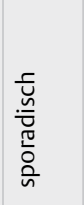 & 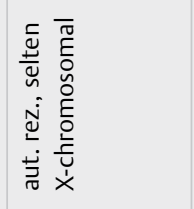 & 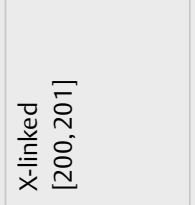 & 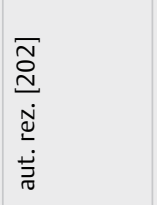 & 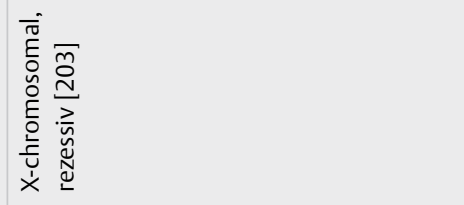 \\
\hline ভ্ & 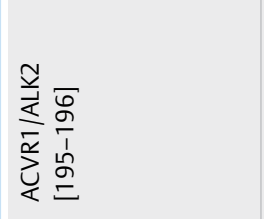 & $\sum_{j}^{n}$ & & 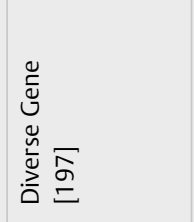 & 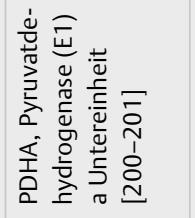 & 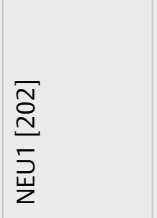 & $\begin{array}{l}\overline{\tilde{n}} \\
\stackrel{\tilde{U}}{\underline{\varrho}}\end{array}$ \\
\hline 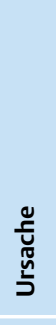 & 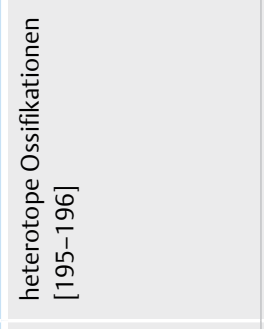 & 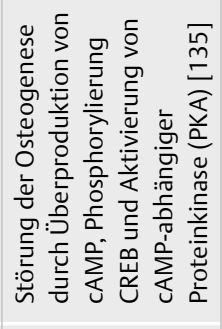 & 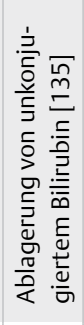 & 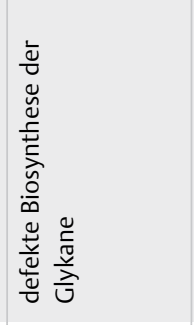 & 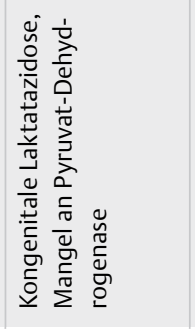 & 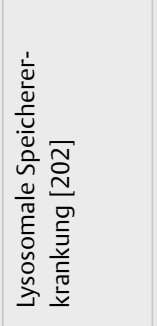 & \\
\hline 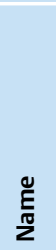 & 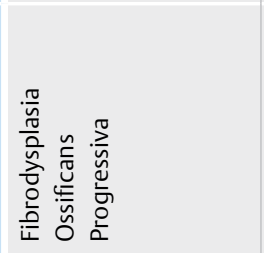 & 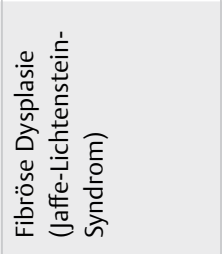 & 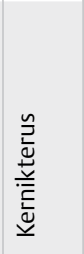 & 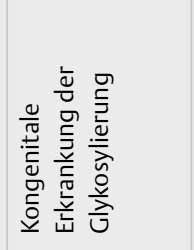 & 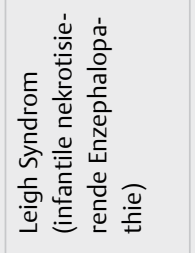 & 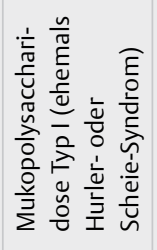 & 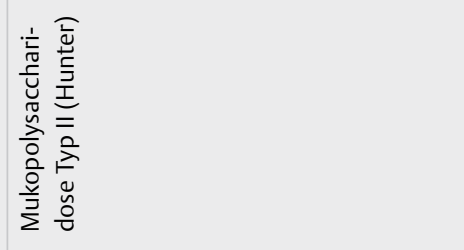 \\
\hline
\end{tabular}




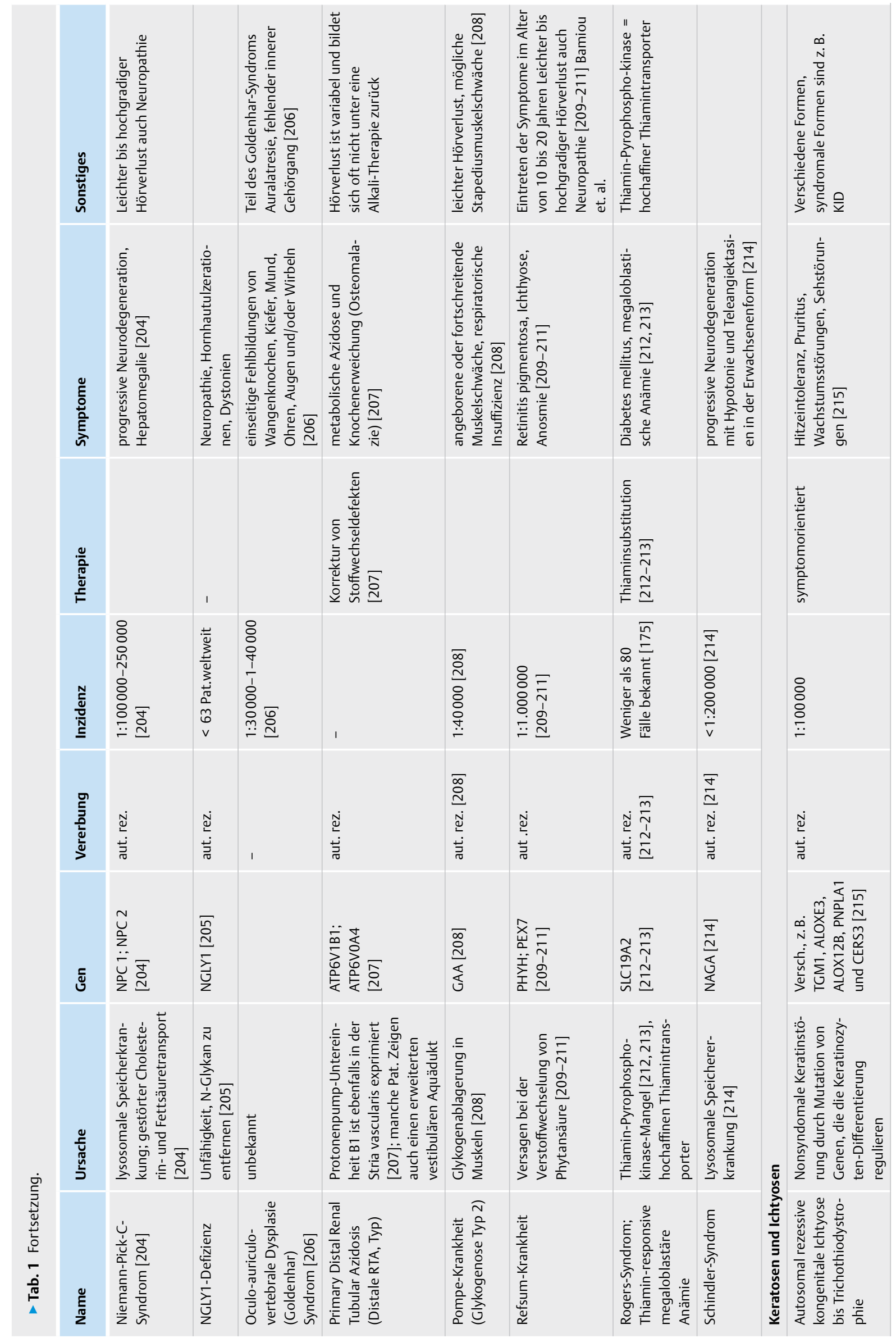




\begin{tabular}{|c|c|c|c|c|c|c|c|c|c|}
\hline 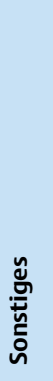 & & 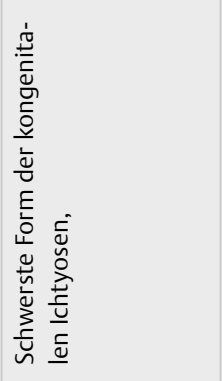 & 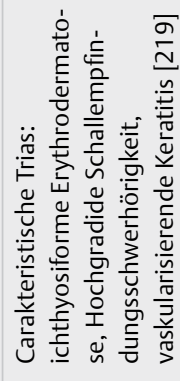 & & 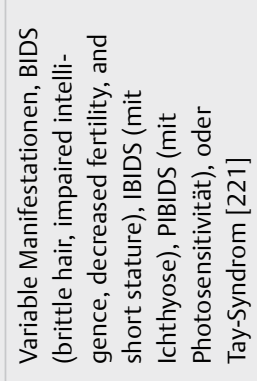 & & & & \\
\hline ڤั & 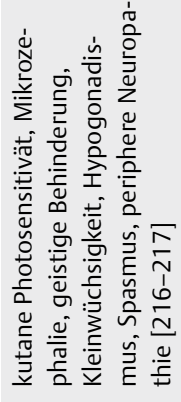 & 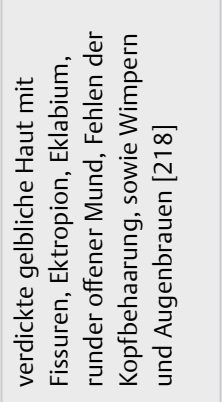 & 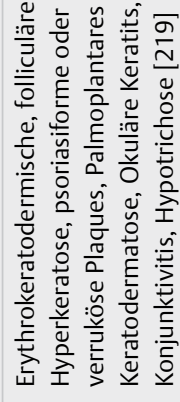 & 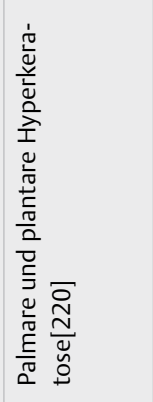 & 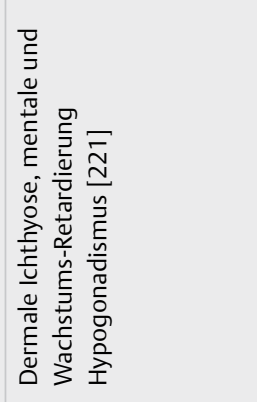 & & 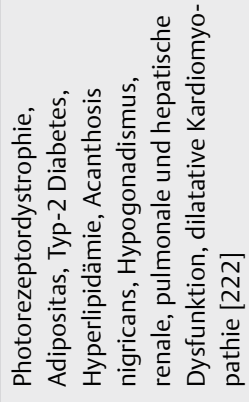 & 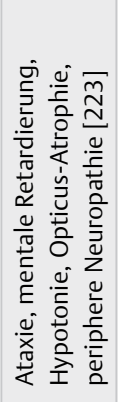 & 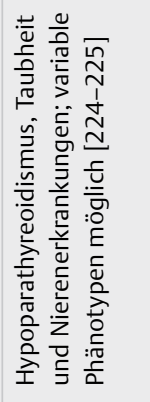 \\
\hline 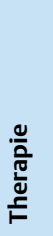 & 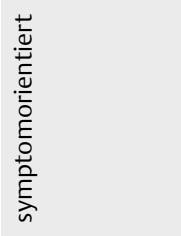 & 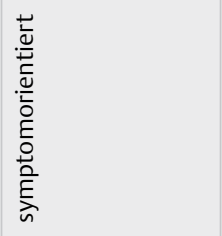 & & & & & ஏ & & 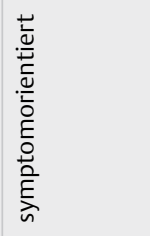 \\
\hline 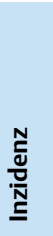 & 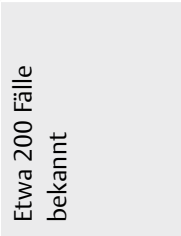 & 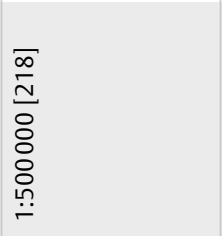 & 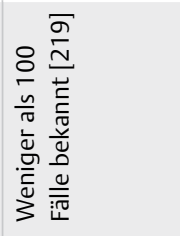 & 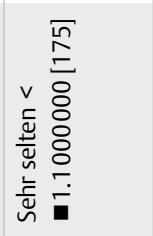 & 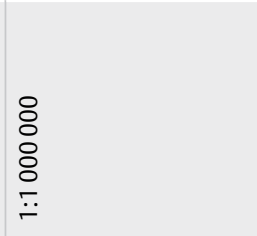 & & 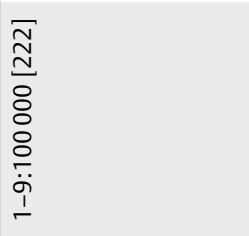 & 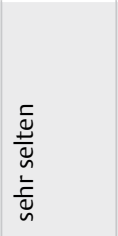 & 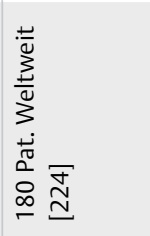 \\
\hline 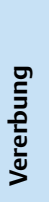 & 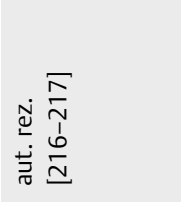 & 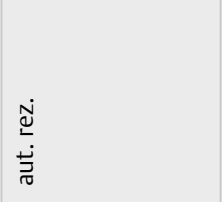 & 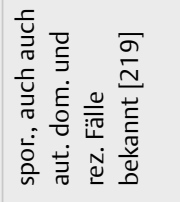 & 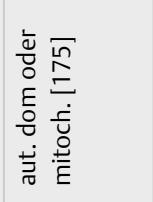 & 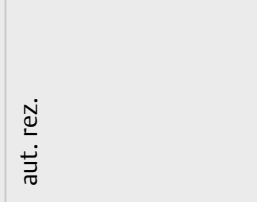 & & 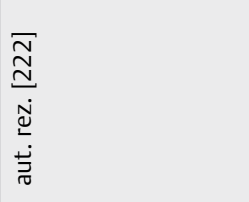 & 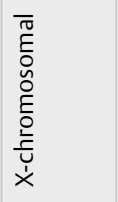 & $\begin{array}{l}\dot{\dot{E}} \\
\text { o } \\
\dot{\vec{J}}\end{array}$ \\
\hline ভ్ & 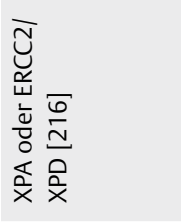 & 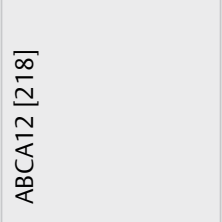 & $\begin{array}{l}\frac{\sigma}{\stackrel{N}{N}} \\
\frac{N}{\sigma}\end{array}$ & 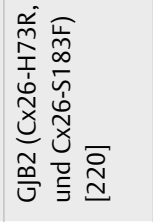 & 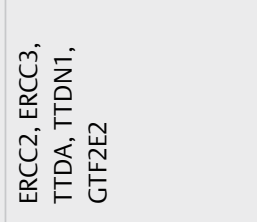 & & 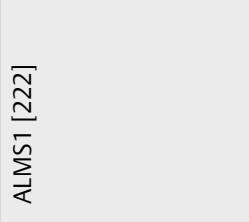 & 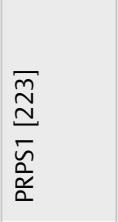 & 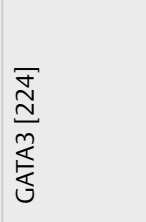 \\
\hline 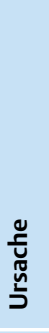 & 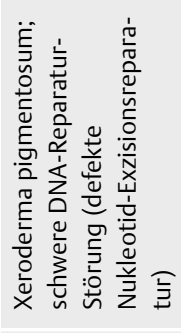 & 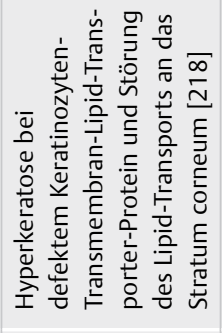 & 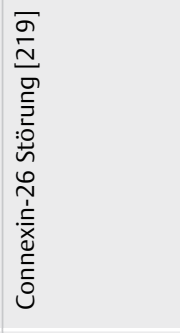 & 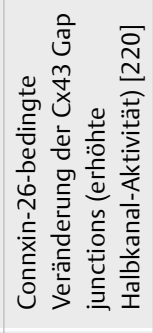 & 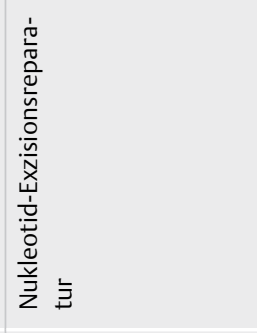 & & 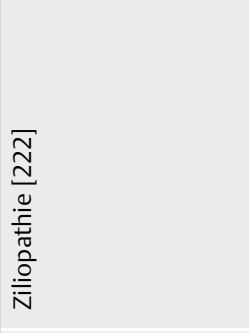 & 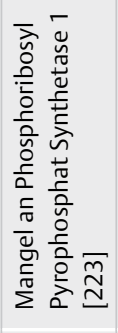 & 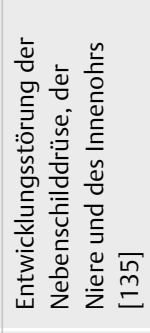 \\
\hline $\begin{array}{l}\text { 导 } \\
\text { ż }\end{array}$ & 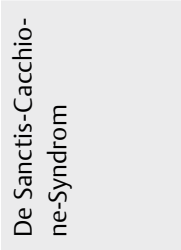 & 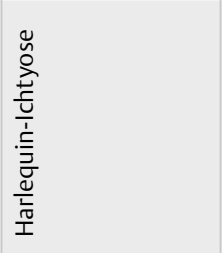 & 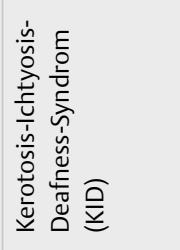 & 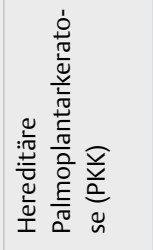 & 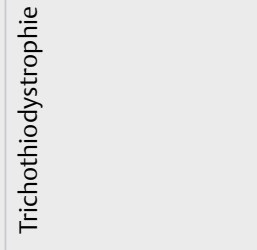 & & 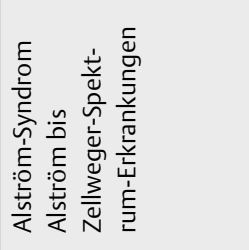 & 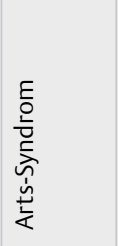 & 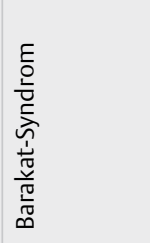 \\
\hline
\end{tabular}




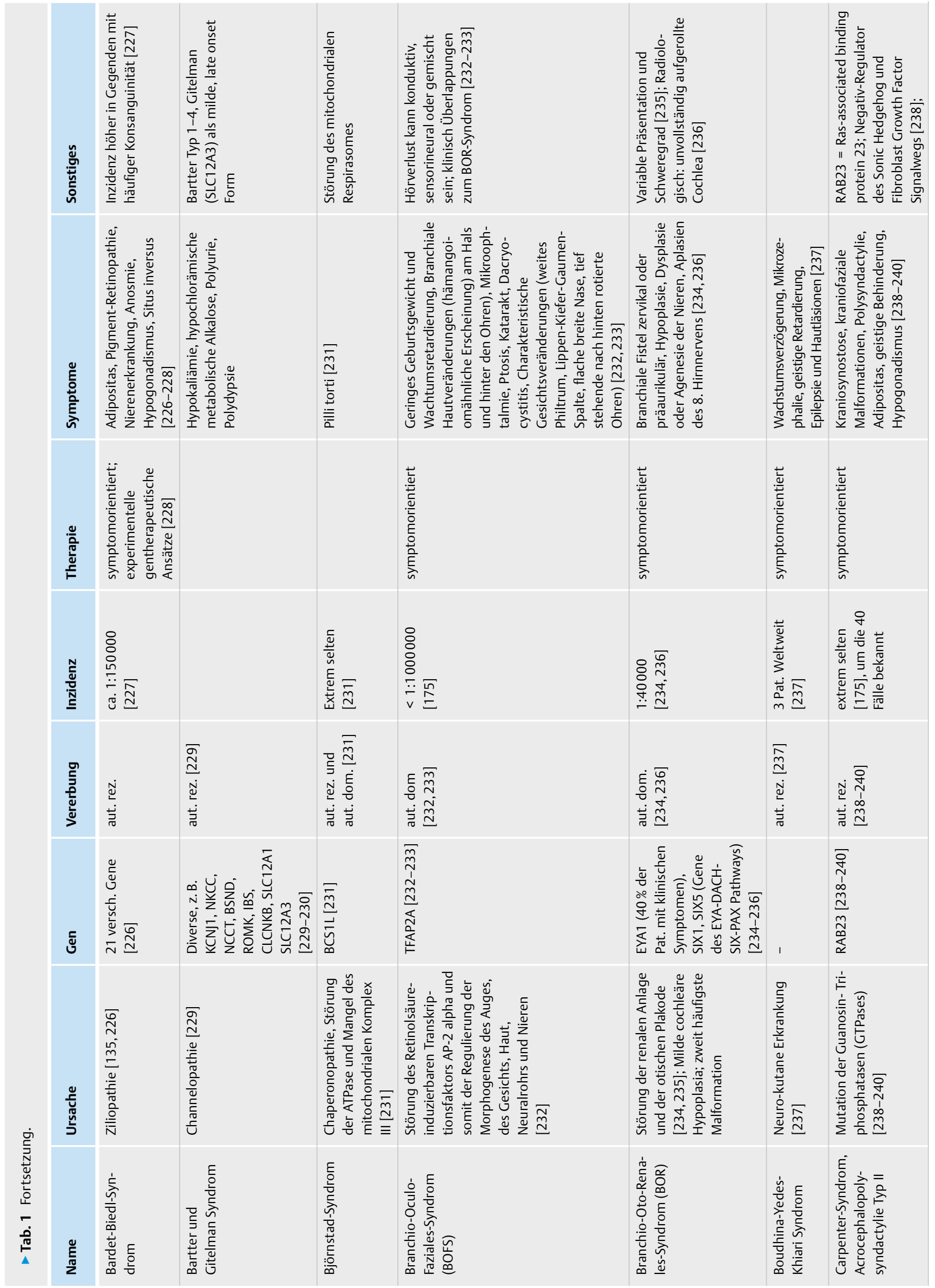




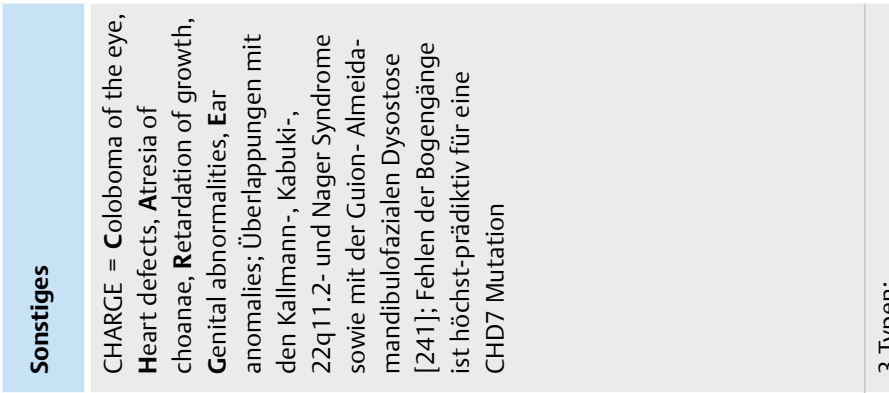

$\underset{m}{\stackrel{0}{\grave{\Delta}}}$
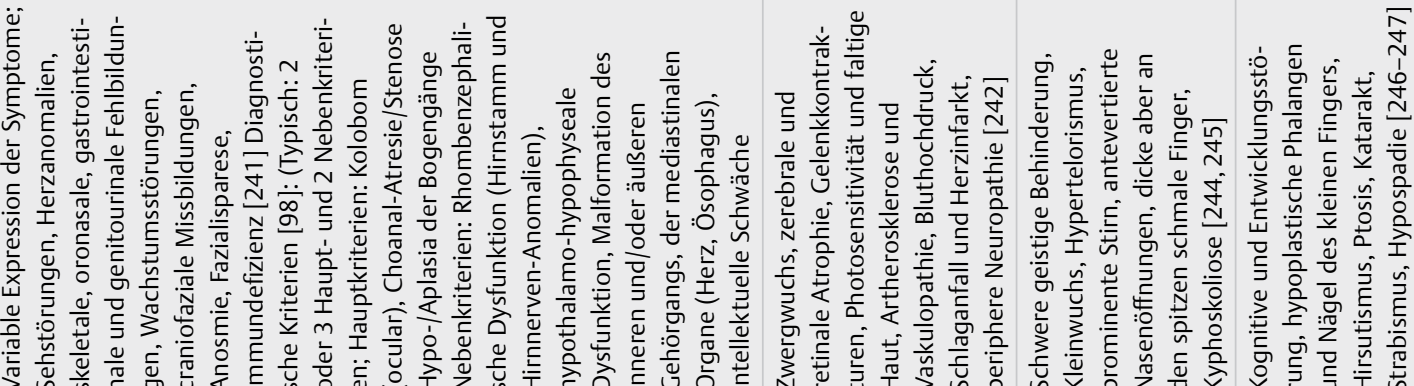

总

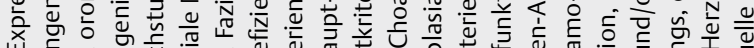

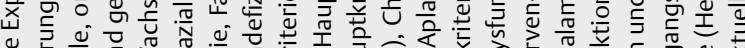
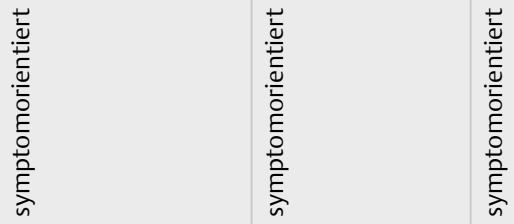

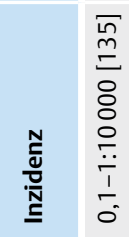

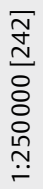

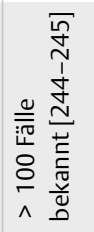

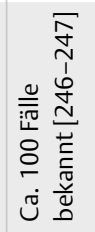

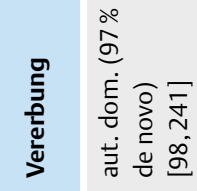

离

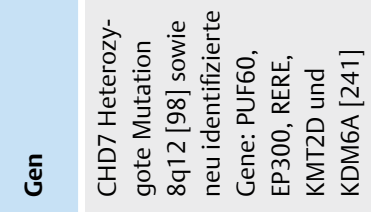

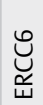

$\underset{\mathscr{U}}{\mathscr{\Psi}}$

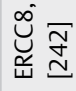

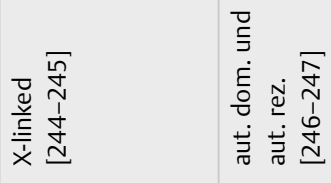
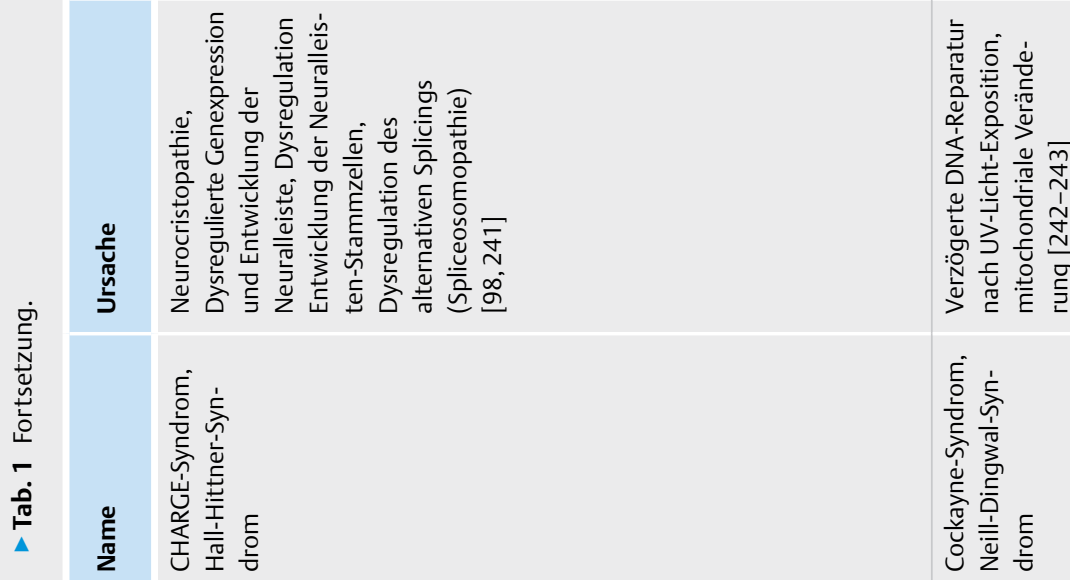

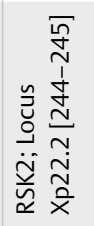
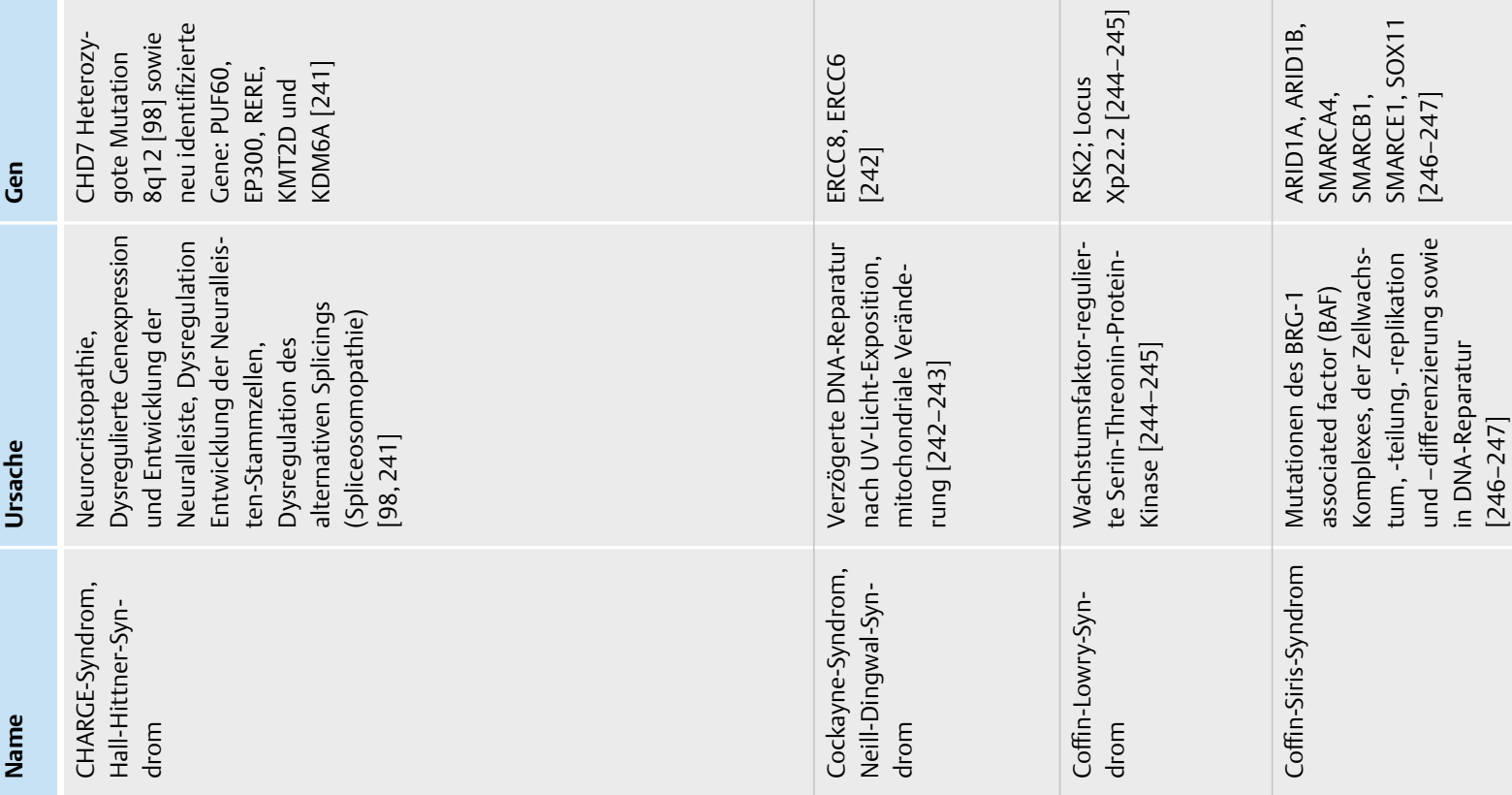

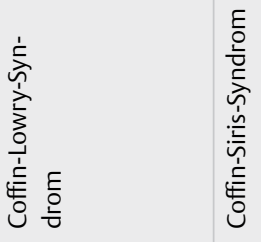




\begin{tabular}{|c|c|c|c|c|c|c|c|c|c|}
\hline & 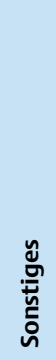 & & 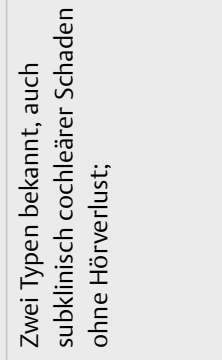 & & 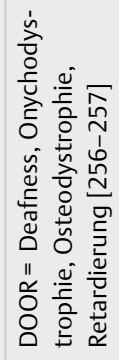 & 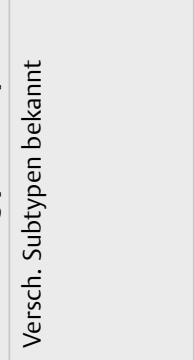 & & 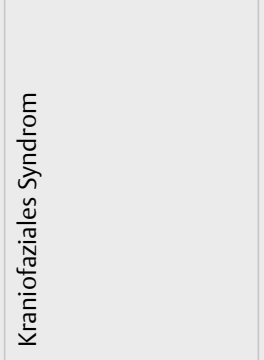 & 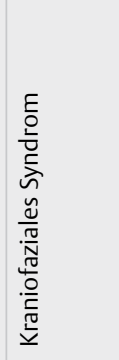 \\
\hline & $\begin{array}{l}\text { Еั } \\
\text { ڤัँ } \\
\text { जे }\end{array}$ & 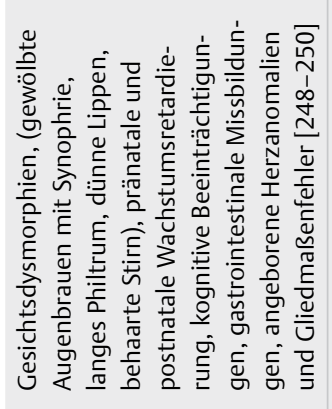 & 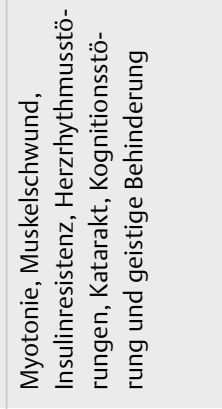 & 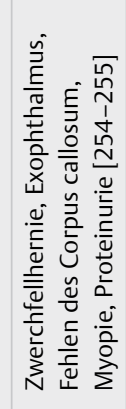 & 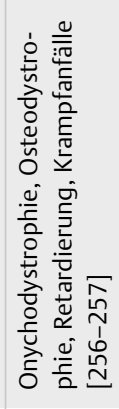 & 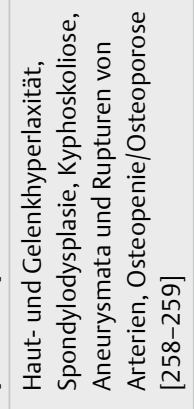 & 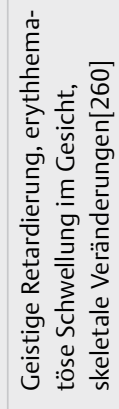 & 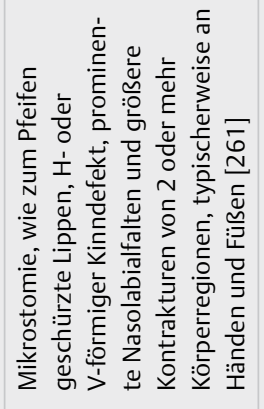 & 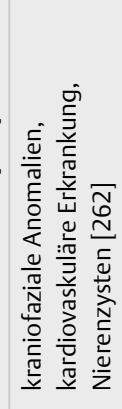 \\
\hline & 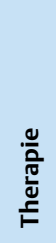 & 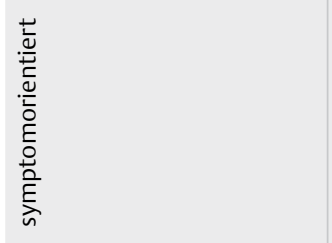 & & 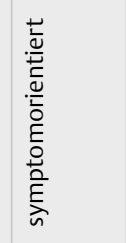 & 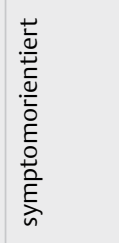 & 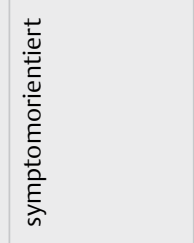 & 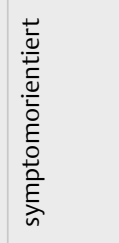 & 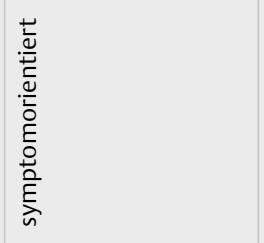 & 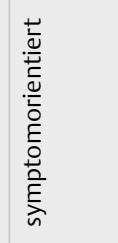 \\
\hline & & 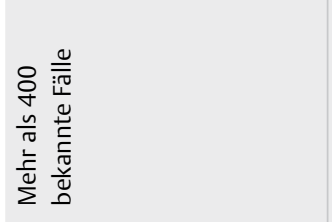 & & 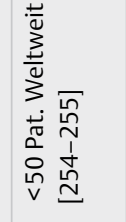 & 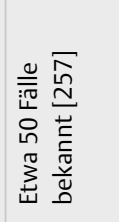 & 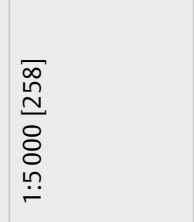 & 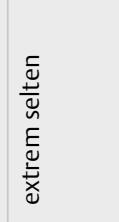 & 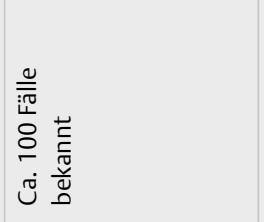 & 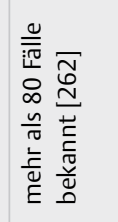 \\
\hline & 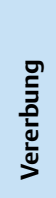 & 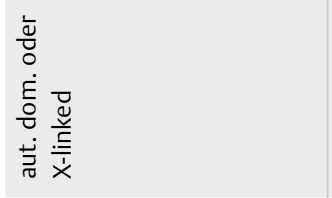 & $\begin{array}{l}\dot{E} \\
\dot{0} \\
\dot{0} \\
\dot{J}\end{array}$ & 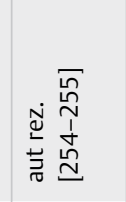 & 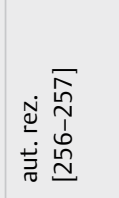 & 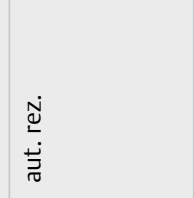 & $\begin{array}{l}\dot{N} \\
\stackrel{N}{J} \\
\stackrel{J}{J}\end{array}$ & 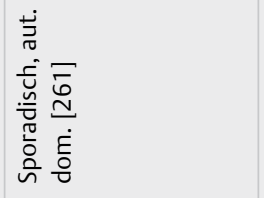 & $\begin{array}{l}\dot{E} \\
\stackrel{0}{0} \\
\dot{\vec{J}} \\
\bar{\sigma}\end{array}$ \\
\hline & ভٓ & 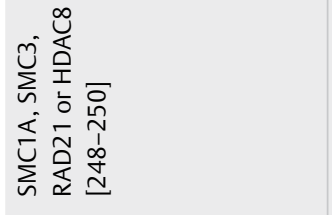 & 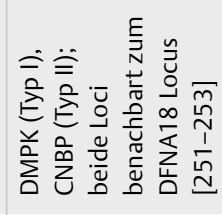 & 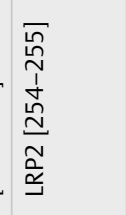 & 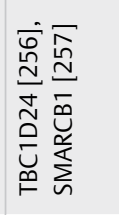 & 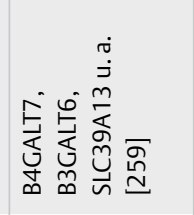 & 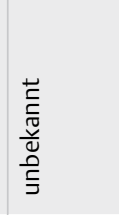 & 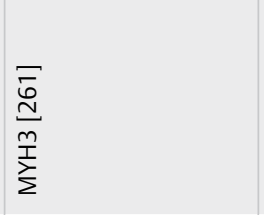 & 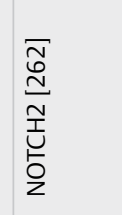 \\
\hline 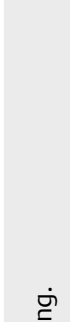 & 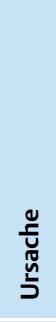 & 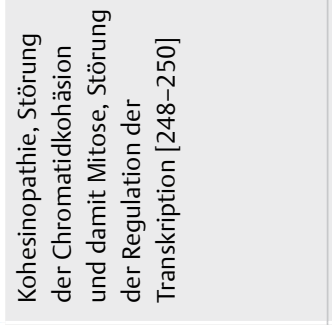 & 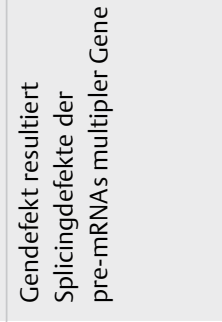 & 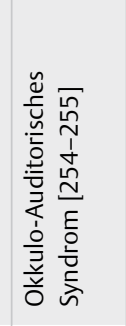 & 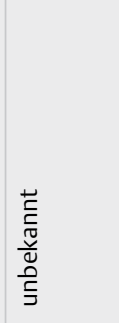 & 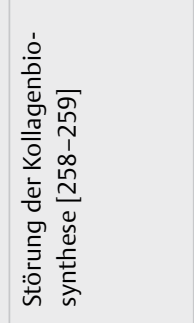 & 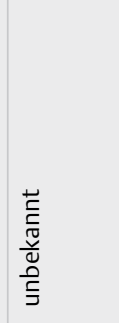 & 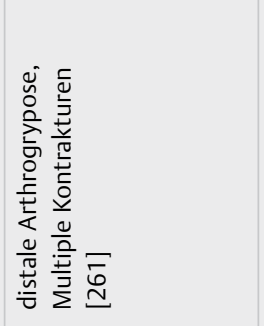 & 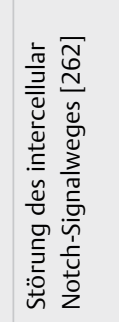 \\
\hline 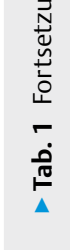 & 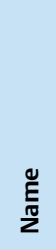 & 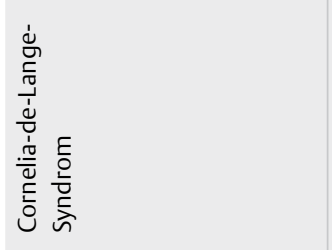 & 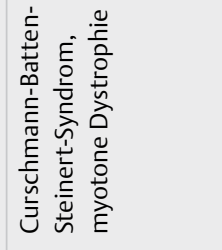 & 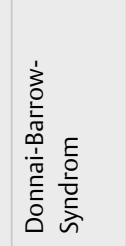 & 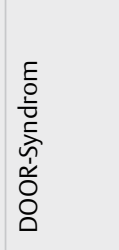 & 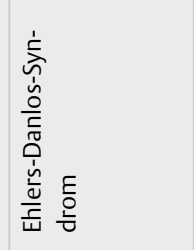 & 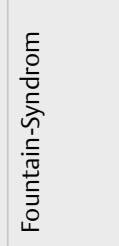 & 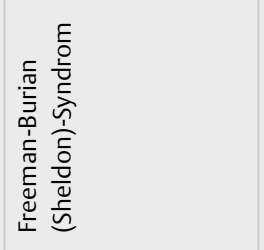 & 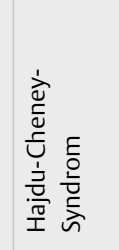 \\
\hline
\end{tabular}




\begin{tabular}{|c|c|c|c|c|c|c|}
\hline & 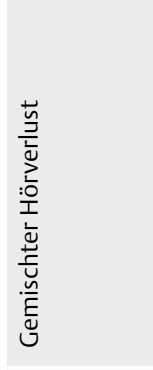 & & & 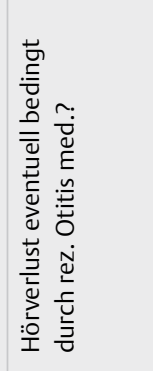 & & 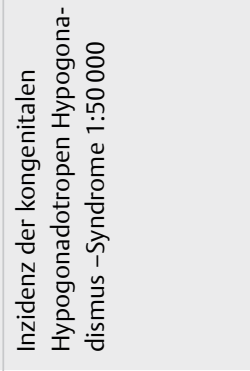 \\
\hline & 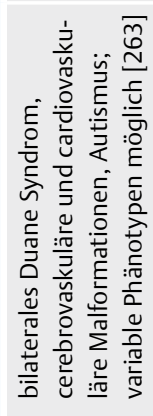 & 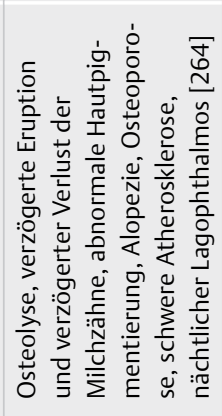 & 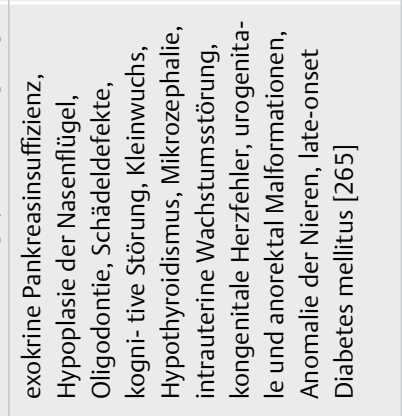 & 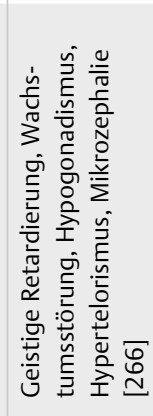 & 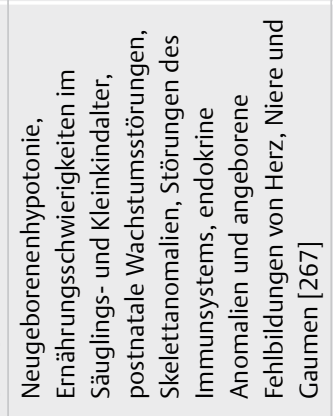 & 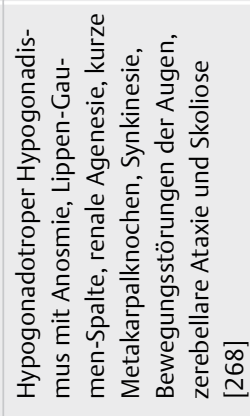 \\
\hline & & & & 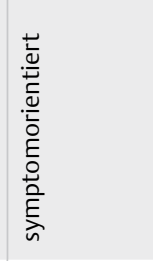 & & 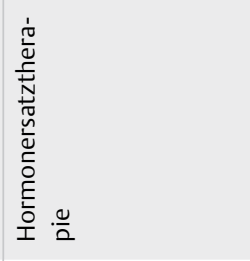 \\
\hline & 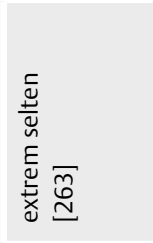 & 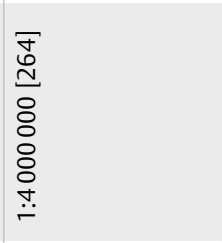 & 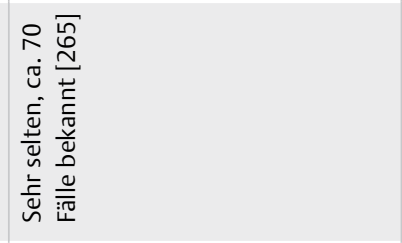 & 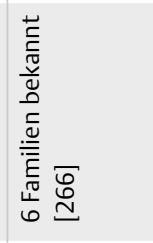 & 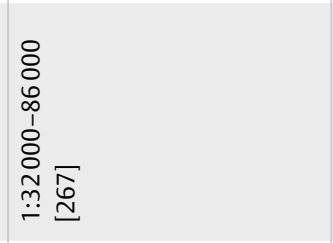 & 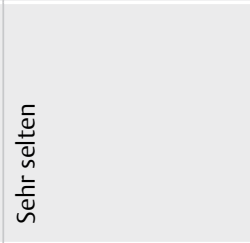 \\
\hline & 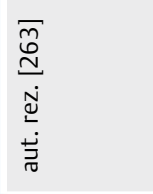 & 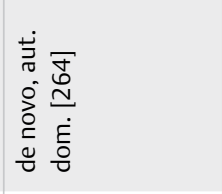 & 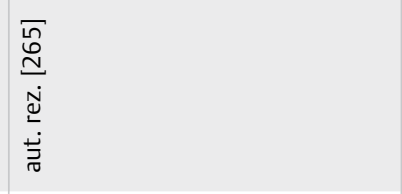 & 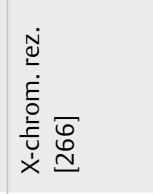 & 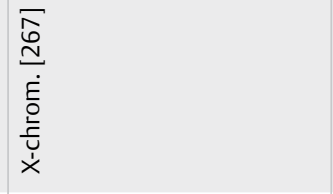 & 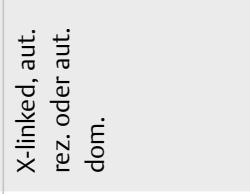 \\
\hline & 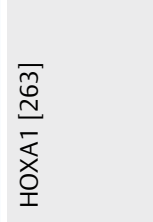 & $\begin{array}{l}\bar{F} \\
\stackrel{D}{d} \\
\vdots \\
\sum\end{array}$ & 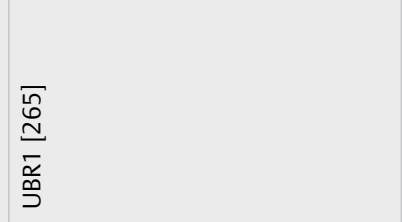 & 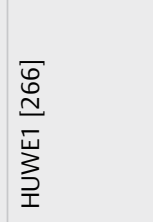 & 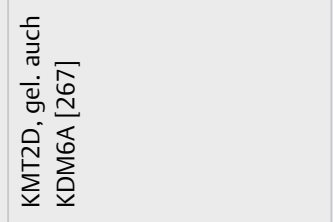 & 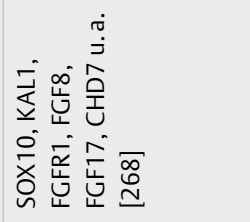 \\
\hline & 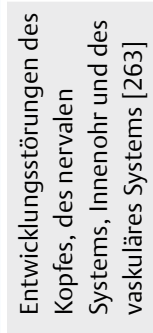 & 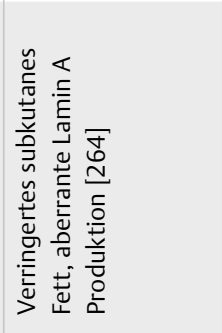 & 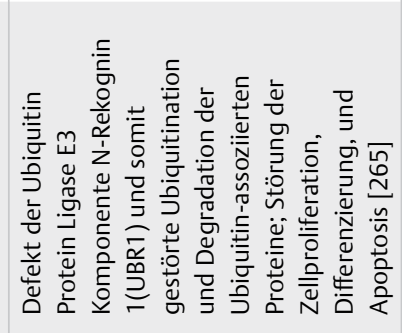 & 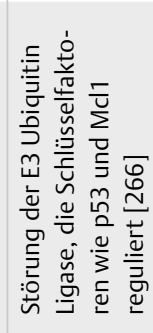 & 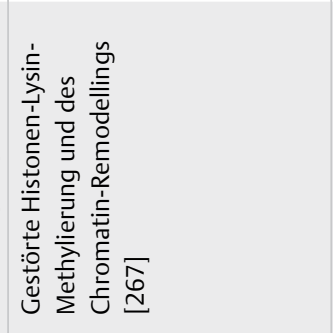 & 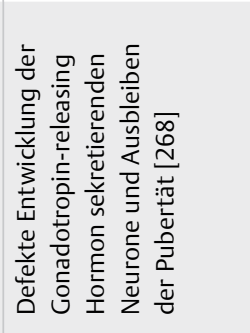 \\
\hline & 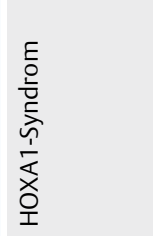 & 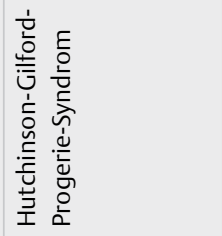 & 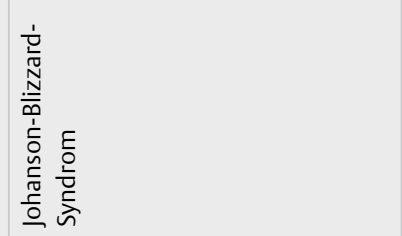 & 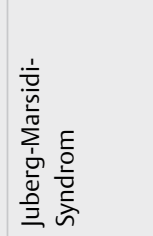 & 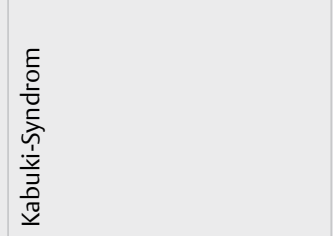 & 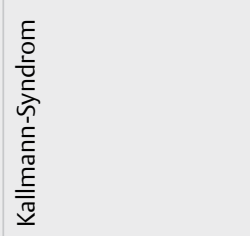 \\
\hline
\end{tabular}




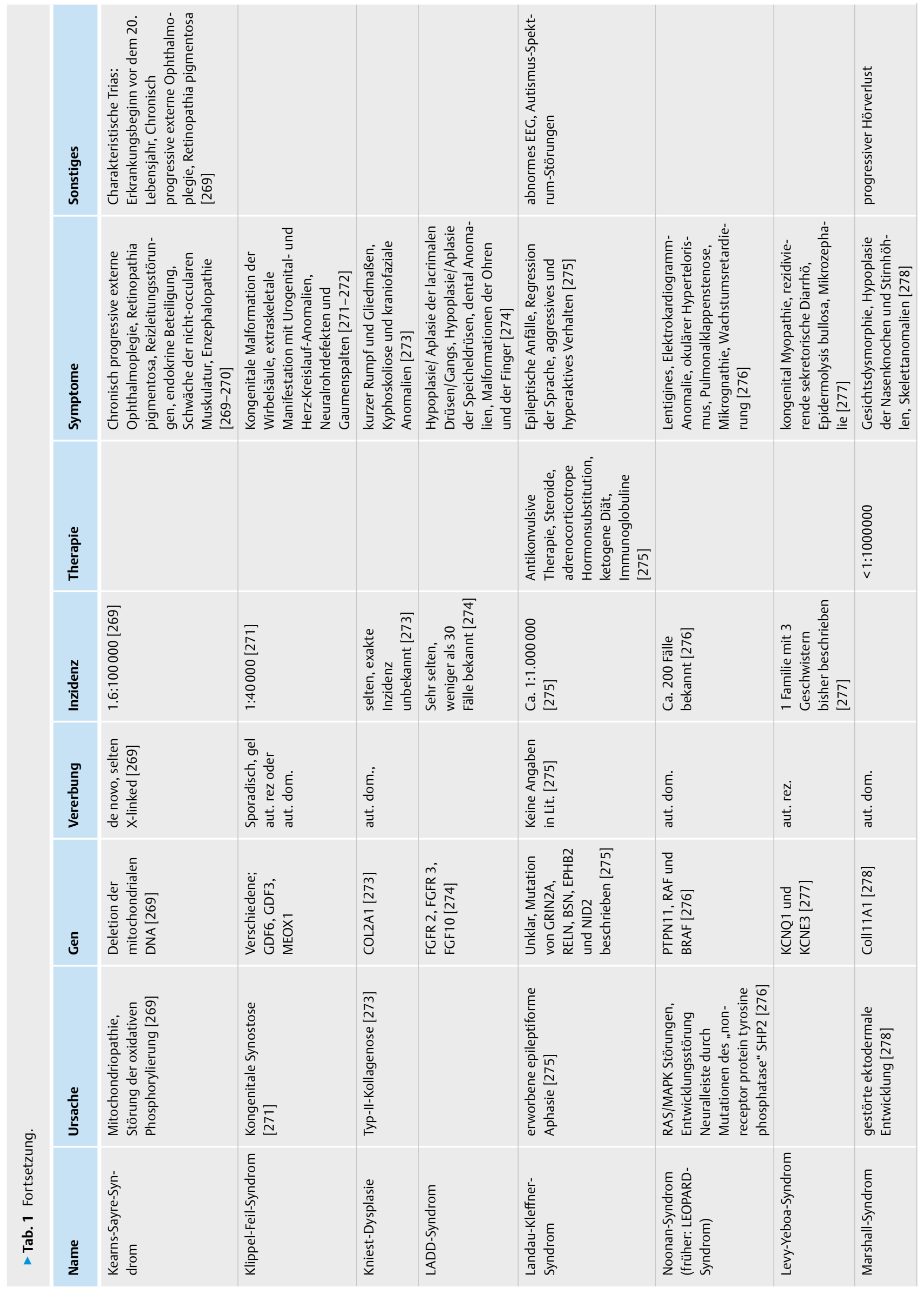




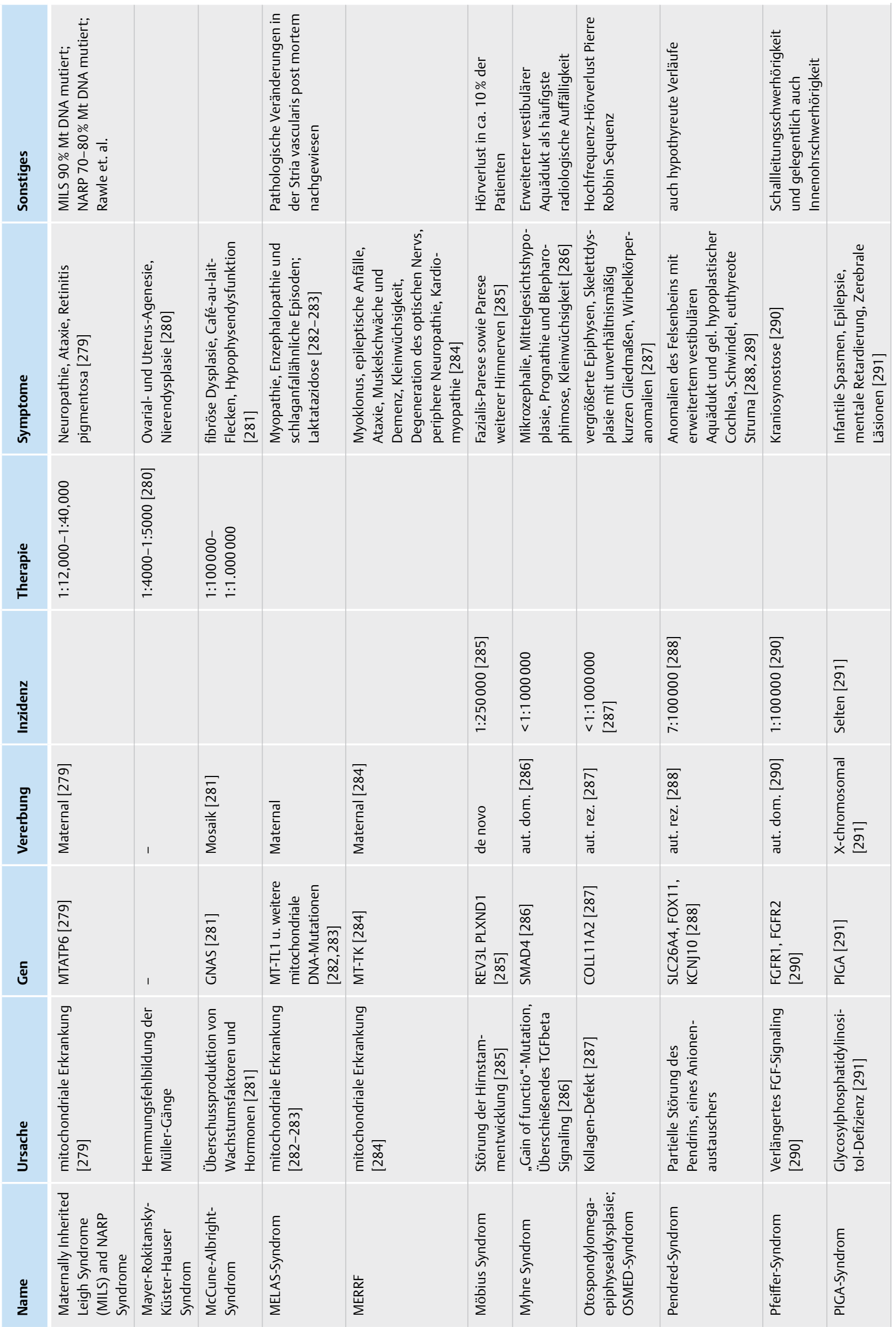




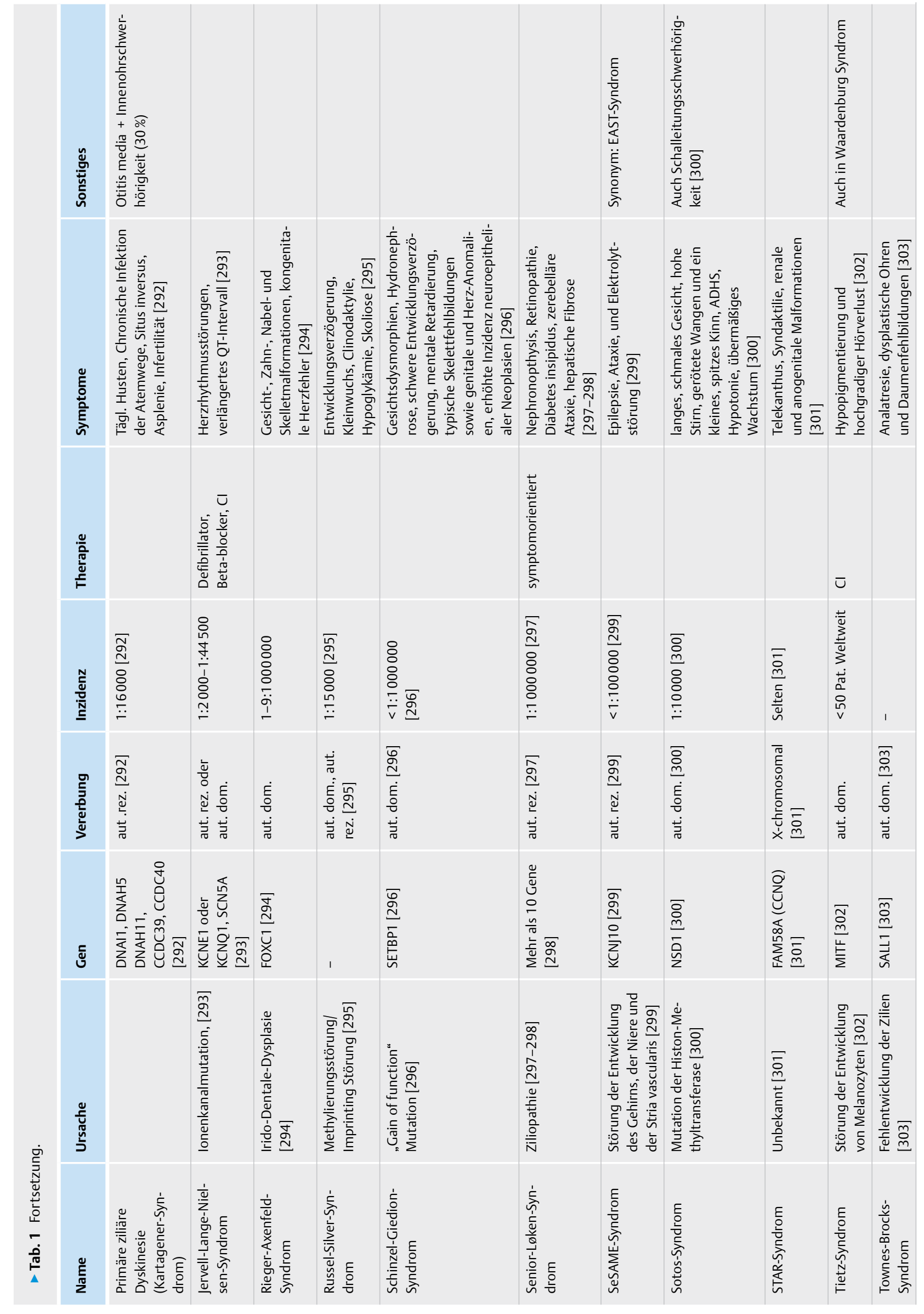




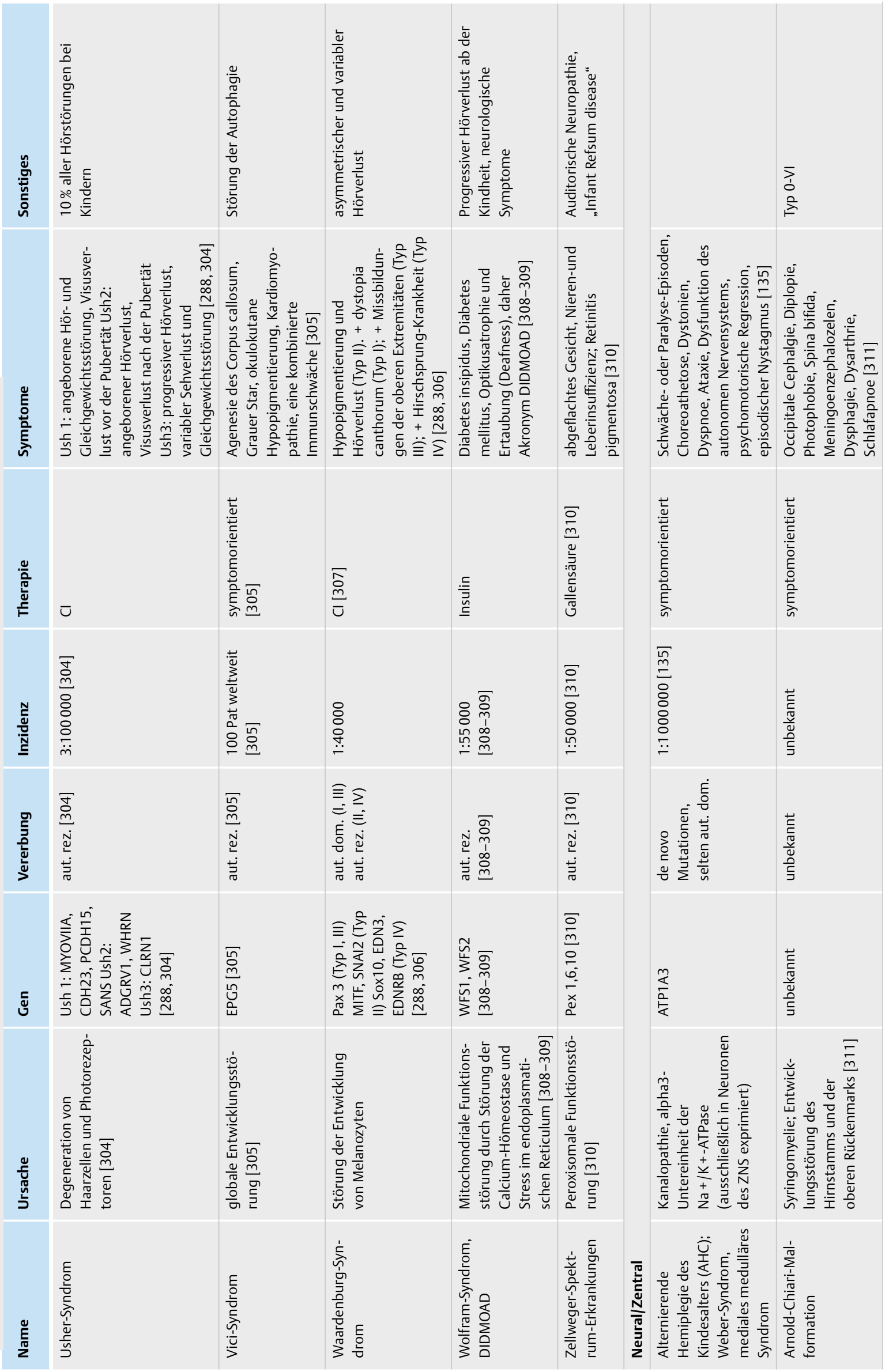




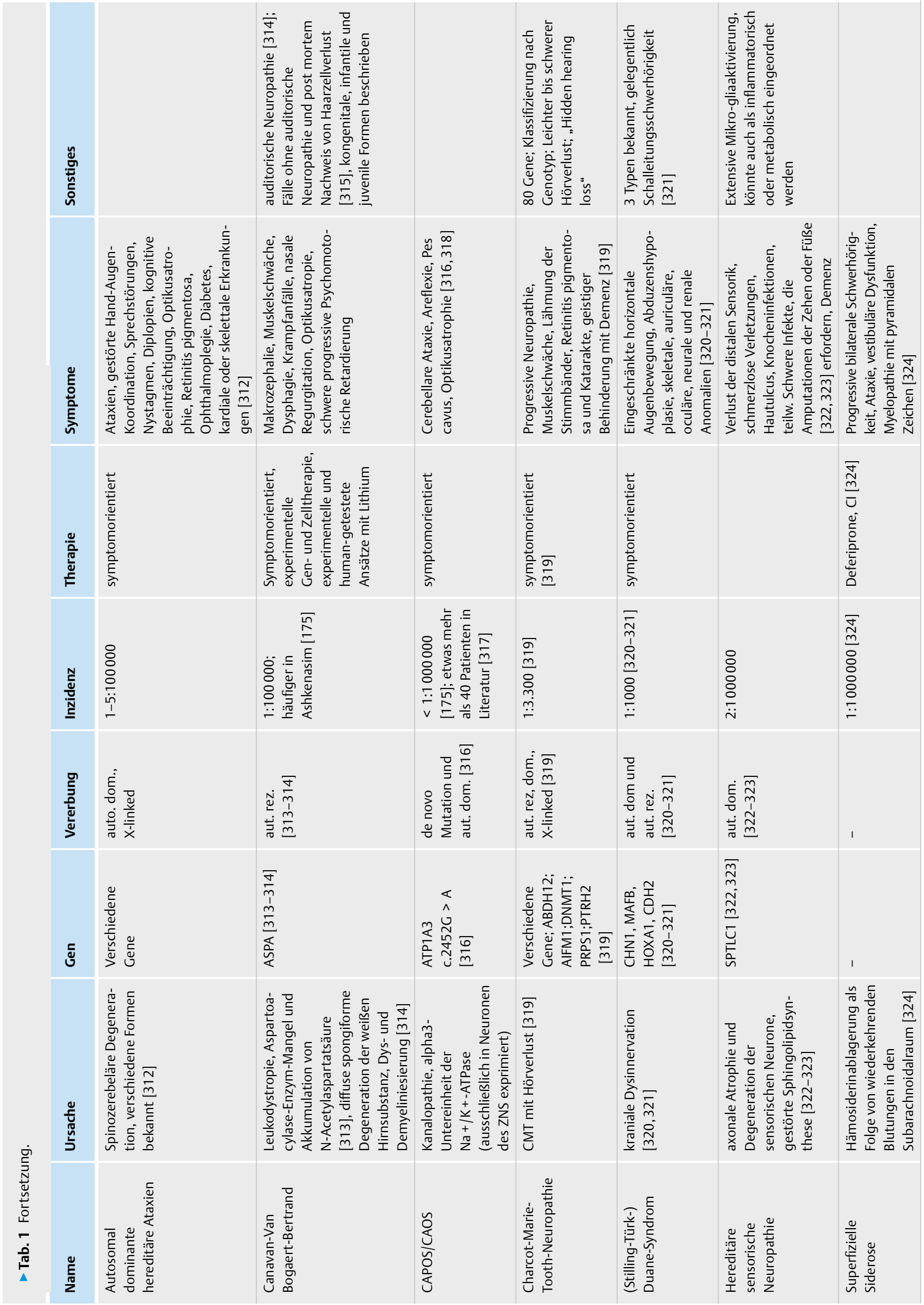




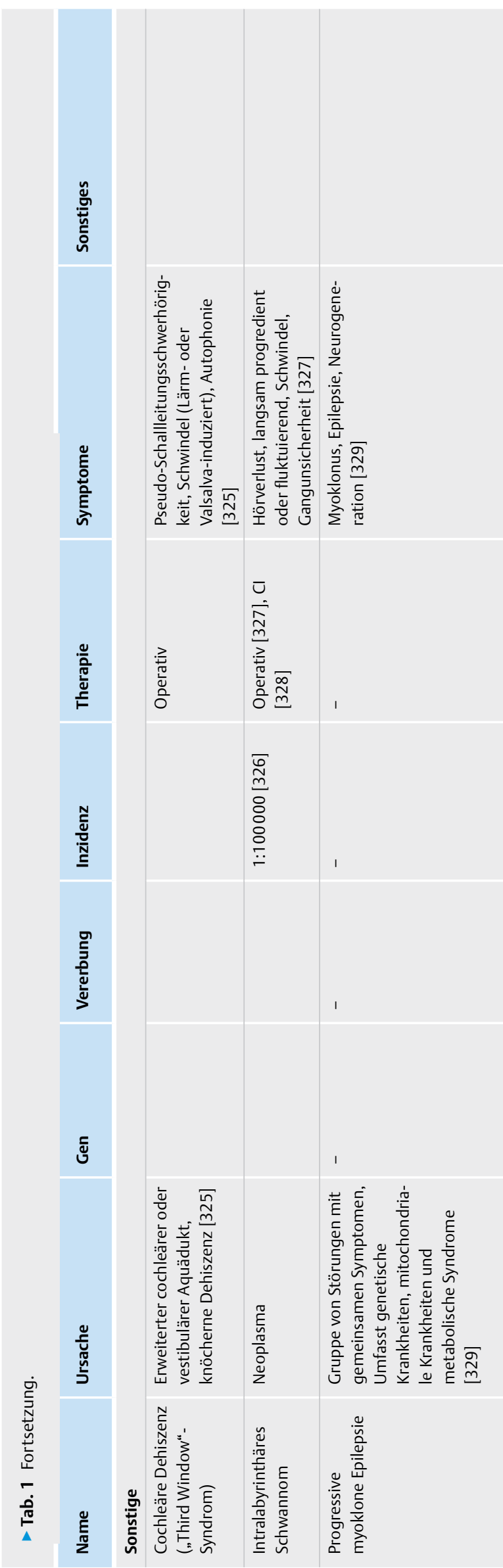

die mit zunehmendem Alter verloren gehen, ermöglicht werden [53]. Des weiteren hat die Entdeckung Wnt-reaktiver Vorläuferzellen in der murinen Cochlea, die positiv für LGR5 sind [54], gezeigt, dass Haarzellregeneration durch die Blockierung des Notch-Signals gefördert wird [55] und in der erwachsenen Cochlea auch bei Säugetieren durchaus möglich ist [56]. Im Rahmen der humanen Embryonalentwicklung des Innenohrs steigt die Expression von LGR5 von der 8. bis zur 12. Gestationswoche an [57]. In diesem Zeitraum findet auch die Entwicklung des Corti-Organs statt. Interessanterweise ist der LGR5-Proteinkomplex, der in den apikalen Polen des sensorischen Epithels der Cochlea nachgewiesen wurde, ab der 12. Gestationswoche nur noch auf die Haarsinneszellen begrenzt [57].

Aktuelle Studien zeigen, dass insbesondere auch Proteoglykane der extrazellulären Matrix an der Entwicklung der Haarsinneszellen und Spiralganglienneurone beteiligt sind, indem sie bestimmte Gene hoch- oder runterregulieren [58].

\subsection{Embryonale Entwicklungsprinzipien - Verknüp- fung zu anderen Organsystemen}

Im Rahmen der Organogenese werden im Rahmen der Embryonalentwicklung organspezifische Gene hochreguliert, während Gene, die an der Zellteilung und der allgemeinen Morphogenese beteiligt sind, herunterreguliert werden [59]. Später werden dann Gene hochreguliert, die organspezifische Funktionen kodieren [59]. Speziesübergreifende und longitudinale Genexpressionsanalysen zeigen eine hohe Überlappung des Transkriptoms über die gesamte embryonale Entwicklungsspanne und insbesondere von Gehirn, Kleinhirn, Leber, Niere, Testis und Ovarien [59].

„Next generation sequencing“ Analysen zeigen auf, dass neben den „house keeping“ Genen, die hauptsächlich den Metabolismus koordinieren, auch spezifische Gene für die Organentwicklung und selektive Gene für einen „Crosstalk“ und Interaktion zwischen den Organen exprimiert und als „organ pattern genes“ zusammen gefasst werden [60]. Die spezifischen biologischen Eigenschaften dieser Organmustergene können mögliche Hinweise auf neue Biomarker oder therapeutische Ziele für eine präzise und effiziente Prognose und die Behandlung komplizierter und v. a. auch seltener Krankheiten liefern [60]. Auch könnten sie erklären, wie ein Gendefekt zur Beteiligung verschiedener Organsysteme führt.

Die obige Skizzierung der Embryonalentwicklung der Cochlea und des Hörnervens zeigt, dass die einzelnen Prozesse deutlich komplexer sind und von vielen verschiedenen Faktoren abhängen. Dies zeigt sich insbesondere auch bei den Malformationen, die häufig nicht, wie initial angenommen, den Arrest der Entwicklung zu bestimmten Zeitpunkten widerspiegeln. Verschiedene Gene und Genfamilien sind für die Entwicklung des Innenohrs verantwortlich und viele dieser Gene und Genfamilien sind ebenso Regulatoren der Organogenese anderer Systeme. Zum Beispiel spielen Forkhead-Box-Transkriptionsfaktoren eine Rolle bei der Entwicklung verschiedener Organsysteme durch Regulierung und posttranslationale Modifizierung verschiedener Gene wie Neurod und Sox2 [61]. Sox2 ebenso wie BMP, WNT und FGF sind in der Kardiogenese [62], Otogenese [63], Skeletogenese [64] sowie in der retinalen [65] Entwicklung involviert. Eine weitere Gruppe von evolutionär konservierten Faktoren, die für die Entwicklung zahlreicher Organe (Augen, Nieren, Herz, Muskel und Innenohr) involviert sind, sind die Eya (eyes absent)-Moleküle [66]. Insbesondere konserviert ist 
die Karboxyl-Domäne bei den Eya-Molekülen, die Six (Sine oculis) Proteine bindet [66]. Eya4-Mutationen sind z. B. Ursache für eine seltene autosomal dominante vererbbare Hörstörung, die gelegentlich mit einer dilatativen Kardiomyopathie einhergeht [66].

\section{Nicht-syndromale Hörstörungen}

Nicht-syndromaler Hörverlust (NSHL) wird vorwiegend autosomal rezessiv (ca. $80 \%$ ) übertragen, aber auch autosomal dominant (ca. $15 \%)$, X-chromosomal (2-5\%) sowie mitochondrial (1\%) weitervererbt. Einige, aber nicht alle dieser Mutationen sind in den Tabellen wiederzufinden. Trotz der bekannten Genmutation und des Vererbungsmusters ist das vollständige Verständnis der nicht-syndromalen Hörstörungen aufgrund der extremen klinischen und genetischen Heterogenität eine große Herausforderung [67].

Fast 100 Gene sind bislang identifiziert, die zu einer nicht-syndromalen Hörstörung führen können. Eine gelungene Übersicht der bis 2015 identifizierten Gene findet sich bei Vona et al. [67]. Aus den bei den nicht-syndromalen Hörstörungen betroffenen Genen resultiert ein wesentlicher Erkenntnisgewinn zur Funktion der ausgereiften Cochlea. Die bei den seltenen und v. a. nicht-syndromalen Erkrankungen beteiligten Signalwege erlauben insbesondere das Aufdecken neuer pathophysiologischer Vorgänge, die zu einem Hörverlust führen. Variationen in der Genotyp-PhänotypKorrelation sind bei Mutationen einzelner Gene bekannt, und trotz autosomal dominantem Vererbungsmuster können Geschwister unterschiedliche Schweregrade der Hörstörung aufweisen [67]. Solche Variationen sind im Rahmen der Recherche auch bei syndromalen Erkrankungen aufgefallen. Hier sind ganze Organsysteme teilweise nicht betroffen (unvollständige oder reduzierte Penetranz), auch wenn die gleiche Genmutation vorliegt [68]. Sekundäre genetische Faktoren oder Umwelteinflüsse könnten z. B. für die Variationen verantwortlich gemacht werden (Epigenetik). Bereits 1941 wurden statistische Methoden eingesetzt, um die Existenz von Modifyer-Genen bei Chorea Huntington nachzuweisen, sodass das Konzept dominanter Modifyer -und Suppressor-Gene für den hohen Grad an Variabilität verantwortlich gemacht wird [69]. Tatsächlich sind 2 Loci für Modifyer-Gene identifiziert worden, die die Variabilität bei bestimmten Hörstörungen bedingen könnten [67].

Trotz der Variationen (z. B. kann das Einsetzen der Hörstörung auch bei gleicher Genmutation sehr variable sein) zeigen die autosomal-dominanten Hörstörungen (DFNA-Loci) häufig ein charakteristisches Audioprofil [70], das sogar bei der Diagnose behilflich sein kann. Obwohl bemerkenswerte Fortschritte zur Identifizierung einer Vielzahl von Genen geführt haben, deren Störung zum Hörverlust führen kann, ist das mechanistische Verständnis insbesondere der nicht-syndromalen Hörstörungen bisher nicht ausreichend, um eine vollständige Aufklärung der Pathophysiologie oder effektive Therapien zu ermöglichen.

Im Zeitalter der modernen molekularbiologischen Methoden, gepaart mit künstlicher Intelligenz und maschinellem Lernen erscheint nicht nur eine individuelle ursachenorientierte Versorgung von Patienten mit Hörstörungen in greifbarer Nähe. Auch präventive Maßnahmen, z. B. durch Kontrolle der strukturellen, mutationellen und epigenetischen Veränderungen der Hörstörungen sind denkbar. Dies bedeutet, dass neben den klassischen, mittlerweile sehr weit verbreiteten und zugänglichen Omics-Technologien und bildgebenden Verfahren zur Sicherung der Diagnose, eine intensivierte Diagnostik der Patienten zur Sicherung post-translationaler Veränderungen, zur Erfassung einer pathologischen Viruslast oder des Inflammasoms [71] entwickelt werden müsste. Hierbei eignen sich Screening-Technologien, die z. B. neben der Untersuchung von Protein-Protein-Interaktionen [72] auch miRNA-Bestimmungen in der Perilymphe [73] sowie Untersuchungen an Modellzellen oder patienteneigenen Zellen integrieren [74] und so echte personalisierte Medizin ermöglichen könnten.

\section{Fehlbildungen der Cochlea}

Berichte über Fehlbildungen des Innenohrs gehen auf post-mortem Untersuchungen zurück, und erste Pioniere wie Carlo Mondini (1729-1803) beschrieben Veränderungen wie ein Fehlen der apikalen Windung und einem erweiterten vestibulären Aquädukt, die unter dem Namen Mondini-Dysplasie bekannt ist [75]. Eugene Michel (1819-1883), der Deutsche HNO-Arzt Arno Scheibe (18641937), Gustav Alexander (1873-1932) sowie der Schweizer Neurologe Paul Robert Bing (1878-1956) sind Namensgeber charakteristischer Fehlbildungen des Innenohrs [76]. Im Rahmen der post mortem Untersuchungen sind charakteristische Fehlbildungen des Innenohres sowohl das knöcherne (20\%) als auch das membranöse Labyrinth ( $80 \%$ ) betreffend erfasst worden. Im Jahr 1974 publizierte der amerikanische Otologe Harold Frederick Schuknecht (1917-1996) sein Standardwerk über die Pathologie des Ohres, indem er auf der Basis histologischer Untersuchungen an einer großen Schläfenbeinsammlung neben den Malformationen auch alle anderen, die Cochlea betreffenden Erkrankungen auflistete.

Basierend auf der Bildgebung mittels Polytomografie und z. T. CT wurde 1987 von Jackler und seinen Kollegen Luxford und House die erste und auch heute noch klinisch verbreitete Klassifikation der kongenitalen Malformationen der Cochlea und des Labyrinths [77] publiziert.

Fast 100 fehlgebildete Innenohren wurden wie folgt klassifiziert: 1. Komplette Aplasie (Michel-Aplasie)

2. "Common cavity“

3. Cochleäre Aplasie mit normal entwickeltem Labyrinth

4. Cochleäre Hypoplasie

5. Inkomplette Partition (kleine Hörschnecke mit inkomplettem oder fehlendem interskalarem Septum; Bogengang normal oder malformiert)

Der bis dato revolutionäre Aspekt dieser Klassifizierung war das Konzept des embryologischen Entwicklungsarrests zur Erklärung der verschiedenen Formen von Malformationen [76]. Ein Ausbleiben der Entwicklung des Innenohrs in verschiedenen Stadien der Embryonalentwicklung als Pathomechanismus der Malformationen erklärt jedoch nur einen Teil der beobachteten Veränderungen. Auch Jackler erklärte in seiner Studie bereits, dass auch Malformationen vorkommen, die eher auf eine gestörte und weniger auf eine fehlende Entwicklung hinweisen [77]: die Fehlbildungen wurden entsprechend der Gestationswoche, in der die embryologische Entwicklung anscheinend gestört ist, aufgelistet. Jackler und seine Kollegen begründen dies mit der Ähnlichkeit von polytomographischem Bild und den (gezeichneten) Entwicklungsstadien nach Streeter [78]. Die Reihe beginnt mit der Labyrinthären Aplasie (Michel-Deformität, dritte Gestationswoche). Es folgt die „common cavity“ in der 4. Ge- 
stationswoche, die cochleäre Agenesie in der 5. Gestationswoche und die schwere und milde cochleäre Hypoplasie in der frühen und späten 6. Gestationswoche. Die inkomplette Partition, die klassische Mondini-Fehlbildung, stellt die zeitlich letzte Fehlbildung in der 7. Gestationswoche dar. Die Einteilung von Jackler et al. unterscheidet weiter eine Gruppe A mit einer fehlenden oder fehlgebildeten Cochlea (komplette labyrinthäre Aplasie, cochleäre Aplasie, cochleäre Hypoplasie, inkomplette Partition und „common cavity“) und eine Gruppe B mit normaler Cochlea (erweiterter vestibulärer Aquädukt, eine genau beschriebene Bogengangsdysplasie, die aus einem erweiterten Vestibulum und einem kurzen, aber dilatierten lateralen Bogengang besteht). Sennaroglu und Kollegen entwickelten die Jackler-Klassifikation im Hinblick auf die chirurgische Anatomie für die Cochlea Implantation weiter [79]. Als inkomplette Partition Typ I (IPT1) wird eine ausgeprägte Form mit fehlender Partitionierung der gesamten Cochlea mit auffällig erweitertem Vestibulum und nicht nachweisbarem Modiolus bezeichnet. Die äußere Begrenzung der Cochlea ist plump und oft aufgetrieben. Eine begleitende Fehlbildung von Vestibulum und Bogengängen ist zu erwarten, hingegen kommt ein erweiterter vestibulärer Aquädukt nicht vor. Eine klare Abgrenzung von der „common cavity“ gibt es nach den gängigen Definitionen nicht. Der weite Übergang von der Cochlea zum Vestibulum charakterisiert auch die IPT1, was sich in dem Synonym „zystische cochleovestibuläre Fehlbildung“ widerspiegelt [80-82]. Die „common cavity“ wurde als Fehlbildung mit gemeinsamer Höhle von Cochlea und Vestibulum, die durch einen weiten Übergang verbunden sind, beschrieben. Diese Definition, ursprünglich durch den histologischen Bericht von Edward Cock 1838 geprägt [83], reicht für eine klare Abgrenzung gegenüber der inkompletten Partition Typ I nicht aus. Das Resultat ist eine unscharfe Verwendung in der Literatur. Ähnlich wie beim erweiterten vestibulären Aquädukt, der bei zahlreichen anderen Fehlbildungen begleitend vorliegen kann, ist der Modiolus auch regelmäßig bei der „X-linked deafness“ und der IPT1 nicht in seiner typischen Form im CT abgrenzbar. Als „inkomplette Partition Typ 2“ wird heute die ursprünglich von Mondini beschriebene Fehlbildung verstanden.

Der Aspekt der Klassifikation weg von der „developmental arrest“" Theorie hin zu multifaktoriellen genetischen Defekten wird in einer Übersichtsarbeit über Cochlea Implantation bei Kindern mit cochleovestibulären Malformationen deutlich [84]. Die genetische Codierung der Mäuseotozyste ( $\triangleright$ Abb. 2 und 3) schließt nach Papsin et al. die Hypothese des „developmental arrest“ eines einzelnen Entwicklungspfades weitestgehend aus [84]. Stattdessen werden mögliche multiple distinkte Wege der Entwicklung des Innenohres beschrieben. Die Aufdeckung der genetischen Signatur einzelner Fehlbildungen und die Korrelation zu radiologischen Befunden verändert das Verständnis der Pathogenese in diesem Gebiet entscheidend.

\subsection{X-chromosomale Schwerhörigkeit (X-linked deafness DFN3, Gusher assoziiert)}

Die als X-chromosomale Schwerhörigkeit bezeichnete Ertaubung zeigt ein charakteristisches CT-Bild (IPT3) mit weit offener Verbindung zwischen Cochlea und innerem Gehörgang. Der Fundus des inneren Gehörgangs ist dabei dilatiert ( $\mathbf{A b b}$. 4). Der Modiolus und die Lamina cribrosa fehlen, sodass hier eine direkte Verbindung zwischen der Perilymphe des Innenohres und dem Liquor im Sub- arachnoidalraum besteht. Weitere Charakteristika sind die korkenzieherartige Erscheinung der Cochlea, weite Nervenkanäle für den N. Fazialis und den N. ampullaris posterior aus dem N. vestibularis inferior (im Canalis singularis) sowie plumpe Ausstülpungen am Vestibulum. Auffällig ist auch ein kleiner, meist vollständig knöchern umbauter Saccus endolymphaticus.

Klinisch präsentiert sich die X-linked deafness zumeist als tiefgreifende gemischte Schalleitungs- und Schallempfindungsschwerhörigkeit beidseits. Nance et al. beschrieben 1971 zuerst eine kongenitale Fixierung der Stapesfußplatte bei X-chromosomaler kombinierter Schwerhörigkeit und Gusher [85]. Die offene Verbindung zum Liquor führt bei einer Stapesmobilisation zum Austritt von Liquor, dem sogenannten Gusher. Weibliche Träger sind beschrieben, weisen aber nur zu einer kleinen Zahl anatomische Auffälligkeiten im CT auf und ihr Hörverlust fällt deutlich geringer aus [86].

In einigen Fällen ist eine Versorgung mit Hörgeräten ausreichend, oft aber besteht eine Indikation für ein $\mathrm{Cl}$. Chirurgisch ist hier v. a. das Vorschieben des Elektrodenträgers eine Herausforderung, da es leicht durch die offene Verbindung in den inneren Gehörgang gelangt ( $\triangleright$ Abb. 5). Die Anfertigung einer intraoperativen digitalen Volumentomographie ist hier sinnvoll. Das Sprachverstehen nach Cochlea Implantation ist gut und vergleichbar mit Patienten ohne Innenohrfehlbildung [87, 88].

Die Lokalisation auf dem Gen POU3F4 wurde als erstes 1995 von Kok et al. beschrieben [89]. Seitdem wurden über 63 ursächliche Mutationen auf dem POU3F4 (DFNX2) Gen berichtet, darunter 44 Punktmutationen und unterschiedliche Deletionen [90]. POU3F4 wird im sich entwickelnden Neuralrohr exprimiert und später besonders in den Regionen des Großhirns, supraoptisch und paraventrikulär in den Hypothalamuskernen. Bereits 1982 berichtete Myhre et al. über eine rezessive $X$-chromosomale Störung mit congenitaler Taubheit und Hypogonadismus [91]. Die Patienten aus unserer eigenen Klinik weisen in über $90 \%$ Hamartome des Hypothalamus auf, die ungleich der üblichen Klinik bei Hamartomen mit Lachan-

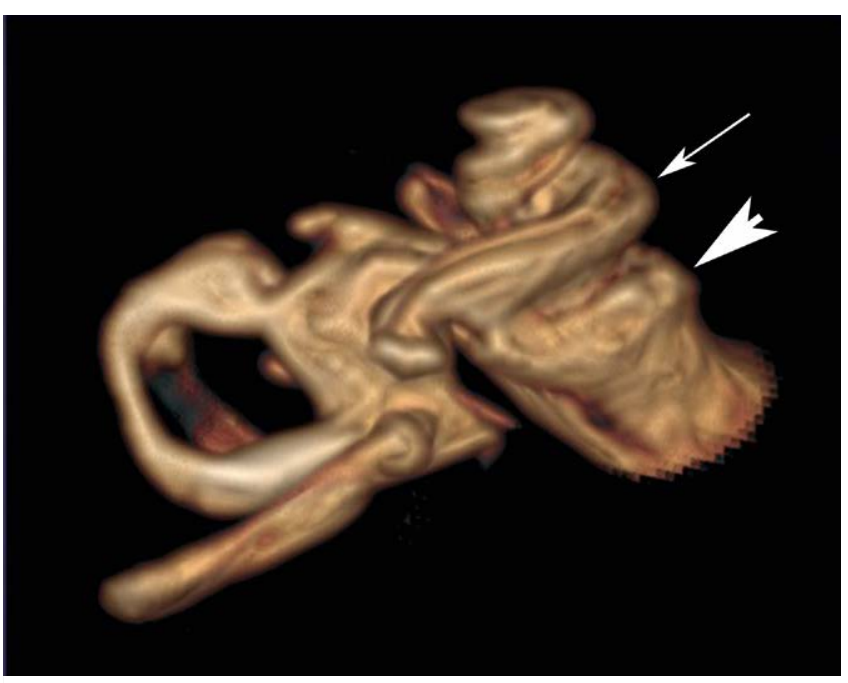

- Abb. 4 Volume Rendering aus dem T2-Datensatz einer MRT - Untersuchung eines Patienten mit X-chromosomaler Schwerhörigkeit. Typisches korkenzieherartiges Bild der Cochlea (weißer Pfeil auf basaler Windung). Der Fundus (Pfeilspitze) des inneren Gehörganges ist aufgeweitet. 

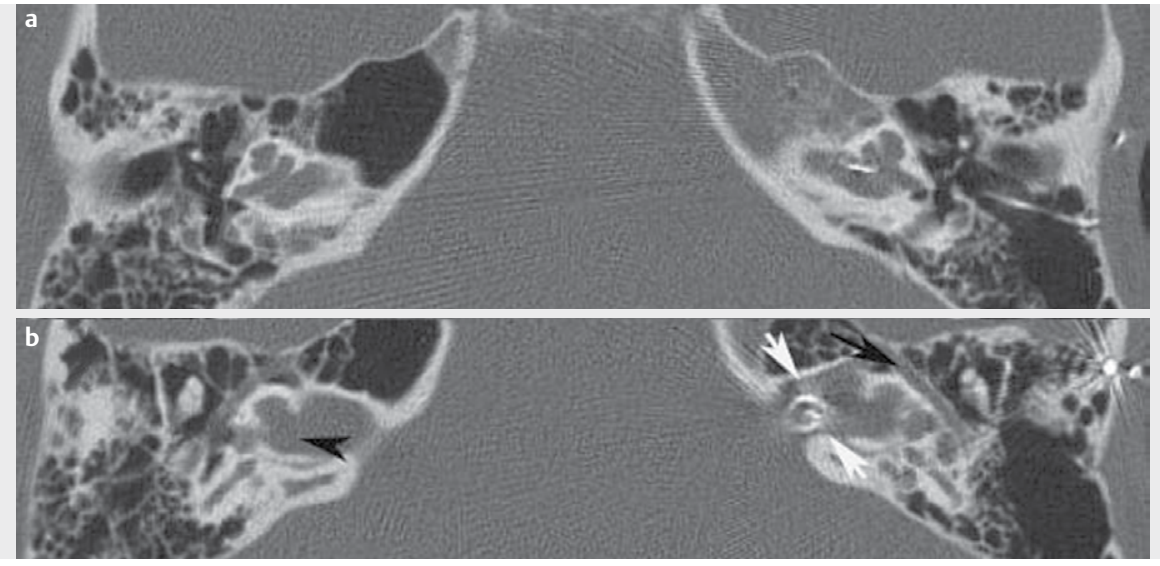

- Abb. 5 Patient mit einer X-chromosomale Schwerhörigkeit. CT Schläfenbein axial in 2 Ebenen (a) Es zeigt sich eine weite, offene Verbindung zwischen dem inneren Gehörgang und der basalen Windung, einer fehlender Modiolus und eine fehlende Lamina cribrosa (schwarzer Pfeil). (b) Links ist der breite Fazialiskanal gut darstellbar (schwarze Pfeilspitze). Nach Cochlea Implantation zeigt sich eine Fehllage des linksseitig eingebrachten ClElektroden-Arrays im inneren Gehörgang (weiße Pfeile).

fällen und einer Pubertas praecox sich durch das Gegenteil, nämlich einen hypogonadotrophen Hypogonadismus auszeichnen [92]. Auch Siddiqui et al. beschreiben hypothalamische Fehlbildungen bei Patienten mit einer X-chromosomalen Schwerhörigkeit und IPT3, womit diese unter den syndromalen Fehlbildungen eingeordnet werden kann [93].

Die X-chromosomale Schwerhörigkeit mit identifiziertem Gendefekt in POU3F4 stellt nicht die einzige mit Mutationen auf dem XChromosom identifizierte Hörstörung dar. Zusammen machen diese etwa 1-2\% der syndromalen und nicht-syndromalen Hörverluste aus. Es wurden bisher 6 Loki und 5 Gene für den nicht-syndromalen Hörverlust und mindestens 15 für syndromalen Hörverlust identifiziert [94], darunter das Norrie-Syndrom, Cornelia-de-Lange-Syndrom, Fabry-Syndrom, Alport-Syndrom, STAR-Syndrom, PIGA-Syndrom und die X-chromosomale Adrenoleukodystrophie, um nur einige zu nennen, die alle zu den seltenen Erkrankungen zählen.

\subsection{Komplette Bogengangsaplasie und CHARGE-Syn- drom}

Die komplette Aplasie der Bogengänge stellt ein Hauptkriterium des CHARGE Syndroms dar, kann aber auch isoliert vorkommen und ist in Kombination mit dem Wildervanck, Noonan, Goldenhar oder VACTERL-Syndrom beschrieben $[95,96]$. Die erste Beschreibung erfolgte 1979 unabhängig von Hall und von Hittner, das Krankheitsbild ist daher auch unter dem Namen Hall-Hittner-Syndrom bekannt. Das Akronym CHARGE wurde hingegen 1981 von Pagon et al, vorgeschlagen [97]: „Coloboma, Heart defects, Choanal atresia, Retardation, Genitourinary und Ear abnormalities “. Die heute verwendeten Kriterien wurden von Blake et al. 1998 vorgeschlagen und 2005 von Verloes et al. 2005 überarbeitet [98]. Verloes stellt dabei v. a. die drei „C“ als Haupt-Kriterien heraus: Colobom, Choanalatresie und Hypo/Aplasie der Bogengänge (semicircular canals). Abhängig von der Zahl der erfüllten Kriterien wird zwischen typischem, partiellem und atypischem CHARGE unterschieden, wichtig ist aber, dass bereits bei wenigen erfüllten Kriterien eine Diagnose vorliegt. Die phänotypische Ausprägung ist insbesondere beim CHARGE Syndrome sehr breit gestreut. Von den Hauptkriterien wird die Ohrfehlbildung in 95-100\%, davon Innenohr $90 \%$ beschrieben [99], es folgt das Colobom mit $90 \%$ und die Nervenfehlbildungen insbesondere vom N. facialis in 50-90\%, je nach Literatur. Die komplette Aplasie der Bogengänge (SCC-Aplasie) ist eine bildmorphologische Diagnose basierend auf der Computer-Tomografie. Sie stellt unter den Innenohrfehlbildungen eine Besonderheit dar, da hier der phylogenetisch ältere Teil des Labyrinths fehlt. Entsprechend tiefgreifende genetische Veränderungen liegen vor, sichtbar an der Vielzahl der beschriebenen assoziierten Malformationen von Auge, Mittellinienstrukturen des Gesichtsschädels, mediastinalen Fehlbildungen (cardiale und ösophageale; Thymusaplasie möglich) und Fehlbildungen der ableitenden Harnwege und Genitalien, die alle unterschiedlichen, nicht aneinander angrenzenden embryonalen Territorien zugehören. Die CT und MRT des Schläfenbeines ist bei bestehenden Hörstörungen die Untersuchung der Wahl zur Abklärung vorliegender Innenohrfehlbildungen. Dabei zeigt das CT des Schläfenbeines ein vollständiges Fehlen der Bogengänge einschließlich des Utrikulus ( meist kommaförmig und enthält nur den zur pars inferior gehörigen Sacculus ( A Abb. 7). Die Cochlea weist zumeist eine verminderte Windungszahl (Hypoplasie) auf. Eine fehlende Separierung der Skalen kann begleitend bestehen. Bei häufigen Nervenhypo- und -aplasien ist auch der innere Gehörgang zumeist schmal. Die Darstellung der Nerven erfolgt im MRT mittels einer hochauflösenden T2-Sequenz. Der N. fazialis und N. vestibulocochlearis können vollständig fehlen (4\% der Fälle), meistens liegt aber ein N. fazialis vor und die Hypo- und Aplasien betreffen häufiger einen Teil des $\mathrm{N}$. vestibularis als den $\mathrm{N}$. cochlearis. Eine weitere begleitende Fehlbildung im Bereich des Schläfenbeines stellt in bis zu $80 \%$ ein persistierender petrosquamöser Sinus dar. Dieser stellt ebenso wie ein fehlendes ovales oder rundes Fenster und ein kleines Mittelohr eine chirurgische Herausforderung bei der Cochlea Implantation dar. Ein aberranter Fazialisverlauf im Mittelohr wird ebenso beobachtet. Der petrosquamöse Sinus kann in seltenen Fällen die venöse Drainage des intrakraniellen Raumes führend vom Sinus transversus übernehmen. Zudem erfolgt in einem kleinen Teil der Austritt der Vene über ein Foramen postglenoidale dorsal des Kiefergelenks. In diesen Fällen findet sich nur noch ein entsprechend kleines Foramen jugulare. 

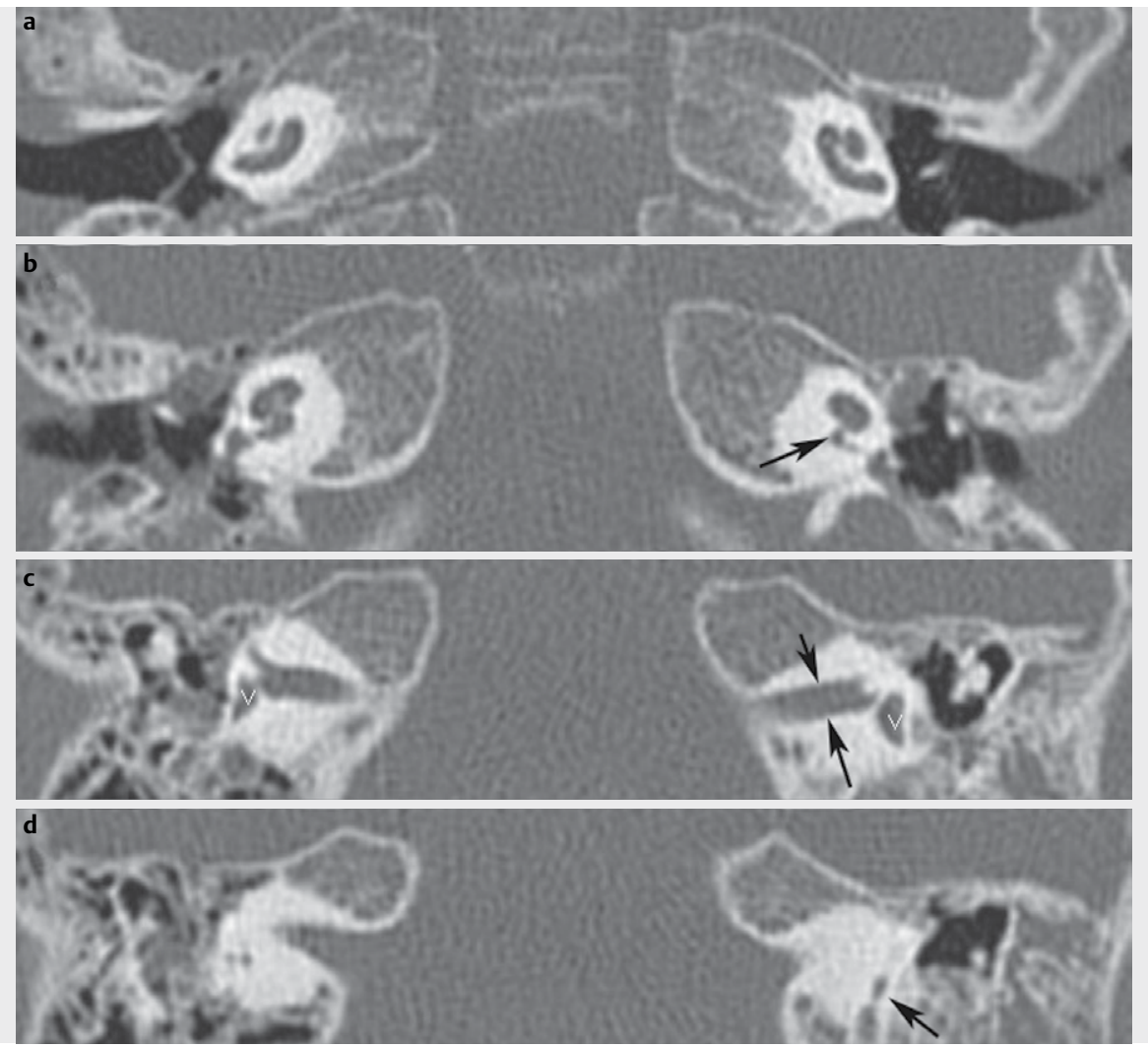

- Abb. 6 Komplette Bogengangsaplasie. Axiale CT des Schläfenbeines bei kompletter Bogengangsaplasie. a Beidseitig hypoplastische Cochlea; b Rechts zeigt sich eine normale Weite der cochleären Apertur, links ist die Öffnung hochgradig eingeengt (Pfeil) - hier kann man eine Hypo- oder Aplasie des N. cochlearis bereits vermuten, beweisend ist dann aber erst das MRT; c Schmale Innere Gehörgänge (schwarze Pfeile) sind ebenso typisch wie das kommaförmig angelegte Vestibulum bds (weißes V); $\mathbf{d}$ Es sind keine Bogengänge erkennbar, der Aquäduktus vestibularis (Pfeil) stellt die einzige schmale Struktur dar.

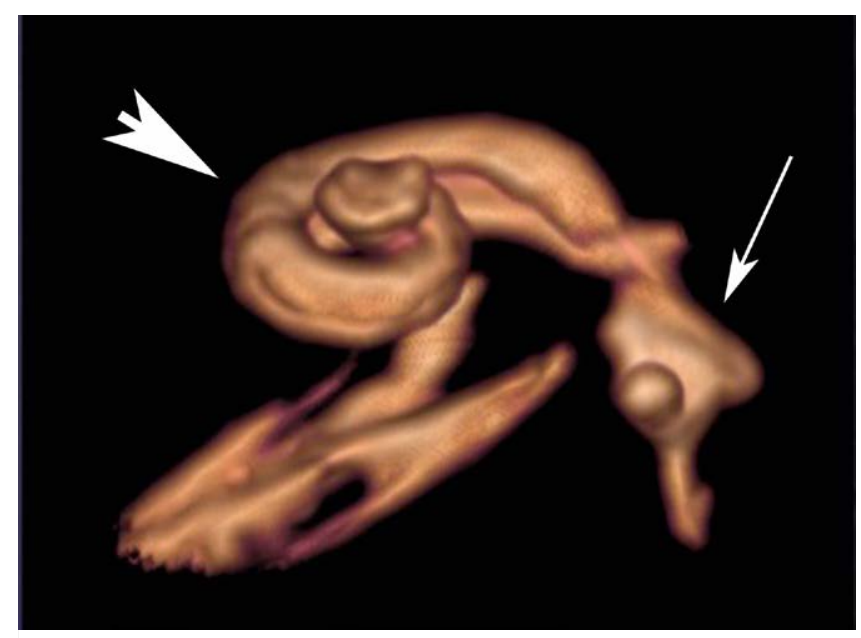

Abb. 7 Aplasie der Bogengänge. Volume Rendering aus dem T2-Datensatz einer MRT-Untersuchung eines Patienten mit kompletter Bogengangsaplasie und CHARGE-Syndrom. Die Cochlea (Pfeilspitze) ist hypoplastisch und das Vestibulum (Pfeil) enthält nur den Sacculus. Bogengänge sind keine ausgebildet.
In manchen Fällen ist auch ein Colobom des Auges direkt im Bild dargestellt: hier handelt es sich um ein weiteres der „drei C“, den Hauptkriterien nach Verloes 2005. Das Colobom ist eine angeboren Spaltbildung von Iris, Linse oder Augenhintergrund. Im letzteren Fall ist dies im Schnittbild als Ausstülpung des Augenbulbus um oder neben dem N. optikus sichtbar ( $\triangleright$ Abb. 8). Es kann eine begleitende Mikroophthalmie bestehen. Das dritte „C“ lässt sich ebenfalls im CT darstellen, es handelt sich um die Choanalatresie. Diese kann einseitig oder beidseitig sowie knöchern oder nur als Weichteilverschluß bestehen. Sie wird allerdings insbesondere bei beidseitiger Ausprägung direkt nach Geburt auffällig und ist bei Diagnostik zur Eignung für eine $\mathrm{Cl}$ bereits behandelt.

Die Angaben zur Inzidenz der begleitenden Hörstörung bei CHARGE schwanken für die schwere Hörstörung bzw. Surditas zwischen 50 und $90 \%$. In unserem eigenen Patientenkollektiv mit ausschließlich Patienten mit kompletten Bogengangsaplasien weisen praktisch alle Fälle eine schwere Hörstörung bzw. eine Surditas auf. Hier ist bei vorhandenem N. cochlearis eine Cochlea Implantation die Therapie der Wahl. Die Implantation kann eine Herausforderung darstellen, denn die begleitenden Fehlbildungen erschweren den Zugangsweg zur Cochlea. Daher sollte eine sorgfältige Auswertung des CT für den besten Zugangsweg hier vorausgehen. Das Sprachverstehen nach Cl zeigt ein breites Spektrum abhängig von den vorhandenen Fähigkeiten bei möglicher begleitender Retar- 


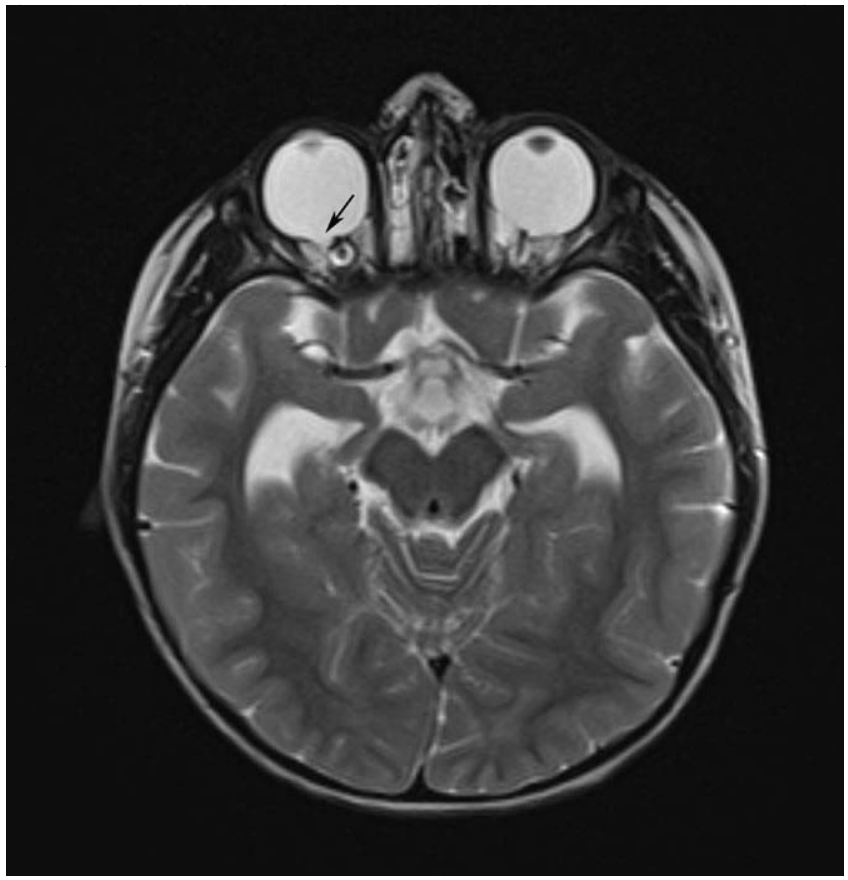

- Abb. 8 T2 gewichtete axiale MRT eines Kindes mit CHARGE im Rahmen einer Cochlea-Implant-Voruntersuchung. Kolobom am rechten (schwarzer Pfeil) und linken Auge.

CHARGE gefunden. Immundefekte sind häufig bei 22q11.2 Deletion, können aber auch bei CHARGE auftreten. Wie bei der 22q11.2 Deletion kann eine Thymusaplasie bestehen. Daran sollte man bei rezidivierenden Mittelohrinfektionen bei CHARGE denken, da diese nicht immer allein durch die anatomischen Gegebenheiten bedingt sein können.

\subsection{Cochlea Implantation bei Fehlbildungen der Cochlea}

Die Rehabilitation des Gehörs hat nicht nur bei Patienten mit einem im CT normal ausgebildeten anatomischen Labyrinth eine hohe Erfolgsrate, sondern auch bei den Patienten, die eine knöcherne Fehlbildungen im Rahmen der Cochlea-Implant-Voruntersuchung aufweisen (ca. 20\%) [100]. Die Versorgung dieser Patienten stellt eine besondere Herausforderung dar. Komplikationen z. B. durch einen aberranten Verlauf des Nervus fazialis oder durch das erhöhte Risiko einer Meningitis beim Vorliegen eines „Gushers“ können bei Anomalien der Hörschnecke besonders häufig auftreten [79, 84, 101103]. Gerade deswegen ist eine eingehende Evaluation jedes Cochlea-Implant-Kandidaten und insbesondere von Kindern in erfahrenen Zentren von Bedeutung. Eine Reihe unterschiedliche Beschreibungen der Fehlbildungen des Innenohrs ist in der Literatur zu finden und derselbe Begriff kann je nach Autor ganz unterschiedliche Bedeutungen haben. Nicht nur Lenarz und Kollegen bereits in den 90er Jahren und Sennaroglu et al. 2017 haben daher eine einheitliche Beschreibung der Fehlbildungen gefordert [79, 103] um nicht nur Vergleiche und einen Wissensaustausch zu ermöglichen, sondern v. a. auch um eine Richtlinie bei der Versorgung dieser Patienten erstellen zu können.
Der Ansatz einer einheitlichen Klassifikation insbesondere unter Berücksichtigung der Anatomie wurde durch Jackler im 20. Jahrhundert und Sennaroglu 2002 sowie durch zahlreiche weitere Autoren verfolgt. Nicht nur das gesamte Spektrum der Fehlbildungen wurde hierbei dargestellt, sondern auch einzelne und z.T. auch seltene Untergruppen. So wurden die inkomplette Partition 1 und 2 um atypische Fälle erweitert: z. B. eine IPT2 (ehemals Mondini im klassischen Sinn) ohne einen erweiterten vestibulären Aquädukt [104]. Oder eine IPT1, die genau diese Erweiterung aufweist [104]. Es wurden die Verläufe des N. fazialis im knöchernen Abschnitt näher betrachtet [105]. Die cochleäre Hypoplasie wurde gleich mehrfach genauer eingeteilt [106-108]. All dies spiegelt die enormen Möglichkeiten wider, in der genetische Faktoren kombiniert werden können, um dieses schier unübersichtliche Spektrum verschiedener Fehlbildungen zu liefern. Allerdings kommen eine ganze Reihe der Fehlbildungen häufiger vor als andere und die sind es, die es sich einzuteilen lohnt.

Am Beispiel des Begriffs „common cavity“ wird klar wie unterschiedlich Begrifflichkeiten verwendet werden und wie inkomplett wir trotz Fortschritten in Genetik und Bildgebung die Entstehung der Innenohrmalformationen verstanden haben. Der Begriff „common cavity “ wird in der Literatur für unterschiedliche Fehlbildungen verwendet, mindestens 3 grundsätzlich verschiedene Gruppen fallen darunter: 1.) Jackler beschrieb mit dem Begriff der „common cavity“ eine Otozyste, die noch die Anlage für sowohl die Cochlea als auch das Vestibulum und die Bogengänge in sich trägt, also eine Fehlbildung auf einer sehr frühen Entwicklungsstufe. 2.) Andere Arbeiten verwenden die Bezeichnung in dem Sinn, dass die Cochlea und das Vestibulum, beide plump ausgebildet, unpartitioniert und dilatiert eine gemeinsame Höhle bilden, somit zumeist ein breiter Übergang zwischen den beiden besteht. Im Eintrittsbereich der Nerven sind diese in der Regel nicht in N. cochlearis und N. vestibularis zu trennen. Im amerikanischen Sprachgebrauch taucht hierfür teilweise der Begriff „cystic cochleovestibular anomaly“ („figure 8-deformity“) auf [109]. Gleichzeitig weist diese Fehlbildung keine klaren Abgrenzungskriterien zur inkompletten Partition 1 auf, bei der auch die Cochlea dilatiert und unpartitioniert und das Vestibulum stark verplumpt sind. Eine willkürliche Grenze wäre allenfalls in der Weite des Überganges zu setzen, die jedoch funktionell für die Cochlea Implantation keine Konsequenz hat. 3.) Sennaroglu weist darauf hin, dass die cochleäre Aplasie von der „common cavity“ nicht in allen Fällen sicher abgegrenzt werden kann [79]. Er beschreibt dabei eine Fehlbildung, die ovalär und überwiegend dorsal des inneren Gehörganges gelegen ist und sehr wohl eine nervale Anbindung besitzt (im Gegensatz zur Otozystendeformität von Jackler, die diese nicht benötigt). Beide, sowohl die cochleäre Aplasie als auch die „common cavity “ können rudimentäre oder auch z. T. ausgebildete Bogengänge besitzen. Damit ist die „common cavity“ in der Tat CT-morphologisch formell nicht von der cochleären Aplasie zu trennen. Einzig das Kriterium des bei der cochleären Aplasie häufig bestehenden sklerosierten Bereiches ventral/inferior des Inneren Gehörganges wird nicht mit herangezogen zur Unterscheidung ( $\triangleright$ Abb. 9). Anhang eigener Beobachtungen ist dieser sklerosierte Bereich aber bei fast allen „common cavites“ und cochleären Aplasien vorhanden. Diese Überschneidungen machen eine Abgrenzung schwierig, eine Entscheidung zur Cochlea Implantation sollte unseres Erachtens auf dem Nachweis des inneren Gehörgangs und der Nerven im MRT ba- 


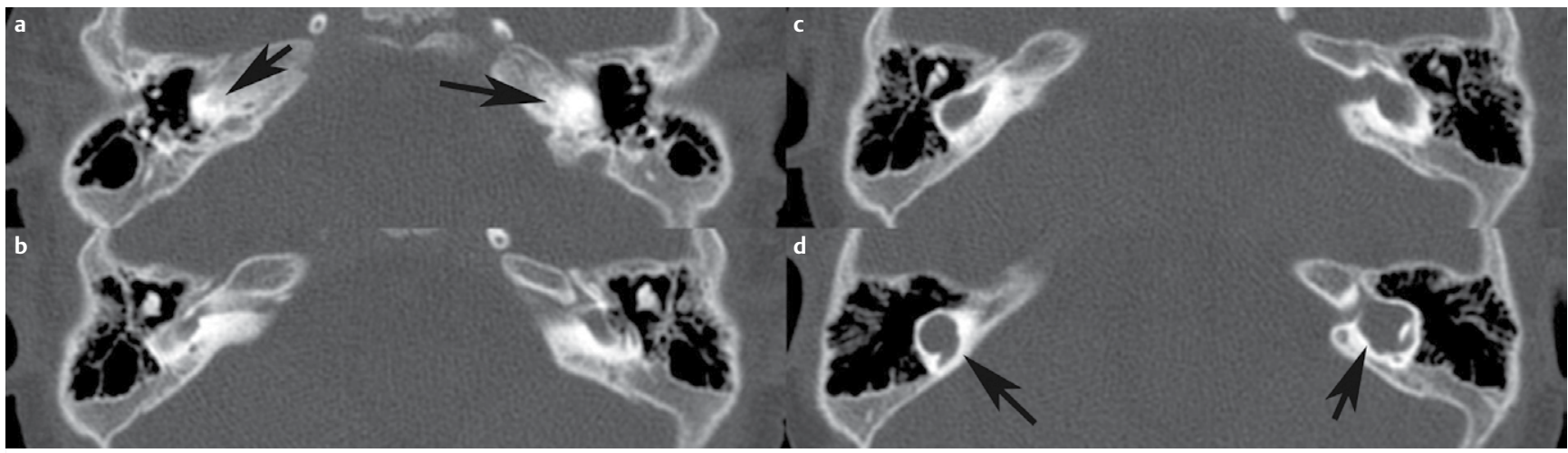

- Abb. 9 Patient mit cochleärer Aplasie. a Die schwarzen Pfeile zeigen den sklerosierten Bereich der otischen Kapsel, wo normalerweise die Cochlea ausgebildet wäre. b und c zeigen weiter dorsal gelegene Bereiche, die das dysplastische Vestibulum erfassen, das in d mit schwarzen Pfeilen beidseits gekennzeichnet ist.

sieren. Dieses Beispiel zeigt wie wichtig Schichten auf multiplen Ebenen des Labyrinths zur Beurteilung der jeweiligen Fehlbildungen sind. Wird nur eine Schicht gezeigt, wie dies oft bei Publikationen zu finden ist, sind die für die Fehlbildung benötigten Kriterien nicht immer nachvollziehbar. In Bezug auf die individuelle Beurteilung und Therapie stellt hier die 3-dimensionale Rekonstruktion und die damit ermöglichte individuelle Anpassung der Elektrode die logische Fortsetzung dar [106].

Es gibt Arbeiten, die bei cochleärer Aplasie ein Sprachverstehen nach Cochlea Implantation berichten [100]. Dies sind genau diejenigen cochleären Aplasien, die von anderen als common cavity bezeichnet werden. Das Vorhandensein eines stimulierbaren Spiralganglions ist demnach im CT nicht zu beurteilen. Eine Kombination der CT-Morphologie sowie der nervalen Anlage wie sie im MRT erscheint ist besser geeignet zur Beurteilung der Erfolgschancen einer Cochlea Implantation. Dies hat lange Einzug erhalten in der Cochlea-Implant-Voruntersuchung. Eine Einteilung nach Schweregrad der assoziierten Nervenfehlbildungen wurde von Giesemann et al. 2012 publiziert [110]. Hier wird deutlich, dass schwere Fehlbildungen regelmäßig ein ganzes Spektrum unterschiedlicher Nervaplasien mit gewissen Wahrscheinlichkeiten aufweisen. Die Auflösungsgrenze des MRT ist hier entscheidend und weitere Verfahren wie z. B. der Promontorialtest und BERA sollten hinzugezogen werden. Bis zu welcher Grenze Hypoplasien des Nervus cochlearis noch zu erfolgreichen Implantationen führen, ist eine der derzeit noch offenen Fragen im Bereich der Fehlbildungsversorgung.

Beispiele einer Einteilung, die die klinisch wichtigsten Fehlbildungen umfasst, die v. a. Bildmorphologisch gut voneinander zu trennen sind, in Relation zum Vorhandensein eines cochleären Nervens können der $>$ Tab. 1 entnommen werden [110].

\section{Susac - Syndrom}

Eine autoimmun-mikroangiopathische Endotheliopathie, die zum Verschluss der präkapillären Arteriolen des Gehirns, der Retina und des Innenohrs führt wird als Susac-Syndrom definiert [111]. Der Neuroophthalmologe John O. Susac (1940-2012) ist Namensgeber der Erkrankung. Eine systematische Übersichtsarbeit aus dem Jahre 2013 fasst die Daten aller bis dahin beschriebenen Fälle dieser seltenen Erkrankung zusammen [111] und Kriterien, anhand derer diese durch facettenreiche Phänotypen gekennzeichnete $\mathrm{Er}$ krankung diagnostiziert werden kann, wurden definiert [112]. Der überwiegende Anteil (nahezu $80 \%$ ) der Patienten sind Frauen. Da Autoimmunerkrankungen bei Frauen häufiger vorkommen, unterstützt dies die mögliche autoimmune Ursache der Susac-Erkrankung [111]. Auch wenn die Charakteristika der Erkrankung klar definiert sind, so ist die Diagnose oft schwierig und bedeutet einen langwierigen Weg für die Patienten. Schwere neuropsychologische Defizite, Gesichtsfeldausfälle und Hörverlust, aber auch unspezifische Symptome wie Cephalgie können auftreten.

Die Mehrzahl der Patienten entwickelt zuerst neurologische Symptome, sodass sie oft als multiple Sklerose fehldiagnostiziert wird. Innerhalb von 2 Jahren haben ca. $85 \%$ der Patienten die charakteristische Trias entwickelt [111]. Auch wurden nicht-klassische Symptome bei Patienten mit Susac-Syndrom beschrieben. Eine kürzlich erschienene Arbeit, die den Hörverlust des bekannten spanischen Malers Francisco Goya (1746-1828) vor dem Gesichtspunkt des heutigen Wissenstandes retrospektiv untersucht, geht von einer uncharakteristischen Manifestation des Susac-Syndroms aus, auch wenn der Maler glücklicherweise keine signifikante Störungen des Gesichtsfelds aufwies [113]. Eine otologische Manifestation der Syphilis, andere Vaskulitiden wie z. B. Churg-Strauss oder Autoimmunerkrankungen wie das Cogan-Syndrom können Symptome verursachen, die denen des Susac-Syndroms ähneln. Ein Charakteristikum der Erkrankung ist der Tiefton-betonte Hörverlust, zunächst einseitig und reversibel, später auch beidseits und bleibend $[111,114]$. In seltenen Fällen manifestiert sich der TieftonHörverlust als erstes Symptom, Jahre bevor die Krankheit erkannt wird [115]. Fluoreszenz-Angiographie und Tonaudiometrie sollten so früh wie möglich eingesetzt werden, um bei Verdacht die Diagnose zu sichern [111]. Multiple disseminierte Läsionen, insbesondere schnellballähnliche Veränderungen im Bereich des Corpus callosum und eine leptomeningeale Anreicherung sind charakteristische Veränderungen des Gehirns im MRT [116]. Eine frühe und aggressive Behandlung insbesondere bei neurologischer Manifestation bedingt eine gute Prognose.

Ein interdisziplinäres Vorgehen und eine enge Kommunikation zwischen Neurologen, Ophthalmologen, Neuroradiologen und HNO-Ärzten ist hierbei von wesentlicher Bedeutung und könnte zu 
einer Beschleunigung der Diagnosesicherung führen. Der tieftonbetonte Hörverlust, so wie er auch als erstes Zeichen einer Susac-Erkrankung auftreten kann, kann auch als ein Zeichen eines M. Menière, eines Tieftonhörsturzes oder eines intracochleären Schwammons sein [117]. Mit einer Prävalenz von ca. 0,2 \% gilt auch M. Menière als eine seltene Erkrankung des Innenohrs und wird oft bei Patienten, die sich mit Tiefton-Hörminderung und Schwindel-Symptomatik präsentieren, vermutet. Eine Schwindelsymptomatik allein oder in Kombination mit einer Tieftonschwerhörigkeit kann indes auch bei Patienten mit Susac auftreten. Es ist daher durchaus denkbar, dass Patienten mit Susac zunächst unerkannt bleiben und als Menière-Fälle mit Steroiden behandelt werden. Auch Patienten, die initial mit einem Tieftonhörsturz diagnostiziert werden, könnten u.U. an einem Susac-Syndrom leiden. Aus diesem Gesichtspunkt betrachtet erscheint eine augenärztliche und neurologische Mitbeurteilung aller Patienten, bei denen ein Hörsturz oder ein M. Menière vermutet wird, als sinnvoll.

Die Pathophysiologie beim Susac-Syndrom ist durch eine Okklusion der Lumina der kleinen Gefäße bedingt [114]. Der Verschluss der Lumina wird durch Auto-Antikörper gegen vaskuläre Endothelzellen oder durch ein T-Zellen-vermitteltes Anschwellen der vaskulären Endothezellen erklärt. Auch wurde beim Susac-Syndrom eine Störung der mikrovaskulären Blut-Hirn-Schranke durch entzündliche Veränderungen in der Gefäßwand im MRT nachgewiesen [118].

\section{Schwerhörigkeit und Mikrozirkulation}

Die Funktion des Innenohrs basiert auf einer einwandfreien Mikrozirkulation der Gefäße der Arteria labyrithii, die über den inneren Gehörgang in das Organ eintritt. Das Vorliegen einer gestörten Mikrozirkulation im Innenohr wird bei einer Reihe von Erkrankungen vermutet. Die Versorgung des Innenohrs basiert auf einer Endarterie, d. h., es gibt keine Anastomosen mit anderen Gefäßen, die im Falle eines Gefäßverschlusses die Versorgung des Organs übernehmen könnten. Die Arteria labyrinthii entspringt der Arteria cerebellaris anterior inferior und teilt sich im Innenohr in 3 Hauptstämme auf, die A. vestibularis anterior, die A. vestibulo-cochlearis und die A. cochlearis [119]. Eine Störung der mikrovaskulären BlutLabyrinth-Schranke wird, basierend auf einer vermehrten Gadolinium-Aufnahme der betroffenen Innenohren in MRT-Studien, auch beim M. Menière vermutet [120]. Die Störung der Blut-LabyrinthSchranke im Rahmen des M. Menière soll indes deutlich ausgeprägter sein als z. B. beim Hörsturz [120]. Tatsächlich zeigten post mortem Analysen an Patienten, die zu Lebzeiten an M. Menière litten, eine erhöhte Expression der induzierbaren Stickstoffmonoxid-Synthase, eine Schädigung der vaskulären Endothelzellen, eine Degeneration der perivaskulären Basalmembran und der extrazellulären Matrix und einen Verlust der Blut-Labyrinth-Schranke und diese Veränderungen sind vereinbar mit erhöhtem oxidativem Stress [120]. Interessanter sind ähnliche molekulare Prozesse (Freisetzung pro-inflammatorischer Zytokine und endotheliale und mitochondriale Dysregulation sowie oxidativer Stress) als zugrundeliegendes und als gemeinsames Kennzeichen beim Multiplen Organversagen identifiziert worden [121], sodass diese Prozesse möglicherweise eher als das Resultat einer Reihe von Insulten und Schäden zu sehen sind und nicht als ursächlich betrachtet werden können. Auf molekularer Ebene zeigen sich bei M. Menière-Patienten eine
Hochregulierung von Cochlin sowie eine Herunterregulierung von Kollagen IV und Laminin-beta [122]. Post-mortem-Analysen an Patienten, die am Susac-Syndrom litten, zufolge sind diese indes nicht in der aktuellen Literatur zu finden. Die klassischen Schwindel-Attacken, die von M. Menière-Patienten berichtet werden, fehlen beim Susac-Syndrom. Dennoch ist aus HNO-ärztlicher Sicht neben dem Cogan-Syndrom die akute oder fluktuierende oder (schubweise) progrediente, auf einen endolymphatischen cochleären Hydrops basierende apicocochleäre Schalempfindungsschwerhörigkeit eine der wichtigsten Differenzialdiagnosen des Susac-Syndroms.

Molekulare Marker im Blut und in anderen Körperflüssigkeiten für bestimmte Innenohr-Erkrankungen zu entdecken, wie z. B. das Cochlin bei M. Menière, könnte einer der Wege sein, die in die moderne Hals-Nasen-Ohren-Heilkunde führen. Erste Ansätze zur PerilymphAnalyse bei Patienten im Rahmen von chirurgischen Innneonohreigriffen hat die Identifizierung einer Vielzahl von Proteinen ermöglicht, die nicht im Liquor oder im Plasma detektiert wurden [123]. Auch inflammatorische Markerproteine wurden in der humanen Perilymphe nachgeweisen [71], so dass die Erstellung eines Inflammasom-Profils der Perilymphe Aufschlüsse über den Pathomechanismus bestimmter Erkrankungen in Zukunft bedeuten könnte. Vor allem für die Charakterisierung seltener Erkrankungen des Innenohres könnte dies eine wertvolle Methode darstellen. Auch wenn die Perilymph-Entnahme während der Cochlea Implantation keinen Einfluss auf das Restgehörvermögen der Patienten hat [123], also möglichweiser eine zusätzliche Schädigung des Innenohrs anhand dieser Daten als unwahrscheinlich erscheint, steht die Entwicklung einer Perilymph-Entnahme als minimal-invasiver Eingriff unter lokaler Betäubung beim noch signifikanten Restgehör noch aus. Auch die Charakterisierung der Perilymphe einer „normalen“ Cochlea gestaltet sich als schwierig, da bislang nur Untersuchungen an Patienten vorliegen, die an anderen Erkrankungen des Nervensystems, z. B. Meningeom, litten [124].

Eine weitere Entwicklung im Zeitalter der „Big Data“, der künstlichen Intelligenz und des „Machine Learning“ ist die Bereitstellung von Datenbanken, die in spezifischen Konsortien idealerweise die kompletten Daten von Patienten weltweit verfügbar machen, die an einer bestimmten (seltenen) Erkrankung leiden. Auch als Anlaufstelle für Patienten zur Vermittlung an Kompetenz-Zentren und Pateinten-Selbsthilfe-Gruppen, sind Krankheits-spezifische Konsortien insbesondere für seltene Erkrankungen besonders wertvoll. Für das Susac-Syndrom werden solche Aktivitäten über das europäische Susac Konsortium (EuSaC), (EuSaC, http://www. eusac.net) koordiniert.

\section{Seltene Erkrankungen der Cochlea: Weiter- führende Betrachtungen und Zusammenfas-}

\section{sung}

Das Innenohr ist ein anatomisch und histologisch hochkomplexes Organ bestehend aus verschiedenen Gewebearten. Entwicklungsstörung und im Verlauf des Lebens eintretende pathophysiologische Prozesse können alle Gewebearten des Innenohrs betreffen und zum Hörverlust führen. Obgleich Hörverlust statistisch gesehen die häufigste degenerative sensorineurale Erkrankung darstellt mit $16 \%$ betroffenen Europäern, ist Hörverlust v. a. auch ein wichtiger Bestandteil vieler seltener Erkrankungen. Insbesondere bei pädiatrischen Patienten können die seltenen Erkrankungen über- 
sehen werden. Auch wenn in der heutigen Zeit der Zugriff zu bioinformatischen Datenbanken und Analyseprogrammen die Diagnostik vieler dieser seltenen Krankheitsbildern erleichtert, ist wegen der stark variierenden Phänotypen eine interdisziplinäre Untersuchung (z. B. Neurologie, Kardiologie, Nephrologie, Rheumatologie, Ophthalmologie sowie Otorhinolaryngologie) obligat.

Aufgrund des spärlichen Vorkommens werden seltene Erkrankungen insbesondere bei der Lehre und Ausbildung junger Ärzte vernachlässigt, da die Wahrscheinlichkeit, solchen Fällen in der täglichen Routine zu begegnen, eher gering ist. Erfolgt indes eine Gruppierung von Störungen (z. B. Augen-Innenohr, muskuloskeletales System-Innenohr, Herz-Niere-Innenohr, Innenohr-Schilddrüse, Innenohr-Gonaden), so wird klar wie, unabhängig vom Mechanismus, diese klinisch tatsächlich gehäuft auftreten können. Es zeigt aber auch, wie wertvoll neben der Embryonalentwicklung auch die klinische Auseinandersetzung mit den selten Erkrankungen eines Organsystems ist, um das Organ in seinem Aufbau, seine Funktionen und seinen Erkrankungen besser begreifen zu können.

Das Humangenomprojekt und die nun verfügbaren „highthroughput" Sequenzierungsmethoden sowie Analysen des Proteoms, Transkriptoms, Epigenoms, Metaboloms sowie des Mikrobioms bieten uns bereits jetzt die Chance, Krankheitsprofile zu schärfen. Verschiedene Störungen, die ähnliche Symptome (Phänotyp) aufweisen, können sich sehr wohl auf der molekularen Ebene voneinander unterscheiden und müssen daher auch anders behandelt werden müssen (z. B. mitochondriale Erkrankungen versus lysosomale Speicherkrankheiten). Wir erkennen, dass Gene, die mehrere Signale kontrollieren und Chromosomenanomalien, die gleichzeitig zum Verlust mehrerer Gene führen, Breitbandeffekte und schwerwiegende Manifestationen auslösen. So zeigt z. B. das ursprüngliche Klassifikationssystem des Charcot-Marie-Tooth-Syndroms, wie das klinische Denken über seltene Erkrankungen sich in den letzten Jahren verändert hat. Zunächst basierend auf den Phänotypen, wurde das Klassifikationssystem auf der Grundlage der Progression und physiologischer Messungen erweitert, bis schließlich die aktuelle Klassifikation auf der Grundlage des Genotyps (aktuell über 80 Gene) entwickelt wurde. Obwohl gezeigt wurde, dass Krankheitsgene im Allgemeinen dazu neigen, in einer begrenzten Anzahl von Geweben exprimiert zu werden, ist nach wie vor unklar, wie die gewebespezifischen Expressionsmuster von Krankheitsgenen mit ihren pathologischen Manifestationen korrelieren. Proteom-Analysen zeigen, dass die meisten Genprodukte ihre Funktion häufig im Verband als Komplexe mehrerer unterschiedlicher Proteine ausüben [125]. Das könnte erklären, warum Mutationen verschiedener Proteine zu einem ähnlichen Phänotypen führen könnten. Neue Ansätze zeigen, dass beim Charcot-Marie-Tooth-Syndrom Typ 4F eine gewebsspezifische Überexpression von Genen im Rückenmark, im Dorsalganglion und in den Skeletmuskeln, die für bestimmte Proteinkomplexe kodieren, mit der pathologischen Manifestation korreliert [125]. Die zellulären Komponenten, die betroffen sind, sind die Telomerregionen der Chromosomen und die biologischen Prozessen, die gestört sind, gehören zur Mechanosensorik [125]. Solche Klassifikationssysteme bedeuten auch, dass mehrere, bis jetzt unerkannte biologische Prozesse zum Hörverlust führen können: Basalmembran/Kollagendefekte, Überexpression von Wachstumsfaktoren (z. B. TGF Beta/Interleukine) sowie Störungen der Melanozyten, der Autophagie und der Methylierung. Wie wir diese Erkenntnisse nutzen können, um neue Be- handlungsmöglichkeiten insbesondere für diejenigen Patienten zu entwickeln, die an seltenen Erkrankungen leiden, könnte Inhalt künftiger Studien sein.

Das Beispiel des Susac-Syndroms zeigt, dass nicht nur andere Innenohrerkrankungen als Differenzialdiagnose zu erwägen sind, sondern auch ophthalmologische und neurologische Erkrankungen. Wichtig ist es, bei einer Schallempfindungsschwerhörigkeit unbekannter Ursache auch an eine (ggf. initiale) audiologische Manifestation einer seltenen Erkrankung zu denken. Eine interdisziplinäre diagnostische Abklärung kann helfen, bisher nicht bemerkte Symptome der Patienten zu erkennen und eine korrekte Diagnose eher zu stellen. Inwiefern Hörverlust in solchen Fällen bereits diagnostiziert werden kann, bevor er sich manifestiert hat, wäre eine prognostisch relevante Frage. Patienten mit einem subjektiv ungestörten Gehör in Ruhe können z. B. Schwierigkeiten beim Verstehen von Sprache im Störgeräusch haben (auch als Synaptopathie oder "Hidden Hearing Loss" bekannt, was v. a. auch als Frühzeichen einer progressiven Neurodegenerationserkrankung vorliegen kann). Oft bleibt diese Störung unerkannt, weil sie dem Patienten selten bewusst ist und mit den in der Routine genutzten diagnostischen Verfahren nicht nachweisbar ist. Gezieltes Testen des Sprachverstehens im Störgeräusch kann hier hinweisend sein. Dies würde bei Erkrankungen wie das Susac-Syndrom die frühzeitige Einleitung der Therapie erlauben. Die Identifikation von Patienten, die an „Hidden Hearing Loss“ leiden [126], ist letztlich auch deswegen relevant, weil zur Zeit 3 klinische Studien neue Therapien zur Behandlung mit vielversprechenden Ergebnissen testen.

Eine Vielzahl molekular und zellphysiologischer Prozesse liegen der Hörminderung insbesondere bei den seltenen Erkrankungen zugrunde. Die Zukunft der (auch der rein symptomatischen) Behandlung von Innenohr-Erkrankungen, die ja oft seltene Erkrankungen darstellen, kann insbesondere vom frühzeitigen Erkennen molekularer Störungen profitieren.

Interessenkonflikt

Die Autorinnen/Autoren geben an, dass kein Interessenkonflikt besteht.

Literatur

[1] O'Rahilly R. The timing and sequence of events in the development of the human eye and ear during the embryonic period proper. Anat Embryol (Berl) 1983; 168: 87-99. doi:10.1007/BF00305401

[2] Som PM, Curtin HD, Liu K et al. Current Embryology of the Temporal Bone, Part II: the Middle and External Ears, the Statoacoustic and Facial Nerves, and When Things Go Developmentally Wrong. Neurographics 2016; 6: 332-349. doi:10.3174/ng.5160174

[3] Lavigne-Rebillard M, Pujol R. Surface Aspects of the Developing Human Organ of Corti. Acta Otolaryngol 1987; 104: 43-50. doi:10.3109/00016488709124975

[4] Dabdoub A, Donohue M], Brennan A et al. Wnt signaling mediates reorientation of outer hair cell stereociliary bundles in the mammalian cochlea. Development 2003; 130: 2375-2384. doi:10.1242/ dev.00448 
[5] Tritsch NX, Zhang YX, Ellis-Davies G et al. ATP-induced morphological changes in supporting cells of the developing cochlea. Purinergic Signal 2010; 6: 155-166. doi:10.1007/s11302-010-9189-4

[6] Fettiplace R. Hair Cell Transduction, Tuning, and Synaptic Transmission in the Mammalian Cochlea. In: Comprehensive Physiology.Hoboken, NJ, USA: John Wiley \& Sons, Inc.; 2017: 1197-1227. doi:10.1002/cphy.c160049

[7] Tritsch NX, Yi E, Gale JE et al. The origin of spontaneous activity in the developing auditory system. Nature 2007; 450: 50-55. doi:10.1038/nature06233

[8] Standring S. Gray's anatomy: the anatomical basis of clinical practice. 2016;

[9] Flint P, Haughey B, Lund V et al. Cummings Otolaryngology Head and Neck Surgery. 2020;

[10] Gibaja A, Aburto MR, Pulido S et al. TGF $\beta 2$-induced senescence during early inner ear development. Sci Rep 2019; 9: 1-13. doi:10.1038/s41598-019-42040-0

[11] Pujol R, Lavigne-Rebillard M. Early stages of innervation and sensory cell differentiation in the human fetal organ of Corti. Acta Otolaryngol Suppl 1985; 423: 43-50. doi:10.3109/00016488509122911

[12] Lavigne-Rebillard M, Pujol R. Hair Cell Innervation in the Fetal Human Cochlea. Acta Otolaryngol 1988; 105: 398-402. doi:10.3109/00016488809119492

[13] Moore JK, Linthicum FH. Myelination of the Human Auditory Nerve: Different Time Courses for Schwann Celland Glial Myelin. Ann Otol Rhinol Laryngol 2001; 110: 655-661. doi:10.1177/000348940111000711

[14] Moore JK. Organization of the human superior olivary complex. Microsc Res Tech 2000; 51: 403-412. doi:10.1002/10970029(20001115)51:4<403::AID-JEMT8>3.0.CO;2-Q

[15] Brown R, Groves AK. Hear, hear for notch: Control of cell fates in the inner ear by notch signaling. Biomolecules 2020; 10:1-18. doi:10.3390/biom 10030370

[16] Brigande JV, Kiernan a E, Gao X, et al. Molecular genetics of pattern formation in the inner ear: do compartment boundaries play a role? Proc Natl Acad Sci U S A 2000; 97: 11700-11706. doi:10.1073/ pnas.97.22.11700

[17] Xu Q, Mellitzer G, Robinson V et al. In vivo cell sorting in complementary segmental domains mediated by Eph receptors and ephrins. Nature 1999; 399: 267-271. doi:10.1038/20452

[18] Bergemann AD, Zhang L, Chiang MK et al. Ephrin-B3, a ligand for the receptor EphB3, expressed at the midline of the developing neural tube. Oncogene 1998; 16: 471-480. doi:10.1038/sj.onc.1201557

[19] Gale NW, Flenniken A, Compton DC et al. Elk-L3, a novel transmembrane ligand for the Eph family of receptor tyrosine kinases, expressed in embryonic floor plate, roof plate and hindbrain segments. Oncogene 1996; 13: 1343-1352.Im Internet http://www.ncbi.nlm. nih.gov/pubmed/8808709

[20] Wright T], Hatch EP, Karabagli $\mathrm{H}$ et al. Expression of mouse fibroblast growth factor and fibroblast growth factor receptor genes during early inner ear development. Dev Dyn 2003; 228: 267-272. doi:10.1002/dvdy.10362

[21] Sai X, Ladher RK. Early steps in inner ear development: Induction and morphogenesis of the otic placode. Front Pharmacol 2015; 6: 1-8. doi:10.3389/fphar.2015.00019

[22] Bouchard M, de Caprona D, Busslinger M et al. Pax2 and Pax8 cooperate in mouse inner ear morphogenesis and innervation. BMC Dev Biol 2010; 10: 89. doi:10.1186/1471-213X-10-89

[23] Chatterjee S, Kraus P, Lufkin T. A symphony of inner ear developmental control genes. BMC Genet 2010; 11: 68. doi:10.1186/1471-215611-68

[24] Riccomagno MM. Wnt-dependent regulation of inner ear morphogenesis is balanced by the opposing and supporting roles of Shh. Genes Dev 2005; 19: 1612-1623. doi:10.1101/gad.1303905
[25] Bok J, Brunet L], Howard O et al. Role of hindbrain in inner ear morphogenesis: analysis of Noggin knockout mice. Dev Biol 2007; 311: 69-78. doi:10.1016/j.ydbio.2007.08.013

[26] Bok J, Chang W, Wu DK. Patterning and morphogenesis of the vertebrate inner ear. Int J Dev Biol 2007; 51: 521-533. doi:10.1387| ijdb.072381jb

[27] Wu DK, Nunes FD, Choo D. Axial specification for sensory organs versus non-sensory structures of the chicken inner ear. Development 1998; 125: 11-20. Im Internet: http://www.ncbi.nlm.nih.gov/ pubmed/9389659

[28] Duncan JS, Lim K-C, Engel JD et al. Limited inner ear morphogenesis and neurosensory development are possible in the absence of GATA3. Int J Dev Biol 2011; 55: 297-303. doi:10.1387/ijdb.103178jd

[29] Zou D, Silvius D, Rodrigo-Blomqvist $S$ et al. Eya1 regulates the growth of otic epithelium and interacts with Pax2 during the development of all sensory areas in the inner ear. Dev Biol 2006; 298: 430-441. doi:10.1016/j.ydbio.2006.06.049

[30] Maroon H, Walshe J, Mahmood R et al. Fgf3 and Fgf8 are required together for formation of the otic placode and vesicle. Development 2002; 129: 2099-2108. Im Internet: http://www.ncbi.nlm.nih.gov/ pubmed/11959820

[31] Kiernan AE, Pelling AL, Leung KKH et al. Sox2 is required for sensory organ development in the mammalian inner ear. Nature 2005; 434: 1031-1035

[32] Fritzsch B, Beisel KWK, Hansen L a. The molecular basis of neurosensory cell formation in ear development: a blueprint for hair cell and sensory neuron regeneration? Bioessays 2006; 28: 1181-1193. doi:10.1002/bies.20502

[33] Fritzsch B, Matei $V$ a, Nichols DH et al. Atoh1 null mice show directed afferent fiber growth to undifferentiated ear sensory epithelia followed by incomplete fiber retention. Dev Dyn 2005; 233: 570-583. doi:10.1002/dvdy.20370

[34] Bermingham N a, Hassan B a, Price SD et al. Math1: an essential gene for the generation of inner ear hair cells. Science 1999; 284: 1837-1841. doi:10.1126/science.284.5421.1837

[35] Artavanis-Tsakonas S, Muskavitch MAT. Notch: the past, the present, and the future. Curr Top Dev Biol 2010; 92: 1-29. doi:10.1016/ S0070-2153(10)92001-2

[36] Bryant J, Goodyear RJ, Richardson GP. Sensory organ development in the inner ear: molecular and cellular mechanisms. Br Med Bull 2002; 63: 39-57. Im Internet: http://www.ncbi.nlm.nih.gov/pubmed/12324383

[37] Petit C, Richardson GP. Linking genes underlying deafness to hair-bundle development and function. Nat Neurosci 2009; 12 : 703-710. doi:10.1038/nn.2330

[38] Yin H, Copley CO, Goodrich LV et al. Comparison of phenotypes between different vangl 2 mutants demonstrates dominant effects of the Looptail mutation during hair cell development. PLoS One 2012; 7: e31988 doi:10.1371/journal.pone.0031988

[39] Sipe CW, Lu X. Kif3a regulates planar polarization of auditory hair cells through both ciliary and non-ciliary mechanisms. Development 2011; 138: 3441-3449. doi:10.1242/dev.065961

[40] García-Bellido A, De Celis JF. The complex tale of the achaete-scute complex: A paradigmatic case in the analysis of gene organization and function during development. Genetics 2009; 182: 631-639. doi:10.1534/genetics.109.104083

[41] Gaspard N, Vanderhaeghen P. Mechanisms of neural specification from embryonic stem cells. Curr Opin Neurobiol 2010; 20: 37-43. doi:10.1016/j.conb.2009.12.001

[42] Naka H, Nakamura S, Shimazaki T et al. Requirement for COUP-TFI and II in the temporal specification of neural stem cells in CNS development. Nat Neurosci 2008; 11: 1014-1023. doi:10.1038/ nn. 2168 
[43] Jahan I, Pan N, Kersigo J et al. Neurod1 suppresses hair cell differentiation in ear ganglia and regulates hair cell subtype development in the cochlea. PLoS One 2010; 5: e11661 doi:10.1371/ journal.pone.0011661

[44] Karis A, Pata I, van Doorninck JH et al. Transcription factor GATA-3 alters pathway selection of olivocochlear neurons and affects morphogenesis of the ear. J Comp Neurol 2001; 429: 615-630. doi:10.1002/1096-9861(20010122)429:4<615::aid-cne8>3.0.co;2-f

[45] Huang EJ, Liu W, Fritzsch B et al. Brn3a is a transcriptional regulator of soma size, target field innervation and axon pathfinding of inner ear sensory neurons. Development 2001; 128: 2421-2432. Im Internet: http://www.pubmedcentral.nih.gov/articlerender. fcgi? artid $=2710107 \&$ tool $=$ pmcentrez\&rendertype $=$ abstract

[46] Jahan I, Pan N, Elliott KL et al. The quest for restoring hearing: Understanding ear development more completely. BioEssays 2015; 37: 1016-1027. doi:10.1002/bies.201500044

[47] Pan N, Jahan I, Kersigo J et al. Conditional deletion of Atoh1 using Pax2-Cre results in viable mice without differentiated cochlear hair cells that have lost most of the organ of Corti. Hear Res 2011; 275: 66-80. doi:10.1016/j.heares.2010.12.002

[48] Yang T, Kersigo J, Jahan I et al. The molecular basis of making spiral ganglion neurons and connecting them to hair cells of the organ of Corti. Hear Res 2011; 278: 21-33. doi:10.1016/j.heares.2011.03.002

[49] Fekete DM, Campero AM. Axon guidance in the inner ear. Int J Dev Biol 2007; 51: 549-556. doi:10.1387/ijdb.072341df

[50] Barclay M, Julien J-P, Ryan AF et al. Type III intermediate filament peripherin inhibits neuritogenesis in type II spiral ganglion neurons in vitro. Neurosci Lett 2010; 478: 51-55. doi:10.1016/j.neulet.2010.01.063

[51] Fritzsch B, Dillard M, Lavado A et al. Canal cristae growth and fiber extension to the outer hair cells of the mouse ear require Prox 1 activity. PLoS One 2010; 5: 1-12. doi:10.1371/journal.pone.0009377

[52] Fariñas I, Jones KR, Tessarollo L et al. Spatial shaping of cochlear innervation by temporally regulated neurotrophin expression. J Neurosci 2001; 21: 6170-6180. http://www.pubmedcentral.nih. gov/articlerender.

fcgi?artid $=2710117 \&$ tool $=$ pmcentrez\&rendertype $=$ abstract

[53] Samarajeewa A, Jacques BE, Dabdoub A. Therapeutic Potential of Wnt and Notch Signaling and Epigenetic Regulation in Mammalian Sensory Hair Cell Regeneration. Mol Ther 2019; 27: 904-911. doi:10.1016/j.ymthe.2019.03.017

[54] Chai R, Kuo B, Wang T et al. Wnt signaling induces proliferation of sensory precursors in the postnatal mouse cochlea. Proc Natl Acad Sci U S A 2012; 109: 8167-8172. doi:10.1073/pnas.1202774109

[55] Bramhall NF, Shi F, Arnold K et al. Lgr5-positive supporting cells generate new hair cells in the postnatal cochlea. Stem Cell Reports 2014; 2: 311-322. doi:10.1016/j.stemcr.2014.01.008

[56] McLean W], Yin X, Lu L et al. Clonal Expansion of Lgr5-Positive Cells from Mammalian Cochlea and High-Purity Generation of Sensory Hair Cells. Cell Rep 2017; 18: 1917-1929. doi:10.1016/j.celrep.2017.01.066

[57] Johnson Chacko L, Sergi C, Eberharter T et al. Early appearance of key transcription factors influence the spatiotemporal development of the human inner ear. Cell Tissue Res 2020; 379: 459-471. doi:10.1007/s00441-019-03115-6

[58] Miwa T, Ohta K, Ito $\mathrm{N}$ et al. Tsukushi is essential for the development of the inner ear. Mol Brain 2020; 13: 1-11. doi:10.1186/s13041-02000570-z

[59] Cardoso-Moreira M, Halbert J, Valloton D et al. Gene expression across mammalian organ development. Nature 2019; 571: 505-509. doi:10.1038/s41586-019-1338-5

[60] Qin Y, Pan J, Cai M et al. Pattern Genes Suggest Functional Connectivity of Organs. Sci Rep 2016; 6: 1-7. doi:10.1038/srep26501
[61] Lam EWF, Brosens J], Gomes AR et al. Forkhead box proteins: Tuning forks for transcriptional harmony. Nat Rev Cancer 2013; 13: 482-495. doi:10.1038/nrc3539

[62] Stefanovic S, Abboud N, Désilets S et al. Interplay of Oct4 with Sox2 and Sox 17: A molecular switch from stem cell pluripotency to specifying a cardiac fate. J Cell Biol 2009; 186: 665-673. doi:10.1083/jcb.200901040

[63] Som PM, Curtin HD, Liu K et al. Current Embryology of the Temporal Bone, Part I: the Inner Ear. Neurographics 2016; 6: 250-265. doi:10.3174/ng.4160166

[64] Lefebvre V. Roles and regulation of SOX transcription factors in skeletogenesis. Curr Top Dev Biol 2019; 133: 171-193. doi:10.1016/ bs.ctdb.2019.01.007

[65] Heavner WE, Andoniadou CL, Pevny LH. Establishment of the neurogenic boundary of the mouse retina requires cooperation of SOX2 and WNT signaling. Neural Dev 2014; 9 doi:10.1186/17498104-9-27

[66] Wang L, Sewell WF, Kim SD et al. Eya4 regulation of $\mathrm{Na}+/ \mathrm{K}+$-ATPase in required for sensory system. development in zebrafish. Development 2008; 135: 3425-3434. doi:10.1242/dev.012237

[67] Vona B, Nanda I, Hofrichter MAH et al. Non-syndromic hearing loss gene identification: A brief history and glimpse into the future. Mol Cell Probes 2015; 29: 260-270. doi:10.1016/j.mcp.2015.03.008

[68] Girirajan S, Eichler EE. Phenotypic variability and genetic susceptibility to genomic disorders. Hum Mol Genet 2010; 19: R176-R187. doi: $10.1093 / \mathrm{hmg} / \mathrm{ddq} 366$

[69] Génin E, Feingold J, Clerget-Darpoux F. Identifying modifier genes of monogenic disease: strategies and difficulties. Hum Genet 2008; 124: 357-368. doi:10.1007/s00439-008-0560-2

[70] Hildebrand MS, DeLuca AP, Taylor KR et al. A contemporary review of AudioGene audioprofiling: A machine-based candidate gene prediction tool for autosomal dominant nonsyndromic hearing loss. Laryngoscope 2009; 119: 2211-2215. doi:10.1002/lary.20664

[71] Warnecke A, Prenzler NK, Schmitt $\mathrm{H}$ et al. Defining the Inflammatory Microenvironment in the Human Cochlea by Perilymph Analysis: Toward Liquid Biopsy of the Cochlea. Front Neurol 2019; 10: 1-10. doi:10.3389/fneur.2019.00665

[72] Yue Q, Stahl F, Plettenburg O et al. The Noncompetitive Effect of Gambogic Acid Displaces Fluorescence-Labeled ATP but Requires ATP for Binding to Hsp90/HtpG. Biochemistry 2018; 57: 2601-2605. doi:10.1021/acs.biochem.8b00155

[73] Shew M, Warnecke A, Lenarz T et al. Feasibility of microRNA profiling in human inner ear perilymph. Neuroreport 2018; 29: 894-901. doi:10.1097/WNR.0000000000001049

[74] Wang H, Stahl F, Scheper T et al. Microarray-based screening system identifies temperature-controlled activity of Connexin 26 that is distorted by mutations. Sci Rep 2019; 9: 13543 doi:10.1038/ s41598-019-49423-3

[75] Mondini C. Minor works of Carlo Mondini: the anatomical section of a boy born deaf. Am J Otol 1997; 18: 288-293

[76] Brotto D, Uberti A, Manara R. From Mondini to the latest inner ear malformations' classifications: an historical and critical review. Hear Balanc Commun 2019; 17: 241-248. doi:10.1080/21695717.2019.1 663041

[77] Jackler RK, Luxford WM, House WF. Congenital malformations of the inner ear: A classification based on embryo genesis. Laryngoscope 1987; 97: 2-14. doi:10.1002/lary.5540971301

[78] Streeter GL. Developmental horizons in human embryos; a review of the histogenesis of cartilage and bone. Contrib Embryol 1949; 33: 149-168.Im Internet http://www.ncbi.nlm.nih.gov/pubmed/18144445 
[79] Sennaroğlu L, Bajin MD. Classification and current management of inner ear malformations. Balkan Med J 2017; 34: 397-411. doi:10.4274/balkanmedj.2017.0367

[80] Sennaroglu L, Saatci I. Unpartitioned Versus Incompletely Partitioned Cochleae: Radiologic Differentiation. Otol Neurotol 2004; 25: 520-529. doi:10.1097/00129492-200407000-00020

[81] Giesemann A, Götz F, Lanfermann H. Fehlbildungen des Innenohrs - Diagnostik und Einteilung in CT und MRT. Radiol up2date 2013; 13: 201-218. doi:10.1055/s-0033-1344189

[82] Phelps PD, Michaels L. The Common Cavity Congenital Deformity of the Inner Ear. ORL 1995; 57: 228-231. doi:10.1159/000276746

[83] Cock E. A contribution to the pathology of congenital deafness. Guys Hosp Rep. 1838; 7 :

[84] Papsin BC. Cochlear implantation in children with anomalous cochleovestibular anatomy. Laryngoscope 2005; 115: 1-26. doi:10.1097/00005537-200501001-00001

[85] Nance WE, Setleff R, McLeod A et al. X-linked mixed deafness with congenital fixation of the stapedial footplate and perilymphatic gusher. Birth Defects Orig Artic Ser 1971; 07: 64-69.Im Internet http://www.ncbi.nlm.nih.gov/pubmed/5173351

[86] Phelps PD, Reardon W, Pembrey M et al. X-linked deafness, stapes gushers and a distinctive defect of the inner ear. Neuroradiology 1991; 33: 326-330. doi:10.1007/BF00587816

[87] Kang WS, Shim BS, Lee KS. Audiologic performance after cochlear implantation in children with X-linked deafness: Comparison with deaf children with a normal inner ear structure. Otol Neurotol 2013; 34: 544-548. doi:10.1097/MAO.0b013e3182839864

[88] Smith JD, El-Kashlan N, Darr OAF et al. Systematic Review of Outcomes After Cochlear Implantation in Children With X-Linked Deafness-2. Otolaryngol - Head Neck Surg (United States) 2020; 1-8. doi:10.1177/0194599820932138

[89] de Kok Y], van der Maarel SM, Bitner-Glindzicz M et al. Association between $\mathrm{X}$-linked mixed deafness and mutations in the POU domain gene POU3F4. Science 1995; 267: 685-688. doi:10.1126/science.7839145

[90] Pollak A, Lechowicz U, Kędra A, et al. Novel and De Novo mutations extend association of POU3F4 with distinct clinical and radiological phenotype of hearing loss. PLoS One 2016; 11: 1-13. doi:10.1371/ journal.pone. 0166618

[91] Myhre SA, Ruvalcaba RHA, Kelley VC. Congenital deafness and hypogonadism: a new X-linked recessive disorder. Clin Genet 2008; 22: 299-307. doi:10.1111/j.1399-0004.1982.tb01843.x

[92] Giesemann A, Hartmann H, Franke D et al. Hamartome in Kombination mit X-chromosomaler Taubheit zeigen keine Epilepsie und keine Pubertas praecox. In: Clinical Neuroradiology. 2013; 0177

[93] Siddiqui A, D’Amico A, Colafati GS et al. Hypothalamic malformations in patients with $X$-linked deafness and incomplete partition type 3 . Neuroradiology 2019; 61: 949-952. doi:10.1007/s00234-01902230-z

[94] Corvino V, Apisa P, Malesci R et al. X-Linked Sensorineural Hearing Loss: A Literature Review. Curr Genomics 2017; 19: 327-338. doi:10. 2174/1389202919666171218163046

[95] Satar B, Mukherji SK, Telian SA. Congenital Aplasia of the Semicircular Canals. Otol Neurotol 2003; 24: 437-446. doi:10.1097/00129492200305000-00014

[96] Lanson BG, Green JE, Roland JT et al. Cochlear implantation in Children with CHARGE syndrome: therapeutic decisions and outcomes. Laryngoscope 2007; 117: 1260-1266. doi:10.1097| MLG.0b013e31806009c9

[97] Pagon RA, Graham JM, Zonana J et al. Coloboma, congenital heart disease, and choanal atresia with multiple anomalies: CHARGE association. J Pediatr 1981; 99: 223-227. doi:10.1016/s00223476(81)80454-4
[98] Verloes A. Updated diagnostic criteria for CHARGE syndrome: a proposal. Am J Med Genet A 2005; 133A: 306-308. doi:10.1002/ ajmg.a.30559

[99] Hsu P, Ma A, Wilson M et al. CHARGE syndrome: A review. J Paediatr Child Health 2014; 50: 504-511. doi:10.1111/jpc.12497

[100] Kontorinis G, Goetz F, Giourgas A et al. Aplasia of the cochlea: Radiologic assessment and options for hearing rehabilitation. Otol Neurotol 2013; 34: 1253-1260. doi:10.1097| MAO.0b013e318291c48f

[101] Phelps PD. Cochlear Implants For Congenital Deformities. J Laryngol Otol 1992; 106: 967-970. doi:10.1017/S0022215100121486

[102] Dahm MC, Weber BP, Lenarz T. Cochlear implantation in a Mondini malformation of the inner ear and the management of perilymphatic gusher. Adv Otorhinolaryngol 1995; 50: 66-71. doi:10.1159/000424437

[103] Weber BP, Lenarz T, Hartrampf R et al. Cochlear implantation in children with malformation of the cochlea. Adv Otorhinolaryngol 1995; 50: 59-65. doi:10.1159/000424436

[104] Kontorinis G, Goetz F, Giourgas A et al. Radiological diagnosis of incomplete partition type I versus type II: significance for cochlear implantation. Eur Radiol 2012; 22: 525-532. doi:10.1007| s00330-011-2301-5

[105] Sennaroğlu L, Tahir E. A Novel Classification: Anomalous Routes of the Facial Nerve in Relation to Inner Ear Malformations. Laryngoscope 2020; 1-8. doi:10.1002/lary.28596

[106] Halawani RT, Dhanasingh A. New Classification of Cochlear Hypoplasia Type Malformation: Relevance in Cochlear Implantation. J Int Adv Otol 2020; 16: 153-157. doi:10.5152/iao.2020.7690

[107] Cinar BC, Batuk MO, Tahir E et al. Audiologic and radiologic findings in cochlear hypoplasia. Auris Nasus Larynx 2017; 44: 655-663. doi:10.1016/j.anl.2016.12.002

[108] Giesemann AM, Goetz F, Neuburger J et al. Appearance of hypoplastic cochleae in CT and MRI: A new subclassification. Neuroradiology 2011; 53: 49-61. doi:10.1007/s00234-010-0777-3

[109] Harnsberger HR. Diagnostic Imaging Head and Neck. 2004;

[110] Giesemann AM, Kontorinis G, Jan Z et al. The vestibulocochlear nerve: Aplasia and hypoplasia in combination with inner ear malformations. Eur Radiol 2012; 22: 519-524. doi:10.1007/ s00330-011-2287-z

[111] Dörr ], Krautwald S, Wildemann B et al. Characteristics of Susac syndrome: A review of all reported cases. Nat Rev Neurol 2013; 9 : 307-316. doi:10.1038/nrneurol.2013.82

[112] Kleffner I, Dörr J, Ringelstein M et al. Diagnostic criteria for Susac syndrome. J Neurol Neurosurg Psychiatry 2016; 87: 1287-1295. doi:10.1136/jnnp-2016-314295

[113] Hertzano R, Tomlinson JA, Mackowiak PA. Goya's Lost Hearing: A Twenty-First Century Perspective on Its Cause, Effects and Possible Treatment. Am J Med Sci 2019; 357: 275-279. doi:10.1016/j. amjms.2018.12.009

[114] Schelenz D, Kleffner I, Tsiampalis $N$ et al. Susac syndrome - interdisciplinary tracking of the chameleon: two different case reports. Ophthalmologe 2020; 117: 369-375. doi:10.1007/s00347-0190926-y

[115] Wang Y, Burkholder B, Newsome SD. Progressive sensorineural hearing loss many years preceding completion of Susac's syndrome triad: A case report. Mult Scler Relat Disord 2020; 37: 101436 doi:10.1016/j.msard.2019.101436

[116] Kleffner I, Duning T, Lohmann $\mathrm{H}$ et al. A brief review of Susac syndrome. J Neurol Sci 2012; 322: 35-40. doi:10.1016/j. jns.2012.05.021 
[117] Plontke SK, Caye-Thomasen P, Strauss C et al. Management of transmodiolar and transmacular cochleovestibular schwannomas with and without cochlear implantation. HNO. 2020; doi:10.1007/ s00106-020-00919-9

[118] Baskin J, Hardy TA, Law LY et al. Black blood MRI: endotheliopathy of Susac syndrome unmasked. Neurol Sci 2020; 8-10. doi:10.1007/ s10072-020-04562-8

[119] Mei X, Glueckert R, Schrott-Fischer A et al. Vascular Supply of the Human Spiral Ganglion: Novel Three-Dimensional Analysis Using Synchrotron Phase-Contrast Imaging and Histology. Sci Rep 2020; 10: 5877 doi:10.1038/s41598-020-62653-0

[120] Ishiyama G, Wester ], Lopez IA et al. Oxidative stress in the blood labyrinthine barrier in the macula utricle of Meniere's disease patients. Front Physiol 2018; 9: 1-16. doi:10.3389/fphys.2018.01068

[121] Gu C, Qiao W, Wang L et al. Identification of genes and pathways associated with multiple organ dysfunction syndrome by microarray analysis. Mol Med Rep 2018; 18: 31-40. doi:10.3892/ mmr.2018.8973

[122] Ishiyama G, Lopez IA, Acuna D et al. Investigations of the Microvasculature of the Human Macula Utricle in Meniere's Disease. Front Cell Neurosci 2019; 13: 1-11. doi:10.3389/fncel.2019.00445

[123] Schmitt HA, Pich A, Schröder A et al. Proteome Analysis of Human Perilymph using an Intraoperative Sampling Method. J Proteome Res. 2017; acs.jproteome.6b00986 doi:10.1021/acs.jproteome.6b00986

[124] Lin HC, Ren Y, Lysaght AC et al. Proteome of normal human perilymph and perilymph from people with disabling vertigo. PLoS One 2019; 14: 1-21. doi:10.1371/journal.pone.0218292

[125] Lage K, Hansena NT, Karlberg EO et al. A large-scale analysis of tissue-specific pathology and gene expression of human disease genes and complexes. Proc Natl Acad Sci U S A 2008; 105: 20870 20875. doi:10.1073/pnas.0810772105

[126] Knipper M, Hofmeier B, Singer W et al. Differentiating cochlear synaptopathies into different hearing disorders. HNO 2019; 67: 406-416. doi:10.1007/s00106-019-0660-4

[127] Espinoza GM, Wheeler J, Temprano KK et al. Cogan's Syndrome: Clinical Presentations and Update on Treatment. Curr Allergy Asthma Rep 2020; 20: 2-7. doi:10.1007/s11882-020-00945-1

[128] Kuemmerle-Deschner JB, Koitschev A, Ummenhofer K et al. Hearing loss in Muckle-Wells syndrome. Arthritis Rheum 2013; 65: 824-831. doi:10.1002/art.37810

[129] Goldbach-Mansky R, Dailey NJ, Canna SW et al. Neonatal-Onset Multisystem Inflammatory Disease Responsive to Interleukin-1 $\beta$ Inhibition. N Engl J Med 2006; 355: 581-592. doi:10.1056/ NEJMoa055137

[130] Bachor E, Blevins NH, Karmody C et al. Otologic manifestations of relapsing polychondritis. Auris Nasus Larynx 2006; 33: 135-141. doi:10.1016/j.anl.2005.11.020

[131] Noguchi Y, Nishio A, Takase $\mathrm{H}$ et al. Audiovestibular findings in patients with Vogt-Koyanagi-Harada disease. Acta Otolaryngol 2014; 134: 339-344. doi:10.3109/00016489.2013.868604

[132] Kemal O, Anadolu Y, Boyvat A et al. Behçet Disease as a Cause of Hearing Loss: A Prospective, Placebo-Controlled Study of 29 Patients. Ear, Nose Throat J 2013; 92: 112-120. doi:10.1177/014556131309200309

[133] Ovadia S, Dror I, Zubkov T et al. Churg-Strauss syndrome: A rare presentation with otological and pericardial manifestations: Case report and review of the literature. Clin Rheumatol 2009; 28: 35-38. doi:10.1007/s10067-009-1119-x

[134] Moosig F, Holle J. Current treatment of eosinophilic granulomatosis with polyangiitis (Churg-Strauss syndrome). Z Rheumatol 2019; 78: 333-338. doi:10.1007/s00393-018-0580-9

[135] rarediseases.org. Im Internet: https://rarediseases.org/rare-diseases/ alpha-mannosidosis/; Stand: 16.08.2020
[136] Faverio P, Bonaiti G, Bini F et al. Mepolizumab as the first targeted treatment for eosinophilic granulomatosis with polyangiitis: A review of current evidence and potential place in therapy. Ther Clin Risk Manag 2018; 14: 2385-2396. doi:10.2147/TCRM.S159949

[137] Brachet C, Mansbach AL, Clerckx A et al. Hearing Loss Is Part of the Clinical Picture of ENPP1 Loss of Function Mutation. Horm Res Paediatr 2014; 81: 63-66. doi:10.1159/000354661

[138] Maher CO, Piepgras DG, Brown RD et al. Cerebrovascular manifestations in 321 cases of hereditary hemorrhagic telangiectasia. Stroke 2001; 32: 877-882. doi:10.1161/01.STR.32.4.877

[139] Kim GB. Reality of Kawasaki disease epidemiology. Korean J Pediatr 2019; 62: 292-296. doi:10.3345/kjp.2019.00157

[140] Rahne T, Plontke S, Keyßer G. Vasculitis and the ear: A literature review. Curr Opin Rheumatol 2020; 32: 47-52. doi:10.1097/ BOR.0000000000000665

[141] Nadol JB, Eavey RD, Liberfarb RM , et al. Histopathology of the ears, eyes, and brain in norrie's disease (oculoacousticocerebral degeneration). Am J Otolaryngol 1990; 11: 112-124. doi:10.1016/01960709(90)90007-I

[142] Gross CC, Meyer C, Bhatia U et al. CD8 + T cell-mediated endotheliopathy is a targetable mechanism of neuro-inflammation in Susac syndrome. Nat Commun 2019; 10. doi:10.1038/s41467-019-13593-5

[143] Naini AS, Ghorbani J, Elahi SML et al. Otologic manifestations in patients with Wegener's granulomatosis: A survey in 55 patients. Iran J Otorhinolaryngol 2017; 29: 327-331. doi:10.22038/ ijorl.2017.25253.1822

[144] Marsot-Dupuch K, Dominguez-Brito A, Ghasli K et al. CT and MR findings of Michel anomaly: Inner ear aplasia. Am J Neuroradiol 1999; 20: $281-284$

[145] Daneshi A, Farhadi M, Asghari A et al. Three familial cases of Michel's aplasia. Otol Neurotol 2002; 23: 346-348. doi:10.1097/00129492200205000-00020

[146] Giesemann AM, Goetz F, Neuburger ] et al. From labyrinthine aplasia to otocyst deformity. Neuroradiology 2010; 52: 147-154. doi:10.1007/s00234-009-0601-0

[147] Vesseur AC, Verbist BM, Westerlaan HE et al. CT findings of the temporal bone in CHARGE syndrome: aspects of importance in cochlear implant surgery. Eur Arch Oto-Rhino-Laryngology 2016; 273: 4225-4240. doi:10.1007/s00405-016-4141-z

[148] Giesemann AM, Goetz GF, Neuburger J et al. Persistent petrosquamosal sinus: High incidence in cases of complete aplasia of the semicircular canals. Radiology 2011; 259: 825-833. doi:10.1148/ radiol.11101466

[149] Sennaroglu L, Saatci I. A New Classification for Cochleovestibular Malformations. Laryngoscope 2002; 112: 2230-2241. doi:10.1097/00005537-200212000-00019

[150] Bademci G, Abad C, Incesulu A et al. FOXF2 is required for cochlear development in humans and mice. Hum Mol Genet 2019; 28 : 1286-1297. doi:10.1093/hmg/ddy431

[151] Alballaa A, Aschendorff A, Arndt S et al. Incomplete partition type III“ - Langzeitergebnisse nach Cochleaimplantation. HNO 2019; 67: 760-768. doi:10.1007/s00106-019-00733-y

[152] Kaur A, Khetarpal S. 3P Deletion Syndrome. Indian Pediatr 2013; 50 : 795-796

[153] Țuțulan-Cuniță AC, Papuc SM, Arghir A , et al. 3p interstitial deletion: Novel case report and review. J Child Neurol 2012; 27: 1062-1066. doi: $10.1177 / 0883073811431016$

[154] Lindstrand A, Malmgren H, Verri A et al. Molecular and clinical characterization of patients with overlapping 10p deletions. Am J Med Genet Part A 2010; 152: 1233-1243. doi:10.1002/ajmg.a.33366

[155] Ohta S, Isojima T, Mizuno Y et al. Partial monosomy of 10p and duplication of another chromosome in two patients. Pediatr Int 2017; 59: 99-102. doi:10.1111/ped.13181 
[156] Corrêa T, Feltes BC, Riegel M. Integrated analysis of the critical region 5p15.3-p15.2 associated with cri-du-chat syndrome. Genet Mol Biol 2019; 42: 186-196. doi:10.1590/1678-4685-gmb-2018-0173

[157] Swanepoel D. Auditory pathology in cri-du-chat (5p-) syndrome: Phenotypic evidence for auditory neuropathy. Clin Genet 2007; 72: 369-373. doi:10.1111/j.1399-0004.2007.00870.x

[158] Du Q, de la Morena MT, van Oers NSC. The Genetics and Epigenetics of 22q11.2 Deletion Syndrome. Front Genet 2020; 10: 1-16. doi:10.3389/fgene.2019.01365

[159] Bhalla P, Wysocki CA, van Oers NSC. Molecular Insights Into the Causes of Human Thymic Hypoplasia With Animal Models. Front Immunol 2020; 11 doi:10.3389/fimmu.2020.00830

[160] Romagna ES, Appel da Silva MC, Zanetti Ballardin PA. Schmid-Fraccaro Syndrome: Severe Neurologic Features. Pediatr Neurol 2010; 42: 151-153. doi:10.1016/j.pediatrneurol.2009.07.020

[161] Alamer L, Bassant S, Alhazmi R et al. Rare otologic presentation of cat eye syndrome. Ann Saudi Med 2019; 39: 441-443. doi:10.5144/0256-4947.2019.441

[162] Crawford TD, Audia JE, Bellon S, et al. GNE-886: A Potent and Selective Inhibitor of the Cat Eye Syndrome Chromosome Region Candidate 2 Bromodomain (CECR2). ACS Med Chem Lett 2017; 8: 737-741. doi:10.1021/acsmedchemlett.7b00132

[163] Pejcic L, Stankovic T, Ratkovic-Jankovic M et al. Clinical manifestations in trisomy 9 mosaicism. Turk J Pediatr 2018; 60: 729-734. doi:10.24953/turkjped.2018.06.015

[164] Dhangar S, Korgaonkar S, Vundinti BR. Partial trisomy 9 (9pter->9q22.1) and partial monosomy 14 (14pter->14q11.2) due to paternal translocation $\mathrm{t}(9(\mathrm{q} 22.1 ; \mathrm{q} 11.2)$ in a case of Dysmorphic features. Intractable Rare Dis Res 2019; 8: 72-77. doi:10.5582/ irdr.2019.01000

[165] Lee CY, Su HJ, Cheng YT et al. Detection of fetal trisomy 9 mosaicism by noninvasive prenatal testing through maternal plasma DNA sequencing. Taiwan J Obstet Gynecol 2018; 57: 594-597. doi:10.1016/j.tjog.2018.06.021

[166] Thomas S, Parker M, Tan J et al. Ocular manifestations of mosaic trisomy 22: A case report and review of the literature. Ophthalmic Genet 2004; 25: 53-56. doi:10.1076/opge.25.1.53.29004

[167] Abdelgadir D, Nowaczyk MJM, Li C. Trisomy 22 Mosaicism and Normal Developmental Outcome: Report of Two Patients and Review of the Literature. Am J Med Genet Part A 2013; 161: 1126-1131. doi:10.1002/ajmg.a.35812

[168] Schuster M, Hoppe U, Eysholdt U et al. Severe Hearing Loss in Pallister-Killian Syndrome. ORL 2002; 64: 343-345. doi:10.1159/000066080

[169] Brendal MA, King KA, Zalewski CK et al. Auditory Phenotype of Smith-Magenis Syndrome. J Speech, Lang Hear Res 2017; 60: 1076-1087. doi:10.1044/2016_JSLHR-H-16-0024

[170] Lei M, Liang D, Yang Y et al. Long-read DNA sequencing fully characterized chromothripsis in a patient with Langer-Giedion syndrome and Cornelia de Lange syndrome-4. J Hum Genet 2020; 65: 667-674. doi:10.1038/s10038-020-0754-6

[171] Nouws J, Wibrand F, van den Brand M et al. A Patient with Complex I Deficiency Caused by a Novel ACAD9 Mutation Not Responding to Riboflavin Treatment. In: JIMD Reports 2013; 37-45. doi:10.1007/8904_2013_242

[172] Dewulf JP, Barrea C, Vincent MF et al. Evidence of a wide spectrum of cardiac involvement due to ACAD9 mutations: Report on nine patients. Mol Genet Metab 2016; 118: 185-189. doi:10.1016/j. ymgme.2016.05.005

[173] Yazdanfard PD, Madsen CV, Nielsen LH et al. Significant hearing loss in Fabry disease: Study of the Danish nationwide cohort prior to treatment. PLoS One 2019; 14: e0225071 doi:10.1371/journal. pone. 0225071
[174] Syed Haneef SA, George Priya Doss C. Personalized Pharmacoperones for Lysosomal Storage Disorder: Approach for Next-Generation Treatment. Adv Protein Chem Struct Biol 2016; 102: 225-265. doi:10.1016/bs.apcsb.2015.10.001

[175] orpha.net

[176] Ärztezeitung.de. Im Internet: https://www.aerztezeitung.de/Specials/ Lamzede-erste-Enzymersatztherapie-fuer-Patienten-mit-Alpha-Mannosidose-255697.html; Stand: 16.08.2020

[177] Lehalle D, Colombo R, O'Grady M et al. Hearing impairment as an early sign of alpha-mannosidosis in children with a mild phenotype: Report of seven new cases. Am J Med Genet Part A 2019; 179: 1756-1763. doi:10.1002/ajmg.a.61273

[178] Canda E, Kalkan Uçar S, Çoker M. Biotinidase Deficiency: Prevalence, Impact And Management Strategies. . Pediatr Heal Med Ther 2020; 11: 127-133. doi:10.2147/PHMT.S198656

[179] Jaeger B, Bosch AM. Clinical presentation and outcome of riboflavin transporter deficiency: mini review after five years of experience. J Inherit Metab Dis 2016; 39: 559-564. doi:10.1007/s10545-0169924-2

[180] Garg M, Kulkarni S, Hegde A et al. Riboflavin treatment in genetically proven Brown-Vialetto-Van Laere syndrome. J Pediatr Neurosci 2018; 13: 471 doi:10.4103/JPN.JPN_131_17

[181] Dhar SU, Taylor T, Trinh C et al. Cranio-meta-diaphyseal dysplasia: 25 Year follow-up and review of literature. Am J Med Genet Part A 2010; 152: 2335-2338. doi:10.1002/ajmg.a.33582

[182] PLM Huygen, CWRJ Cremers, WIM Verhagen , et al. Camurati-Engelmann disease presenting as ,juvenile otosclerosis“. Int J Pediatr Otorhinolaryngol 1996; 37: 129-141. doi:10.1016/01655876(96)01392-4

[183] Carlson ML, Beatty CW, Neff BA et al. Skull base manifestations of Camurati-Engelmann disease. Arch Otolaryngol - Head Neck Surg 2010; 136: 566-575. doi:10.1001/archoto.2010.68

[184] Kim YM, Kang E, Choi JH et al. Clinical characteristics and treatment outcomes in Camurati-Engelmann disease. Med (United States) 2018; 97: 1-6. doi:10.1097/MD.0000000000010309

[185] Qin Y, Tang S, Zhen G et al. Bone-targeted delivery of TGF- $\beta$ type 1 receptor inhibitor rescues uncoupled bone remodeling in CamuratiEngelmann disease. Ann N Y Acad Sci 2018; 1433: 29-40. doi:10.1111/nyas. 13941

[186] Lenarz T. JG Neuro-otologic early symptoms of Camurati-Engelmann disease. Laryngol Rhinol Otol (Stuttg) 1983; 62: 463-467

[187] Louhichi N, Bahloul E, Marrakchi S et al. Thyroid involvement in Chanarin-Dorfman syndrome in adults in the largest series of patients carrying the same founder mutation in ABHD5 gene. Orphanet J Rare Dis 2019; 14: 1-8. doi:10.1186/s13023-019-1095-4

[188] Faruqi T, Dhawan N, Bahl J et al. Molecular, phenotypic aspects and therapeutic horizons of rare genetic bone disorders. Biomed Res Int. 2014; 2014 doi:10.1155/2014/670842

[189] Sun GH, Samy RN, Tinkle BT et al. Imaging Case of the Month Craniometaphyseal Dysplasia-Induced Hearing Loss. 2011; 9-10

[190] Vasu CK, Rajendran VR, Regi George AN et al. Progressive facial disfigurement and deafness in craniometaphyseal dysplasia. Indian J Pediatr 2006; 73: 1105. doi:10.1007/bf02763055

[191] Haffner D, Emma F, Eastwood DM et al. Clinical practice recommendations for the diagnosis and management of $X$-linked hypophosphataemia. Nat Rev Nephrol 2019; 15: 435-455. doi:10.1038/ s41581-019-0152-5

[192] Morava E, Kühnisch J, Drijvers JM et al. Autosomal recessive mental retardation, deafness, ankylosis, and mild hypophosphatemia associated with a novel ANKH mutation in a consanguineous family. J Clin Endocrinol Metab 2011; 96: 189-198. doi:10.1210/jc.2010-1539 
[193] Kyriakou K, Lederer CW, Kleanthous M et al. Acid ceramidase depletion impairs neuronal survival and induces morphological defects in neurites associated with altered gene transcription and sphingolipid content. Int J Mol Sci 2020; 21: 1-24. doi:10.3390/ ijms21051607

[194] Yu FPS, Amintas S, Levade T et al. Acid ceramidase deficiency: Farber disease and SMA-PME. Orphanet J Rare Dis 2018; 13: 1-19. doi:10.1186/s13023-018-0845-z

[195] Pignolo RJ, Wang H, Kaplan FS. Fibrodysplasia Ossificans Progressiva (FOP): A Segmental Progeroid Syndrome. Front Endocrinol (Lausanne) 2020; 10: 1-8. doi:10.3389/fendo.2019.00908

[196] Kaplan FS, Kobori JA, Orellana C et al. Multi-system involvement in a severe variant of fibrodysplasia ossificans progressiva ( ACVR1 c.772G > A; R258G): A report of two patients. Am J Med Genet Part A 2015; 167: 2265-2271. doi:10.1002/ajmg.a.37205

[197] Jaeken J, Vleugels W, Régal L et al. RFT1-CDG: Deafness as a novel feature of congenital disorders of glycosylation. J Inherit Metab Dis 2009; 32: 335-338. doi:10.1007/s10545-009-1297-3

[198] Kościelak J. Congenital disorders of glycosylation. Handb Carbohydr Eng 2005; 6: 99-140. doi:10.21037/atm.2018.10.45

[199] Mohamed M, Guillard M, Wortmann SB et al. Clinical and diagnostic approach in unsolved CDG patients with a type 2 transferrin pattern. Biochim Biophys Acta - Mol Basis Dis 2011; 1812: 691-698. doi:10.1016/j.bbadis.2011.02.011

[200] Sedel F, Challe G, Mayer JM et al. Thiamine responsive pyruvate dehydrogenase deficiency in an adult with peripheral neuropathy and optic neuropathy. J Neurol Neurosurg Psychiatry 2008; 79: 846-847. doi:10.1136/jnnp.2007.136630

[201] Naito E, Ito M, Yokota I et al. Thiamine-responsive pyruvate dehydrogenase deficiency in two patients caused by a point mutation (F205L and L216F) within the thiamine pyrophosphate binding region. Biochim Biophys Acta - Mol Basis Dis 2002; 1588: 79-84. doi:10.1016/S0925-4439(02)00142-4

[202] Sun A. Lysosomal storage disease overview. Ann Transl Med 2018; 6: 476 doi:10.21037/atm.2018.11.39

[203] D@ Clavanzo F, Rigon L, Zanetti A , et al. Mucopolysaccharidosis type II: One hundred years of research, diagnosis, and treatment. Int J Mol Sci. 2020; 21: doi:10.3390/ijms21041258

[204] King KA, Gordon-Salant S, Yanjanin N et al. Auditory Phenotype of Niemann-Pick Disease, Type C1. Ear Hear. 2014; 35: doi:10.1097| AUD.0b013e3182a362b8

[205] Lipari Pinto P, Machado C, Janeiro P et al. Ngly1 deficiency-a rare congenital disorder of deglycosylation. JIMD Rep 2020; 53: 2-9. doi:10.1002/jmd2.12108

[206] RFM Rosa, da Silva AP, Goetze TB, et al. Ear abnormalities in patients with oculo-auriculo-vertebral spectrum (Goldenhar syndrome). Braz J Otorhinolaryngol 2011; 77: 455-460. doi:10.1590/S180886942011000400008

[207] Vargas-Poussou R, Houillier P, Le Pottier N et al. Genetic Investigation of Autosomal Recessive Distal Renal Tubular Acidosis: Evidence for Early Sensorineural Hearing Loss Associated with Mutations in the ATP6V0A4 Gene. J Am Soc Nephrol 2006; 17: 1437-1443. doi:10.1681/ASN.2005121305

[208] Hanisch F, Rahne T, Plontke SK. Prevalence of hearing loss in patients with late-onset Pompe disease: Audiological and otological consequences. Int J Audiol 2013; 52: 816-823. doi:10.3109/1499202 7.2013.840932

[209] Oysu C, Aslan I, Basaran B et al. The site of the hearing loss in Refsum's disease. Int J Pediatr Otorhinolaryngol 2001; 61: 129-134. doi:10.1016/S0165-5876(01)00559-6

[210] Vandana VP, Bindu PS, Nagappa M et al. Audiological findings in Infantile Refsum disease. Int J Pediatr Otorhinolaryngol 2015; 79: 1366-1369. doi:10.1016/j.ijporl.2015.05.023
[211] Bamiou D-E, Spraggs PRD, Gibberd FB et al. Hearing loss in adult Refsum's disease. Clin Otolaryngol Allied Sci 2003; 28: 227-230. doi:10.1046/j.1365-2273.2003.00694.x

[212] Liberman MC, Tartaglini E, Fleming JC et al. Deletion of SLC19A2, the high affinity thiamine transporter, causes selective inner hair cell loss and an auditory neuropathy phenotype. JARO - J Assoc Res Otolaryngol 2006; 7: 211-217. doi:10.1007/s10162-006-0035-x

[213] Di Giaimo R, Riccio M, Santi S et al. Targeted disruption of Slc19a2, the gene encoding the high-affinity thiamin transporter Thtr-1, causes diabetes mellitus, sensorineural deafness and megaloblastosis in mice. Hum Mol Genet 2002; 11: 2951-2960. doi:10.1093/ $\mathrm{hmg} / 11.23 .2951$

[214] Mohamed FE, Al Sorkhy M, Ghattas MA et al. A Novel Homozygous Missense Variant in the NAGA Gene with Extreme Intrafamilial Phenotypic Heterogeneity. J Mol Neurosci 2020; 70: 45-55. doi:10.1007/s12031-019-01398-6

[215] Rodríguez-Pazos L, Ginarte M, Vega A et al. Autosomal recessive congenital ichthyosis. Actas Dermosifiliogr 2013; 104: 270-284. doi:10.1016/j.adengl.2011.11.021

[216] Fekete R. Xeroderma pigmentosum/De Sanctis-Cacchione syndrome: Unusual cause of ataxia. . Case Rep Neurol 2014; 6: 83-87. doi:10.1159/000362115

[217] Rahbar Z, Naraghi M. De Sanctis-Cacchione syndrome: A case report and literature review. Int J Women's Dermatology 2015; 1: 136-139. doi:10.1016/j.jjwd.2015.05.003

[218] Kale K, Ghonge N, Kaul A. Prenatal diagnosis of congenital harlequin ichthyosis with fetal MRI. Indian J Radiol Imaging 2019; 29: 448. doi:10.4103/ijri.IJRI_105_19

[219] Cammarata-Scalisi F, Willoughby CE, Cárdenas Tadich A et al. Clinical, etiopathogenic, and therapeutic aspects of KID syndrome. Dermatol Ther. 2020; doi:10.1111/dth.13507

[220] Shuja Z, Li L, Gupta S et al. Connexin26 mutations causing palmoplantar keratoderma and deafness interact with connexin43, modifying gap junction and hemichannel properties. J Invest Dermatol 2016; 136: 225-235. doi:10.1038/JID.2015.389

[221] Yoon HK, Sargent MA, Prendiville JS et al. Cerebellar and cerebral atrophy in trichothiodystrophy. Pediatr Radiol 2005; 35: 1019-1023. doi:10.1007/s00247-005-1495-6

[222] Valverde D, Alvarez-Satta M, Castro-Sánchez S. Alström syndrome: current perspectives. Appl Clin Genet 2015; 171. doi:10.2147/TACG. S56612

[223] Mittal R, Patel K, Mittal J et al. Association of PRPS1 Mutations with Disease Phenotypes. Dis Markers 2015; 2015: 1-7. doi:10.1155/2015/127013

[224] Barakat AJ, Raygada M, Rennert OM. Barakat syndrome revisited. Am J Med Genet Part A 2018; 176: 1341-1348. doi:10.1002/ ajmg.a.38693

[225] Sheehan-Rooney K, Swartz ME, Zhao F , et al. Ahsa1 and Hsp90 activity confers more severe craniofacial phenotypes in a zebrafish model of hypoparathyroidism, sensorineural deafness and renal dysplasia (HDR). DMM Dis Model Mech 2013; 6: 1285-1291. doi:10.1242/dmm.011965

[226] Husson H, Bukanov NO, Moreno S et al. Correction of cilia structure and function alleviates multi-organ pathology in Bardet-Biedl syndrome mice. Hum Mol Genet 2020; 00: 1-15. doi:10.1093/hmg/ ddaa138

[227] M'Hamdi O, Ouertani I, Chaabouni-Bouhamed H. Update on the genetics of bardet-biedl syndrome. Mol Syndromol 2014; 5: 51-56. doi:10.1159/000357054

[228] Datta P, Ruffcorn A, Seo S. Limited time window for retinal gene therapy in a preclinical model of ciliopathy. Hum Mol Genet 2020; 29: 2337-2352. doi:10.1093/hmg/ddaa124 
[229] Gajendragadkar A, Bhamkar R. Antenatal Bartter's syndrome with sensorineural deafness. Indian J Nephrol 2009; 19: 23. doi:10.4103/0971-4065.50677

[230] Miyamura N, Matsumoto K, Taguchi T et al. Atypical Bartter Syndrome with Sensorineural Deafness with G47R Mutation of the $\beta$-Subunit for ClC-Ka and ClC-Kb Chloride Channels, Barttin. J Clin Endocrinol Metab 2003; 88: 781-786. doi:10.1210/jc.2002-021398

[231] Zhang J, Duo L, Lin Z et al. Exome sequencing reveals novel BCS1L mutations in siblings with hearing loss and hypotrichosis. Gene 2015; 566: 84-88. doi:10.1016/j.gene.2015.04.039

[232] Min J, Mao B, Wang Y et al. A Heterozygous Novel Mutation in TFAP2A Gene Causes Atypical Branchio-Oculo-Facial Syndrome With Isolated Coloboma of Choroid: A Case Report. Front Pediatr 2020; 8: 1-6. doi:10.3389/fped.2020.00380

[233] Milunsky JM, Maher TA, Zhao G et al. TFAP2A Mutations Result in Branchio-Oculo-Facial Syndrome. Am J Hum Genet 2008; 82: 1171-1177. doi:10.1016/j.ajhg.2008.03.005

[234] Klingbeil KD, Greenland CM, Arslan S et al. Novel EYA1 variants causing Branchio-oto-renal syndrome. Int J Pediatr Otorhinolaryngol 2017; 98: 59-63. doi:10.1016/j.ijporl.2017.04.037

[235] Shah AM, Krohn P, Baxi AB et al. Six1 proteins with human branchiooto-renal mutations differentially affect cranial gene expression and otic development. DMM Dis Model Mech 2020; 13. doi:10.1242/ dmm.043489

[236] Hsu A, Desai N, Paldino MJ. The Unwound Cochlea: A Specific Imaging Marker of Branchio-Oto-Renal Syndrome. AJNR Am J Neuroradiol 2018; 39: 2345-2349. doi:10.3174/ajnr.A5856

[237] Boudhina T, Yedes A, Khiari S et al. Familial syndrome combining short stature, microcephaly, mental deficiency, seizures, hearing loss, and skin lesions. A new syndrome. ediatr (Paris) 1990; 37: 399-403

[238] Hasan MR, Takatalo M, Ma H et al. RAB23 coordinates early osteogenesis by repressing FGF10-pERK1/2 and GLI1. Elife 2020; 9: 1-26. doi:10.7554/eLife.55829

[239] Tarhan E, Oğuz H, Şafak MA, et al. The Carpenter syndrome phenotype. Int J Pediatr Otorhinolaryngol 2004; 68: 353-357. doi:10.1016/j.ijporl.2003.10.009

[240] Twigg SRF, Lloyd D, Jenkins D et al. Mutations in multidomain protein MEGF8 identify a carpenter syndrome subtype associated with defective lateralization. Am J Hum Genet 2012; 91: 897-905. doi:10.1016/j.ajhg.2012.08.027

[241] Bérubé-Simard FA, Pilon N. Molecular dissection of CHARGE syndrome highlights the vulnerability of neural crest cells to problems with alternative splicing and other transcription-related processes. Transcription 2019; 10: 21-28. doi:10.1080/21541264.20 18.1521213

[242] Karikkineth AC, Scheibye-Knudsen M, Fivenson E et al. Cockayne syndrome: Clinical features, model systems and pathways. Ageing Res Rev 2017; 33: 3-17. doi:10.1016/j.arr.2016.08.002

[243] Morris DP, Alian W, Maessen H, et al. Cochlear implantation in Cockayne syndrome: Our experience of two cases with different outcomes. Laryngoscope 2007; 117: 939-943. doi:10.1097| MLG.0b013e3180325106

[244] Hanauer A, Young ID. Coffin-Lowry syndrome: Clinical and molecular features. J Med Genet 2002; 39: 705-713. doi:10.1136/ jmg.39.10.705

[245] Rosanowski F, Eysholdt U. Late-Onset Sensorineural Hearing Loss in Coffin-Lowry Syndrome 1998; 224-226

[246] Vasileiou G, Vergarajauregui S, Endele S et al. Mutations in the BAF-Complex Subunit DPF2 Are Associated with Coffin-Siris Syndrome. Am J Hum Genet 2018; 102: 468-479. doi:10.1016/j. ajhg.2018.01.014
[247] Schrier SA, Bodurtha JN, Burton B et al. The Coffin-Siris syndrome: A proposed diagnostic approach and assessment of 15 overlapping cases. Am J Med Genet Part A 2012; 158A: 1865-1876. doi:10.1002/ ajmg.a.35415

[248] Sarogni P, Pallotta MM, Musio A. Cornelia de Lange syndrome: From molecular diagnosis to therapeutic approach. J Med Genet 2020; 57 : 289-295. doi:10.1136/jmedgenet-2019-106277

[249] Avagliano L, Parenti I, Grazioli P et al. Chromatinopathies: A focus on Cornelia de Lange syndrome. Clin Genet 2020; 97: 3-11. doi:10.1111/cge.13674

[250] Marchisio P, Selicorni A, Bianchini S et al. Audiological findings, genotype and clinical severity score in Cornelia de Lange syndrome. Int J Pediatr Otorhinolaryngol 2014; 78: 1045-1048. doi:10.1016/j. ijporl.2014.03.038

[251] Kurkiewicz A, Cooper A, Mcllwaine E et al. Towards development of a statistical framework to evaluate myotonic dystrophy type 1 mRNA biomarkers in the context of a clinical trial. PLoS One 2020; 15: 1-19. doi:10.1371/journal.pone.0231000

[252] Van Vliet ], Tieleman AA, Van Engelen BGM et al. Hearing impairment in patients with myotonic dystrophy type 2. Neurology 2018; 90 : e615-e622. doi:10.1212/WNL.0000000000004963

[253] Balatsouras DG, Felekis D, Panas M et al. Inner ear dysfunction in myotonic dystrophy type 1. Acta Neurol Scand 2013; 127: 337-343. doi:10.1111/ane. 12020

[254] Khalifa O, Al-Sahlawi Z, Imtiaz F et al. Variable expression pattern in Donnai-Barrow syndrome: Report of two novel LRP2 mutations and review of the literature. Eur J Med Genet 2015; 58: 293-299. doi:10.1016/j.ejmg.2014.12.008

[255] Kantarci S, Al-Gazali L, Hill RS et al. Mutations in LRP2, which encodes the multiligand receptor megalin, cause Donnai-Barrow and facio-oculo-acoustico-renal syndromes. Nat Genet 2007; 39: 957-959. doi:10.1038/ng2063

[256] Campeau PM, Kasperaviciute D, Lu JT et al. The genetic basis of DOORS syndrome: an exome-sequencing study. Lancet Neurol 2014; 13: 44-58. doi:10.1016/S1474-4422(13)70265-5

[257] Campeau PM, Hennekam RC, Aftimos S, et al. DOORS syndrome: Phenotype, genotype and comparison with coffin-siris syndrome. Am J Med Genet Part C Semin Med Genet 2014; 166: 327-332. doi:10.1002/ajmg.c.31412

[258] Pradhan N, Shilawant J, Akkamahadevi CH et al. Ehlers-Danlos syndrome with huge bladder diverticulum in pregnancy - A rare and interesting case report. Eur J Obstet Gynecol Reprod Biol 2020; 250: 231-234. doi:10.1016/j.ejogrb.2020.05.001

[259] Ritelli M, Dordoni C, Cinquina V et al. Expanding the clinical and mutational spectrum of B4GALT7-spondylodysplastic Ehlers-Danlos syndrome. Orphanet J Rare Dis 2017; 12: 1-7. doi:10.1186/ s13023-017-0704-3

[260] Fryns JP. Fountain's syndrome: Mental retardation, sensorineural deafness, skeletal abnormalities, and coarse face with full lips. J Med Genet 1989; 26: 722-724. doi:10.1136/jmg.26.11.722

[261] Poling MI, Dufresne CR, Chamberlain RL. Findings, Phenotypes, Diagnostic Accuracy, and Treatment in Freeman-Burian Syndrome. J Craniofac Surg 2020; 31: 1063-1069. doi:10.1097/ SCS.0000000000006299

[262] Regev M, Pode-Shakked B, Jacobson JM et al. Phenotype variability in Hajdu-Cheney syndrome. Eur J Med Genet 2019; 62: 35-38. doi:10.1016/j.ejmg.2018.04.015

[263] Abu-Amero KK, Hagr A Al, Almomani MO et al. HOXA1 mutations are not commonly associated with non-syndromic deafness. Can J Neurol Sci 2014; 41: 448-451. doi:10.1017/S0317167100018473 
[264] Lai WF, Wong WT. Progress and trends in the development of therapies for Hutchinson-Gilford progeria syndrome. Aging Cell 2020; 19: 1-17. doi:10.1111/acel.13175

[265] Liu S, Wang Z, Jiang J et al. Severe forms of Johanson-Blizzard syndrome caused by two novel compound heterozygous variants in UBR1: Clinical manifestations, imaging findings and molecular genetics. Pancreatology 2020; 20: 562-568. doi:10.1016/j. pan.2020.01.007

[266] Friez M], Brooks SS, Stevenson RE et al. HUWE1 mutations in Juberg-Marsidi and Brooks syndromes: The results of an X-chromosome exome sequencing study. BMJ Open 2016; 6: 1-9. doi:10.1136/ bmjopen-2015-009537

[267] Cuvertino S, Hartill V, Colyer A et al. A restricted spectrum of missense KMT2D variants cause a multiple malformations disorder distinct from Kabuki syndrome. Genet Med 2020; 22: 867-877. doi:10.1038/s41436-019-0743-3

[268] Stamou MI, Georgopoulos NA. Kallmann syndrome: phenotype and genotype of hypogonadotropic hypogonadism. Metabolism 2018; 86: 124-134. doi:10.1016/j.metabol.2017.10.012

[269] Finsterer J, Winklehner M, Stöllberger C et al. Unusual Phenotype and Disease Trajectory in Kearns-Sayre Syndrome. Case Rep Neurol Med 2020; 2020: 1-6. doi:10.1155/2020/7368527

[270] Weidauer H, Lenarz T. Kearns-Sayre syndrome from the otorhinolaryngologic viewpoint. Laryngol Rhinol Otol (Stuttg) 1984; 63: 141-146

[271] Frikha R. Klippel-Feil syndrome: a review of the literature. Clin Dysmorphol 2020; 29: 35-37. doi:10.1097| MCD.0000000000000301

[272] Mayer B, Lenarz T, Haels J. Cervically-induced symptoms of the Klippel-Feil syndrome. Laryngol Rhinol Otol (Stuttg) 1984; 63: 364-370

[273] Husain Q, Cho J, Neugarten J et al. Surgery of the head and neck in patient with Kniest dysplasia: Is wound healing an issue?. Int J Pediatr Otorhinolaryngol 2017; 93: 97-99. doi:10.1016/j.jjporl.2016.12.025

[274] Hey Ryu Y, Kyun Chae J, Kim JW et al. Lacrimo-auriculo-dento-digital syndrome: A novel mutation in a Korean family and review of literature. Mol Genet Genomic Med 2020; 1-11. doi:10.1002/ mgg3.1412

[275] Muzio MR, Cascella M, Al Khalili Y. Landau Kleffner Syndrome. 2020; Im Internet: http://www.ncbi.nlm.nih.gov/pubmed/31613525

[276] Kim J, Kim MR, Kim HJ et al. LEOPARD syndrome with PTPN11 gene mutation showing six cardinal symptoms of LEOPARD. Ann Dermatol 2011; 23: 232-235. doi:10.5021/ad.2011.23.2.232

[277] Levy J, Chung W, Garzon M et al. Congenital myopathy, recurrent secretory diarrhea, bullous eruption of skin, microcephaly, and deafness: A new genetic syndrome?. Am J Med Genet 2003; 116: 20-25. doi:10.1002/ajmg.a.10072

[278] Griffith AJ, Sprunger LK, Sirko-Osadsa DA et al. Marshall Syndrome Associated with a Splicing Defect at the COL11A1 Locus. Am J Hum Genet 1998; 62: 816-823. doi:10.1086/301789

[279] Rawle M, Larner A. NARP Syndrome: A 20-Year Follow-Up. Case Rep Neurol 2013; 5: 204-207. doi:10.1159/000357518

[280] Strubbe EH, CWR] Cremers, Dikkers FG , et al. Hearing loss and the Mayer-Rokitansky-Kuster-Hauser syndrome. Am J Otol 1994; 15: 431-436

[281] Boyce AM, Collins MT. Fibrous Dysplasia/McCune-Albright Syndrome: A Rare, Mosaic Disease of Ga s Activation. Endocr Rev 2020; 41: 345-370. doi:10.1210/endrev/bnz011

[282] Di Stadio A, Pegoraro V, Giaretta L et al. Hearing impairment in MELAS: New prospective in clinical use of microRNA, a systematic review. Orphanet J Rare Dis 2018; 13: 1-9. doi:10.1186/s13023-0180770-1
[283] Handzel O, Ungar O], Lee D] et al. Temporal bone histopathology in MELAS syndrome. Laryngoscope Investig Otolaryngol 2020; 5: 152-156. doi:10.1002/lio2.344

[284] Tsutsumi T, Nishida H, Noguchi $Y$ et al. Audiological findings in patients with myoclonic epilepsy associated with ragged-red fibres. J Laryngol Otol 2001; 115. doi:10.1258/0022215011909224

[285] Picciolini O, Porro M, Cattaneo E et al. Moebius syndrome: clinical features, diagnosis, management and early intervention. Ital J Pediatr 2016; 42: 56. doi:10.1186/s13052-016-0256-5

[286] Gürsoy S, Hazan F, Öztürk T et al. Novel Ocular and Inner Ear Anomalies in a Patient with Myhre Syndrome. Mol Syndromol 2020; 10: 339-343. doi:10.1159/000504829

[287] Melkoniemi M, Brunner HG, Manouvrier S et al. Autosomal recessive disorder otospondylomegaepiphyseal dysplasia is associated with loss-of-function mutations in the COL11A2 gene. Am J Hum Genet 2000; 66: 368-377. doi:10.1086/302750

[288] Koffler T, Ushakov K, Avraham KB. Genetics of Hearing Loss. Otolaryngol Clin North Am 2015; 48: 1041-1061. doi:10.1016/j. otc.2015.07.007

[289] Gettelfinger ], Dahl J. Syndromic Hearing Loss: A Brief Review of Common Presentations and Genetics. J Pediatr Genet 2018; 07: 001-008. doi:10.1055/s-0037-1617454

[290] Desai U, Rosen H, Mulliken JB et al. Audiologic Findings in Pfeiffer Syndrome. J Craniofac Surg 2010; 21: 1411-1418. doi:10.1097| SCS.0b013e3181ebcf58

[291] Tarailo-Graovac M, Sinclair G, Stockler-Ipsiroglu S et al. The genotypic and phenotypic spectrum of PIGA deficiency. Orphanet J Rare Dis 2015; 10 doi:10.1186/s13023-015-0243-8

[292] Knowles MR, Zariwala M, Leigh M. Primary Ciliary Dyskinesia. Clin Chest Med 2016; 37: 449-461. doi:10.1016/j.ccm.2016.04.008

[293] Chang Q, Wang J, Li Q et al. Virally mediated Kcnq1 gene replacement therapy in the immature scala media restores hearing in a mouse model of human Jervell and Lange-Nielsen deafness syndrome. EMBO Mol Med 2015; 7: 1077-1086. doi:10.15252/ emmm.201404929

[294] Zhang Q, Liang D, Yue Y et al. Axenfeld-Rieger syndrome-associated mutants of the transcription factor FOXC1 abnormally regulate NKX2-5 in model zebrafish embryos. J Biol Chem 2020; 2: jbc. RA120.013287 doi:10.1074/jbc.RA120.013287

[295] Wakeling EL, Brioude F, Lokulo-Sodipe O et al. Diagnosis and management of Silver-Russell syndrome: first international consensus statement. Nat Rev Endocrinol 2017; 13: 105-124. doi:10.1038/nrendo.2016.138

[296] Hoischen A, Van Bon BWM, Gilissen C et al. De novo mutations of SETBP1 cause Schinzel-Giedion syndrome. Nat Genet 2010; 42: 483-485. doi:10.1038/ng.581

[297] Tsang SH, Aycinena ARP, Sharma T. Ciliopathy: Senior-Løken Syndrome 2018; 175-178. doi:10.1007/978-3-319-95046-4_34

[298] Kaur A, Dhir SK, Goyal G et al. Senior loken syndrome. J Clin Diagnostic Res 2016; 10: SD03-SD04. doi:10.7860/ JCDR/2016/21832.8816

[299] Abdelhadi O, lancu D, Stanescu H et al. EAST syndrome: Clinical, pathophysiological, and genetic aspects of mutations in KCNJ10. Rare Dis (Austin, Tex) 2016; 4: e1195043 doi:10.1080/21675511.201 6.1195043

[300] Gaudreau P, Zizak V, Gallagher TQ. The otolaryngologic manifestations of Sotos syndrome. Int ] Pediatr Otorhinolaryngol 2013; 77: 1861-1863. doi:10.1016/j.ijporl.2013.08.029

[301] Boczek N], Kruisselbrink T, Cousin MA et al. Multigenerational pedigree with STAR syndrome: A novel FAM58A variant and expansion of the phenotype. Am J Med Genet Part A 2017; 173: 1328-1333. doi:10.1002/ajmg.a.38113 
[302] Smith SD, Kelley PM, Kenyon JB et al. Tietz syndrome (hypopigmentation/deafness) caused by mutation of MITF. J Med Genet 2000; 37: 446-448. doi:10.1136/jmg.37.6.446

[303] Liang Y, Shen D, Cai W. Two coding single nucleotide polymorphisms in the SALL1 gene in Townes-Brocks syndrome: a case report and review of the literature. J Pediatr Surg 2008; 43: 391-393. doi:10.1016/j.jpedsurg.2007.09.079

[304] Géléoc GGS, El-Amraoui A. Disease mechanisms and gene therapy for Usher syndrome. Hear Res 2020; 394: 107932 doi:10.1016/j. heares.2020.107932

[305] Hedberg-Oldfors C, Darin N, Oldfors A. Muscle pathology in Vici syndrome-A case study with a novel mutation in EPG5 and a summary of the literature. Neuromuscul Disord 2017; 27: 771-776. doi:10.1016/j.nmd.2017.05.005

[306] Song J, Feng Y, Acke FR et al. Hearing loss in Waardenburg syndrome: a systematic review. Clin Genet 2016; 89: 416-425. doi:10.1111/ cge. 12631

[307] Kontorinis G, Lenarz T, Giourgas A et al. Outcomes and Special Considerations of Cochlear Implantation in Waardenburg Syndrome. Otol Neurotol 2011; 32: 951-955. doi:10.1097| MAO.0b013e31821b3ae3

[308] La Morgia C, Maresca A, Amore G et al. Calcium mishandling in absence of primary mitochondrial dysfunction drives cellular pathology in Wolfram Syndrome. Sci Rep 2020; 10: 1-15. doi:10.1038/ s41598-020-61735-3

[309] Samara A, Rahn R, Neyman O et al. Developmental hypomyelination in Wolfram syndrome: New insights from neuroimaging and gene expression analyses. Orphanet J Rare Dis 2019; 14: 1-14. doi:10.1186/s13023-019-1260-9

[310] Elumalai V, Pasrija D. Zellweger Syndrome. 2020; Im Internet: http:// www.ncbi.nlm.nih.gov/pubmed/32809511

[311] Sclafani AP, DeDio RM, Hendrix RA. The Chiari-I malformation. Ear Nose Throat J 1991; 70: 208-212. Im Internet: http://www.ncbi.nlm. nih.gov/pubmed/1874153

[312] Barsottini OG, Pedroso JL, Martins CR et al. Deafness and Vestibulopathy in Cerebellar Diseases: a Practical Approach. Cerebellum 2019; 18: 1011-1016. doi:10.1007/s12311-019-01042-4

[313] Bokhari MR, Samanta D, Bokhari SRA. Canavan Disease. 2020; Im Internet: http://www.ncbi.nlm.nih.gov/pubmed/28613566

[314] Roscoe RB, Elliott C, Zarros A et al. Non-genetic therapeutic approaches to Canavan disease. J Neurol Sci 2016; 366: 116-124. doi:10.1016/j.jns.2016.05.012

[315] Ishiyama G, Lopez I, Baloh RW et al. Canavan's leukodystrophy is associated with defects in cochlear neurodevelopment and deafness. Neurology 2003; 60: 1702-1704. doi:10.1212/01. WNL.0000065893.60879.D3
[316] Demos MK, Van Karnebeek CDM, Ross CJD et al. A novel recurrent mutation in ATP1A3 causes CAPOS syndrome. Orphanet J Rare Dis 2014; 9: 1-9. doi:10.1186/1750-1172-9-15

[317] Stenshorne I, Rasmussen M, Salvanos P et al. Fever-related ataxia: A case report of CAPOS syndrome. Cerebellum and Ataxias 2019; 6: 3-7. doi:10.1186/s40673-019-0096-3

[318] Rosewich H, Weise D, Ohlenbusch A et al. Phenotypic overlap of alternating hemiplegia of childhood and CAPOS syndrome. Neurology 2014; 83: 861-863. doi:10.1212/ WNL.0000000000000735

[319] Choi JE, Seok JM, Ahn J et al. Hidden hearing loss in patients with Charcot-Marie-Tooth disease type 1A. Sci Rep 2018; 8: 10335 doi:10.1038/s41598-018-28501-y

[320] Park JG, Tischfield MA, Nugent AA et al. Loss of MAFB Function in Humans and Mice Causes Duane Syndrome, Aberrant Extraocular Muscle Innervation, and Inner-Ear Defects. Am J Hum Genet 2016; 98: 1220-1227. doi:10.1016/j.ajhg.2016.03.023

[321] Weir FW, Kreicher KL, Hatch JL et al. Audiologic and otologic phenotype in children with Duane's Retraction Syndrome: A rare ophthalmologic disorder. Int J Pediatr Otorhinolaryngol 2016; 89: 154-158. doi:10.1016/j.jporl.2016.08.014

[322] Auer-Grumbach M, Bode H, Pieber TR et al. Mutations at Ser331 in the HSN type I gene SPTLC1 are associated with a distinct syndromic phenotype. Eur J Med Genet 2013; 56: 266-269. doi:10.1016/j. ejmg.2013.02.002

[323] Hojo K, Kawamata T, Tanaka C et al. Inflammatory glial activation in the brain of a patient with hereditary sensory neuropathy type 1 with deafness and dementia. Neurosci Lett 2004; 367: 340-343. doi:10.1016/j.neulet.2004.06.030

[324] Tyler GK, Martin TPC, Baguley DM. Systematic review of outcome of cochlear implantation in superficial siderosis. Otol Neurotol 2012; 33: 976-982. doi:10.1097/MAO.0b013e3182565a46

[325] Iversen MM, Rabbitt RD. Biomechanics of Third Window Syndrome. Front Neurol 2020; 11. doi:10.3389/fneur.2020.00891

[326] Marinelli JP, Lohse CM, Carlson ML. Incidence of Intralabyrinthine Schwannoma. Otol Neurotol 2018; 39: 1191-1194. doi:10.1097| MAO.0000000000001875

[327] Plontke SK, Rahne T, Pfister M et al. Intralabyrinthine schwannomas: Surgical management and hearing rehabilitation with cochlear implants. HNO 2017; 65: 136-148. doi:10.1007/s00106-017-0364-6

[328] Plontke SK, Fröhlich L, Wagner L et al. How Much Cochlea Do You Need for Cochlear Implantation? Otol Neurotol 2020; 41: 694-703. doi:10.1097/MAO.0000000000002614

[329] Orsini A, Valetto A, Bertini $V$ et al. The best evidence for progressive myoclonic epilepsy: A pathway to precision therapy. Seizure 2019; 71: 247-257. doi:10.1016/j.seizure.2019.08.012 